ALBERTO FERREIRA DA SILVA

METODOLOGIA DE AUDITORIA DE MENSAGENS GOOSE

EM REDES IEC61850 EM SUBESTAÇÕES DE ENERGIA ELÉTRICA

São Paulo

2021 


\title{
METODOLOGIA DE AUDITORIA DE MENSAGENS GOOSE EM REDES IEC61850 EM SUBESTAÇÕES DE ENERGIA ELÉTRICA
}

\author{
Versão Corrigida
}

Dissertação apresentada à Escola Politécnica da Universidade de São Paulo para obtenção do título de Mestre em Ciências.

Área de Concentração: Sistemas de Potência

Orientador: Profa. Dra. Milana Lima dos Santos

São Paulo 
Autorizo a reprodução e divulgação total ou parcial deste trabalho, por qualquer meio convencional ou eletrônico, para fins de estudo e pesquisa, desde que citada a fonte.

Este exemplar foi revisado e corrigido em relação à versão original, sob
responsabilidade única do autor e com a anuência de seu orientador.
São Paulo, __ de ___
Assinatura do autor:
Assinatura do orientador:

\section{Catalogação-na-publicação}

\footnotetext{
Silva, Alberto

Metodologia de Auditoria de Mensagens GOOSE em Redes IEC61850 em Subestações de Energia Elétrica / A. Silva -- versão corr. -- São Paulo, 2021.

$122 \mathrm{p}$.

Dissertação (Mestrado) - Escola Politécnica da Universidade de São Paulo. Departamento de Engenharia de Energia e Automação Elétricas.

1.GOOSE 2.IEC61850 3.Substation 4.Auditor 5.SCD Files I.Universidade de São Paulo. Escola Politécnica. Departamento de Engenharia de Energia e Automação Elétricas II.t.
} 
Nome: Silva, Alberto Ferreira da

Título: Metodologia de auditoria de mensagens GOOSE em redes IEC-61850 em subestação de energia elétrica.

\author{
Dissertação apresentada \\ à Escola Politécnica da \\ Universidade de São \\ Paulo para obtenção do \\ título de Mestre em \\ Ciências
}

Aprovado em:

Banca Examinadora

Prof. Dr.

Instituição:

Julgamento:

Prof. Dr.

Instituição:

Julgamento:

Prof. Dr.

Instituição:

Julgamento: 


\section{AGRADECIMENTOS}

Agradeço a Deus, que me deu a vida.

Agradeço à minha mãe Carmen Lúcia Ferreira da Silva e à Carmesita Antonia da Silva, minha tia, por me proporcionarem toda a educação e honestidade como pessoa.

Agradeço à Professora Doutora Milana Lima dos Santos, por me orientar com excelência.

Agradeço ao M.e Clovis Paulino, que me despertou a vontade contínua do aprendizado. 


\section{RESUMO}

Silva, A. F. da Metodologia de auditoria de mensagens GOOSE em redes IEC 61850 em subestações de energia elétrica. 2021. 122 f. Dissertação (Mestrado em Engenharia Elétrica) - Escola Politécnica, Universidade de São Paulo, São Paulo, 2021.

Com a digitalização das subestações de energia e a introdução de novos dispositivos de proteção e comando compatíveis com a norma IEC 61850 The International Electrotechincal Commision (IEC) 61850, o cabeamento elétrico de informações foi gradativamente substituído por trocas de mensagens GOOSE (Generic Object Oriented Substation Events). Contudo, não é prevista uma forma de verificar se a transmissão e a recepção das mensagens GOOSE pelos IED estão de acordo com as definidas no projeto inicial, conforme os datasets (conjuntos de dados) dos arquivos de configuração escritos em linguagem SCL (Substation Configuration Language). Dessa forma, no momento de uma anomalia, é preciso utilizar uma grande quantidade de horas das equipes técnicas para identificar a solução do problema. Este trabalho de pesquisa propõe uma metodologia e apresenta o desenvolvimento de uma ferramenta computacional que adquire as mensagens do protocolo GOOSE, definido na norma IEC 61850, e verifica a sua conformidade com a configuração documentada pelos arquivos SCD e com as definidas pelo usuário através de arquivo de configuração privado, auxiliando as equipes de operação e manutenção através da emissão de relatórios detalhados e claros e alertas em caso de falhas detectadas.

Palavras-chave: IEC 61850, Subestações. GOOSE. Arquivos SCD. Arquivos ICD. Arquivos CID. Auditor. 


\begin{abstract}
Silva, A. F. da Methodology for auditing GOOSE messages on IEC 61850 networks in electronic power substation. 2021. 122 f. Dissertação (Mestrado em Engenharia Elétrica) - Escola Politécnica, Universidade de São Paulo, São Paulo, 2021.

With the digitalization of power substations, and the introduction of new protection and control devices compatible with the IEC 61850 standard The International Electrotechincal Commision (IEC) 61850, the electrical information cabling was gradually replaced by exchanges of GOOSE messages (Generic Object Oriented Substation Events). However, there is no way to verify that the transmission and reception of GOOSE messages by the IEDs are in accordance with those defined in the initial project, according to the datasets (data sets) of the configuration files written in SCL (Substation Configuration Language). Thus, in the event of an anomaly, it is necessary to use a large amount of hours from the technical teams to identify the solution to the problem. This research work proposes a methodology and presents the development of a computational tool that acquires the messages of the GOOSE protocol, defined in the IEC 61850 standard, and verifies their compliance with the configuration documented by the SCD files and those defined by the user through a file private configuration, assisting the operation and maintenance teams by issuing detailed and clear reports and alerts in case of detected failures.
\end{abstract}

Keywords: IEC 61850, Substations. GOOSE. SCD files. ICD files. CID files. Auditor. 


\section{LISTA DE FIGURAS}

Figura 1 - Quantidade de cabos conectados no relé ....................................23

Figura 2 - Conexão ethernet para troca de mensagens GOOSE ..................23

Figura 3 - Modelo de referência OSI/ISO ..................................................27

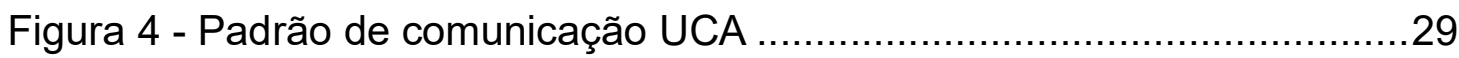

Figura 5 - Estrutura de dados definida pela norma ......................................33

Figura 6 - Comunicação em uma arquitetura IEC-61850................................34

Figura 7 - Serviços de comunicação da norma IEC-61850 no modelo OSI....35

Figura 8 - Frequência da transmissão do GOOSE .........................................36

Figura 9 - Mensagem GOOSE publicada em data sets ................................37

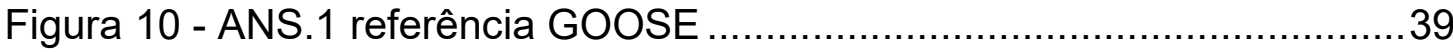

Figura 11 - Linguagem de configuração da subestação ..................................42

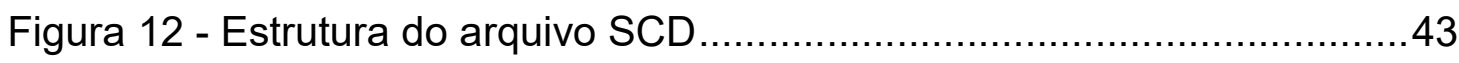

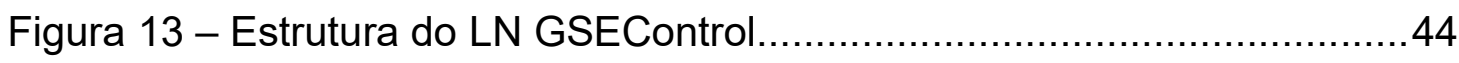

Figura 14 - Estrutura da classe DataSet do arquivo SCD .............................44

Figura 15 - Estrutura da classe Inputs do arquivo SCD ...............................44

Figura 16 - Relacionamento SCD e IEEE802.3 ........................................46

Figura 17 - Metodologia de auditoria e tradução GOOSE ……….................47

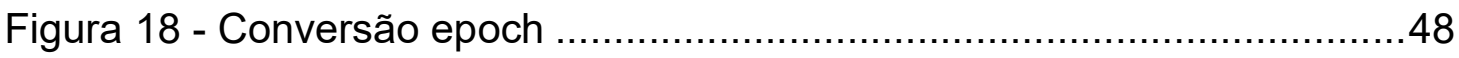

Figura 19 - Classes SCD desmembradas...............................................

Figura 20 - Diagrama de Sequência do Software Auditor GOOSE.................51

Figura 21 - Estrutura XML do arquivo SCD do projeto ................................51

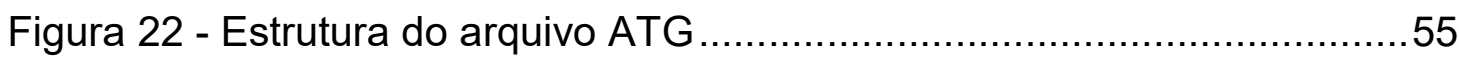

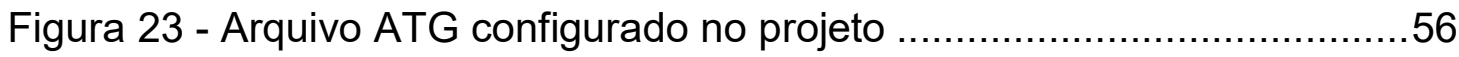

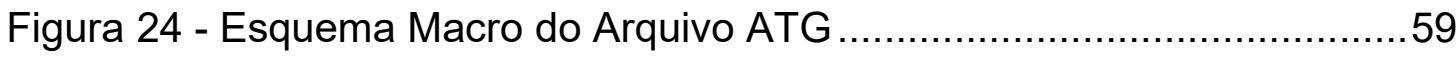

Figura 25 - Identificação de IED e Dataset no SCD......................................61

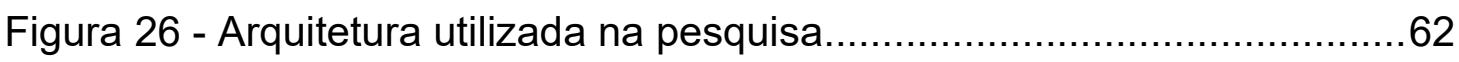

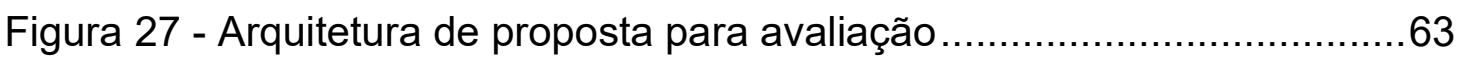

Figura 28 - Endereços IPv4 e MACs configurados no ambiente de teste.......64

Figura 29 - Descrição do modelo da placa de rede instalada .........................65

Figura 30 - Configuração do endereço IPv4 e máscara de rede ....................66

Figura 31 - Resultado da configuração do NTP Server ................................67 
Figura 32 - SEL-487E-3 configurado com opção failover .68

Figura 33 - SEL-451-5 configurado com opção failover 69

Figura 34 - Resultado do comando mac para IED SEL-487E-3 ....................70

Figura 35 - Resultado do comando mac para o IED SEL-451-5 ...................70

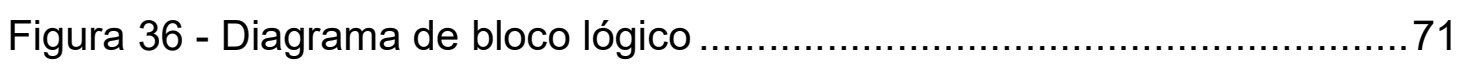

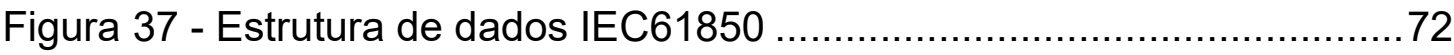

Figura 38 - Projeto acSELerator Architect ……..........................................73

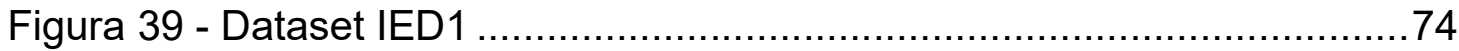

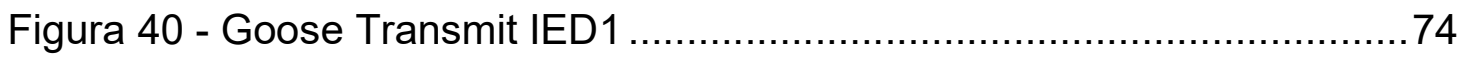

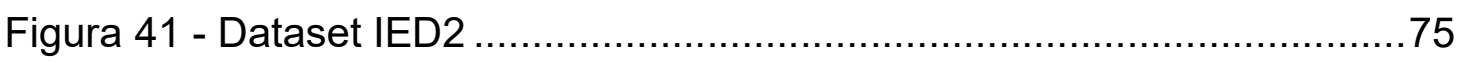

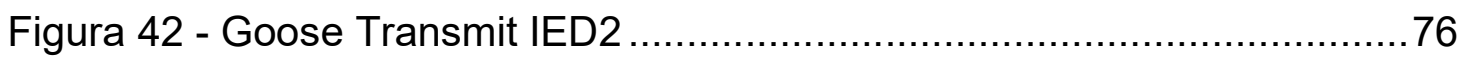

Figura 43 - Recepção de mensagens GOOSE IED1 _..................................76

Figura 44 - Recepção de mensagens GOOS IED2 ……............................77

Figura 45 - Identificação de IED e Dataset ....................................................78

Figura 46 - Identificação dos atributos no arquivo ATG ................................79

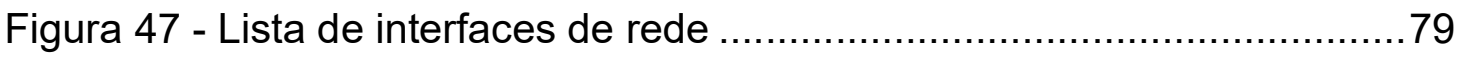

Figura 48 - GOOSE do IED1, botões não pressionados................................. 81

Figura 49 - GOOSE do IED2, botões não pressionados................................82

Figura 50 - GOOSE do IED1 capturado pelo AAG …...................................83

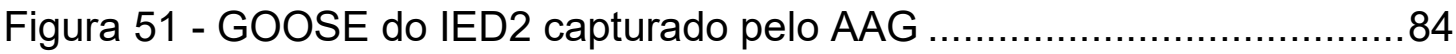

Figura 52 - Não divergência na quantidade de atributos para o IED1 ............86

Figura 53 - Não divergência na quantidade de atributos para o IED2 …........86

Figura 54 - Tradução dos atributos pelo software auditor..............................86

Figura 55 - Tradução dos atributos 2 e 4 pressionados..................................87

Figura 56 - Data set IED1 configurado com apenas 3 atributos ....................87

Figura 57 - Mensagem de divergência encontrada para o IED1 ......................88

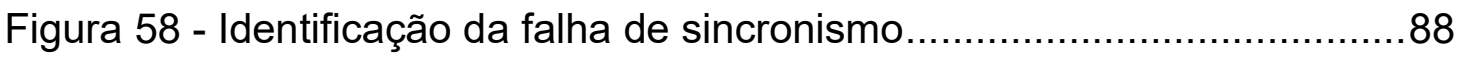

Figura 59 - Identificação da ausência de mensagens GOOSE.........................89

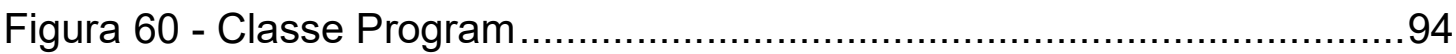

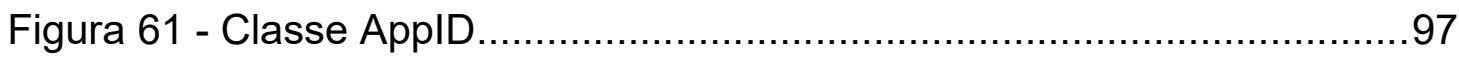

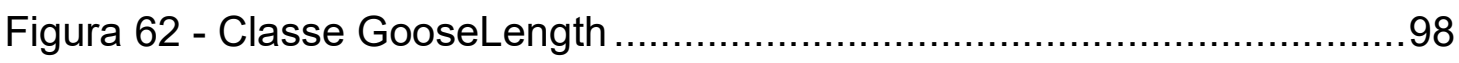

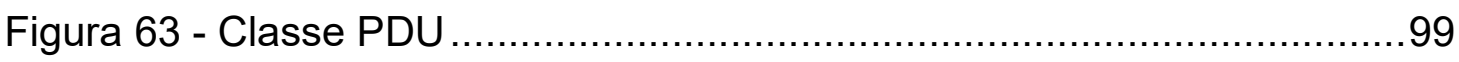

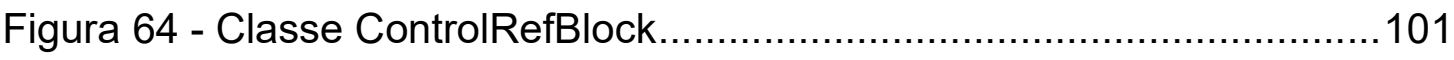

Figura 65 - Classe Time2LiveAllowed....................................................102 


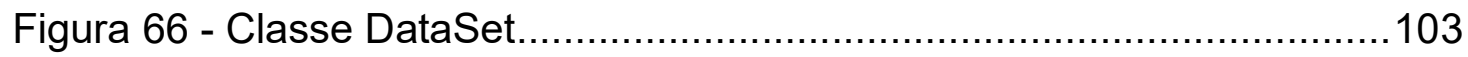

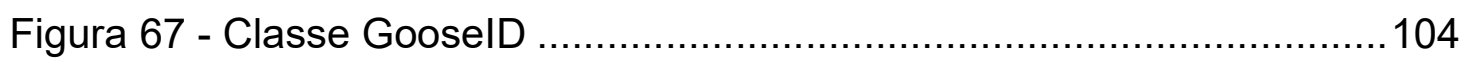

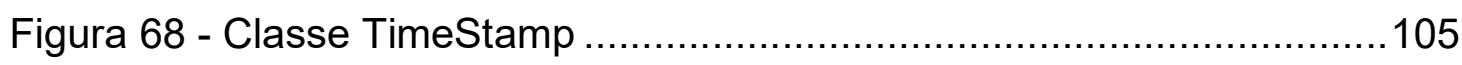

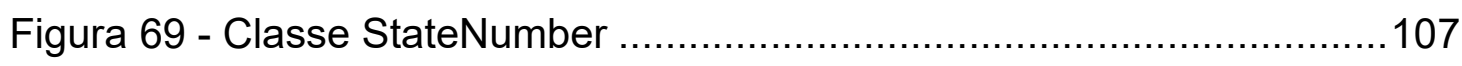

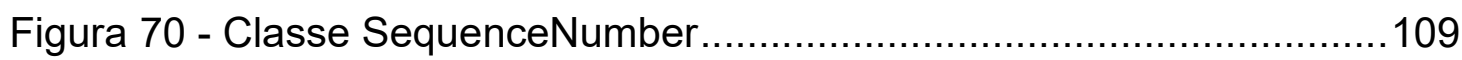

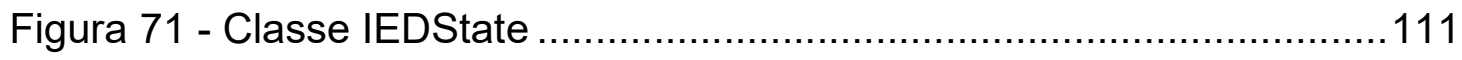

Figura 72 - Classe ConfigRevision ............................................................

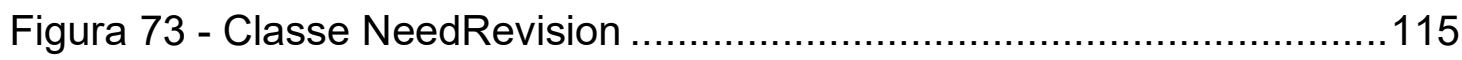

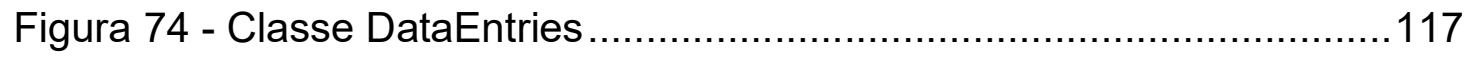

Figura 75 - Código parametrizado para detectar falha GOOSE ..................122 


\section{LISTA DE TABELAS}

Tabela 1 - Partes da Norma IEC 61850 versão 1 .....................................30

Tabela 2 - Estrutura padrão IEEE 802.3, para transmissão de GOOSE ........38

Tabela 3 - Estrutura do pacote GOOSE ........................................... 39

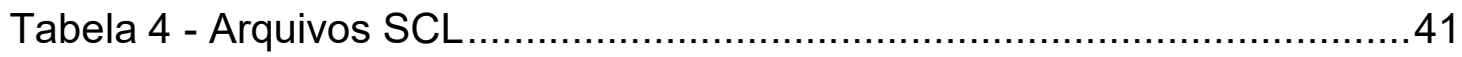

Tabela 5 - Classes desenvolvidas .....................................................49

Tabela 6 - Tabela de tradução dos atributos publicados ............................60

Tabela 7 - Botão e Atributos Lógicos ...................................................... 72

Tabela 8 - Relação Atributos e Leds ....................................................73

Tabela 9 - Conversão de segundos epoch .......................................... 119

Tabela 10 - Conversão epoch milissegundos ......................................121 


\section{LISTA DE ABREVIATURAS E SIGLAS}

AAG

ASN.1

ATG

CID

cos

DNP3

EPRI

GOOSE

GSSE

ICD

IDE

IEC

IED

IEEE

IID

ISO

IP

LAN

LN

MAC

MMS

NTP

MMXU

OSI

SCADA

QoS

SCD

$S C L$

SEL

Aplicativo Auditor GOOSE

Abstract Syntax Notation One

Arquivo de Tradução GOOSE

Configuration IED Description

Centro de Operação do Sistema

Distributed Network Protocol

Electric Power Research Institute

Generic Object Oriented Substation Events

Generic Substation Status Event

IED Capability Description

Integrated Development Envrionment

International Electrotechnical Commission

Intelligent Electronic Device

Electrical and Electronics Engineers

Instantiated IED Description

International Standards Organization

Internet Protocol

Local Area Network

Logical Node

Media Access Control

Manufacturing Message Specification

Network Time Protocol

Logical Node for Measurement

Open Systems Interconnection

Supervisory Control and Data Acquisition

Quality of Service

Substation Configuration Description

Substation Configuration Language

Schweitzer Engineering Laboratories 


$\begin{array}{ll}\text { SE } & \text { Subestação de Energia Elétrica } \\ \text { SEP } & \text { Sistema Elétrico de Potência } \\ \text { SSC } & \text { Sistema de Supervisão e Controle } \\ \text { SSD } & \text { System Specification Description } \\ \text { SV } & \text { Sampled Values } \\ \text { TAC } & \text { Teste de Aceitação de Campo } \\ \text { TAF } & \text { Teste de Aceitação de Fábrica } \\ \text { TC } & \text { Transformador de Corrente } \\ \text { TCP } & \text { Transmission Control Protocol } \\ \text { TP } & \text { Transformador de Potência } \\ \text { UCA } & \text { Utility Communications Architecture } \\ \text { UDP } & \text { User Datagram Protocol } \\ \text { UTP } & \text { Unshielded Twisted Pair } \\ \text { VLAN } & \text { Virtual LAN } \\ \text { XCBR } & \text { Logical Node for Circuit Break } \\ \text { XML } & \text { eXtensible Modeling Language }\end{array}$




\section{SUMÁRIO}

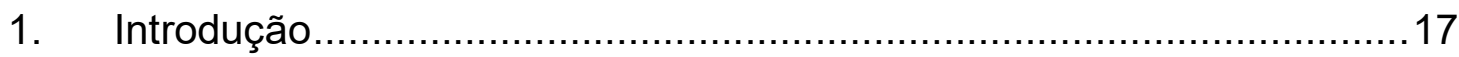

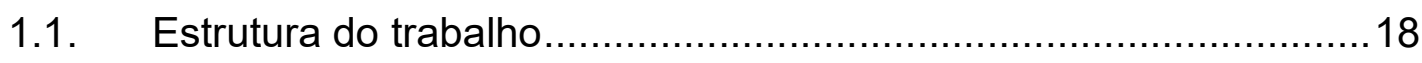

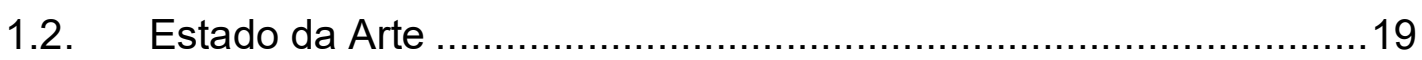

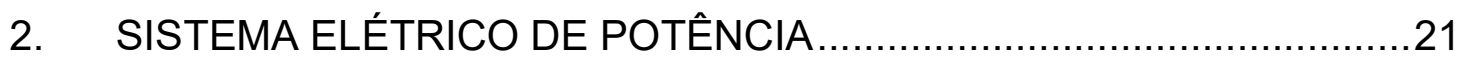

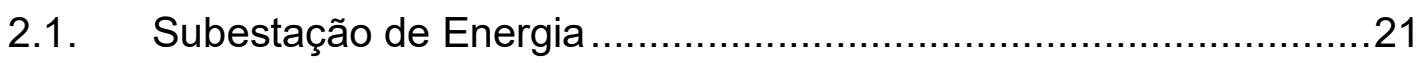

2.2. Dispositivos Eletrônicos Inteligentes de Proteção .......................21

2.3. Automação de Sistemas Elétricos.......................................24

2.4. Sistemas de Supervisão e Controle ...........................................24

2.5. Protocolos de Comunicação …................................................25

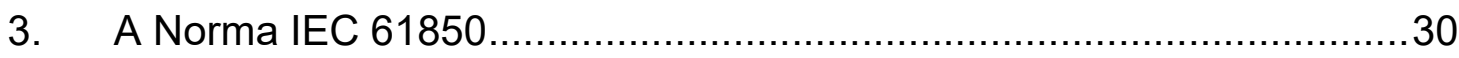

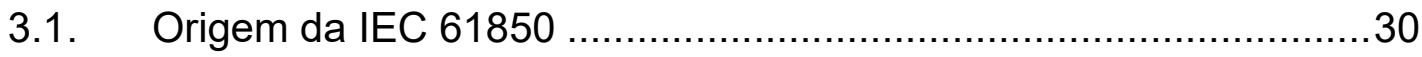

3.2. Modelagem de Objetos de Dados...................................... 31

3.3. Serviços de Comunicação................................................. 33

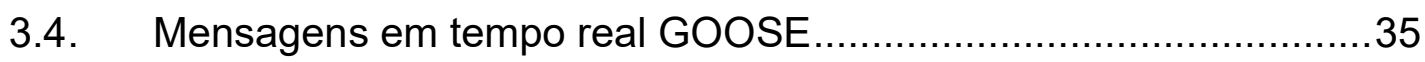

3.5. Arquivos de descrição da configuração ................................41

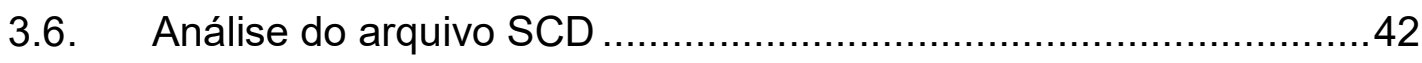

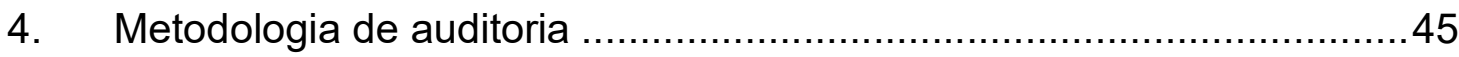

4.1. Processo de Auditoria das Mensagens GOOSE .......................45

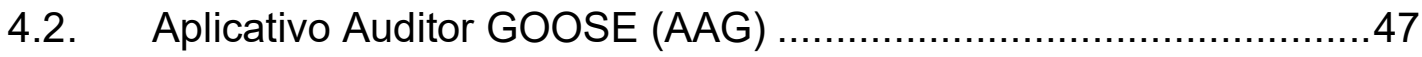

4.3. Arquivo de Tradução GOOSE (ATG) ....................................53

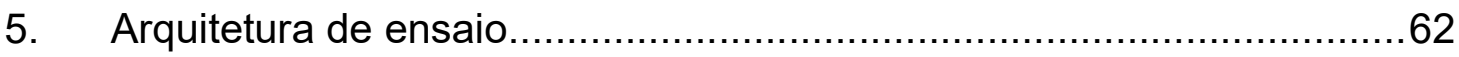

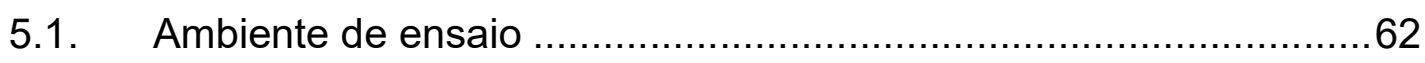

5.2. Configuração do ambiente de ensaio....................................65

5.2.1. Configuração da interface de rede do PC ..............................65

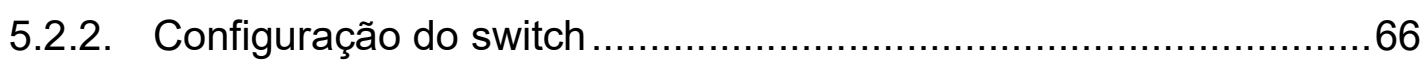

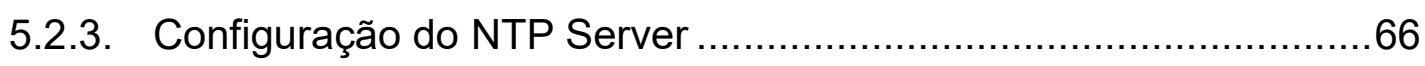




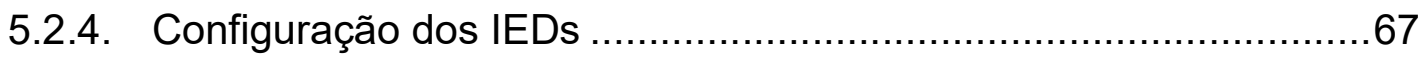

5.3. Definição das funções lógicas ........................................................70

5.4. Configuração da publicação GOOSE............................................73

5.5. Configuração da assinatura das mensagens GOOSE .....................76

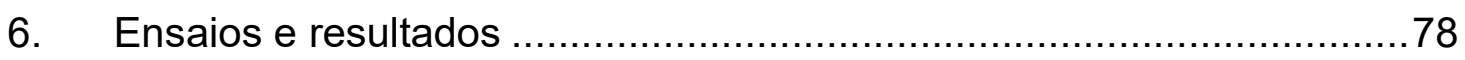

6.1. Identificação de arquivos e interface de rede ................................78

6.2. Validação da Captura do Pacote pelo AAG ………........................80

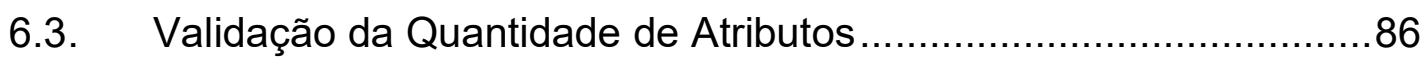

6.4. Tradução dos Atributos GOOSE Capturados................................86

6.5. Identificação de Alteração da Configuração GOOSE.......................87

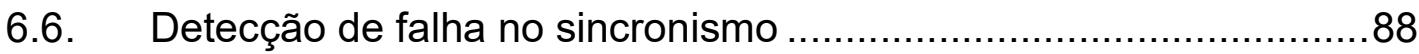

6.7. Detecção da Ausência de Mensagens GOOSE...............................89

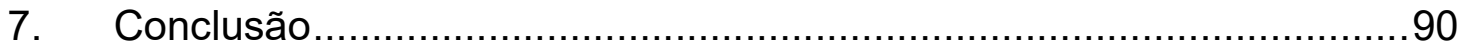

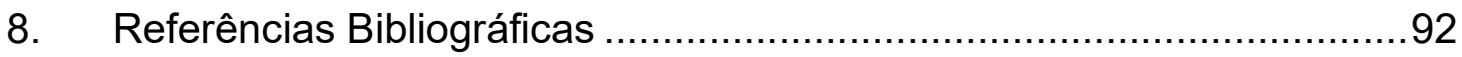

ANEXO A

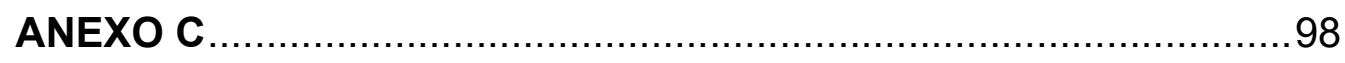

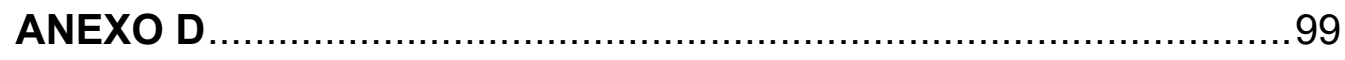

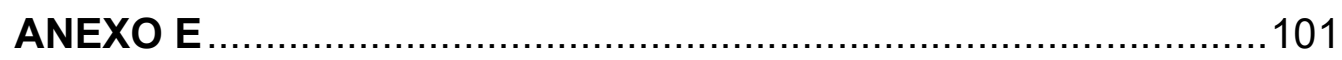

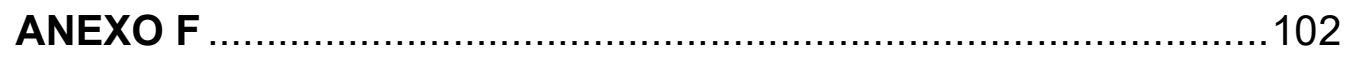

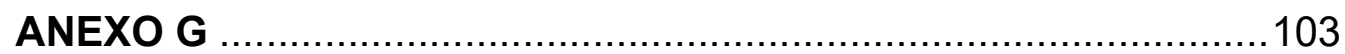

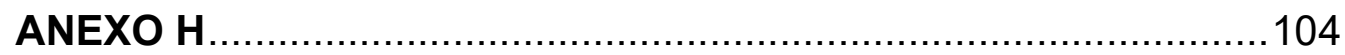

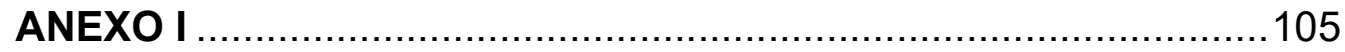

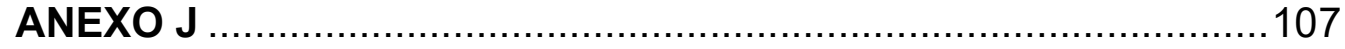

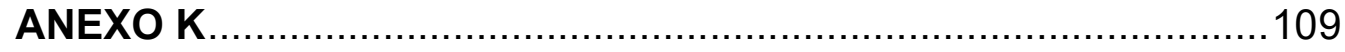

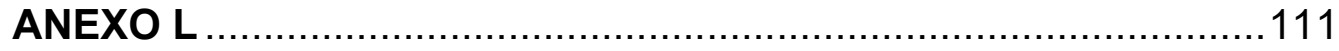

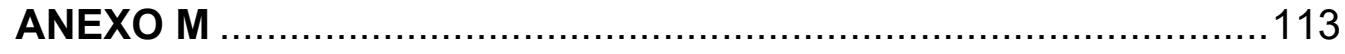

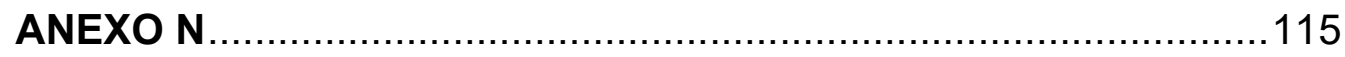


ANEXO $O$

ANEXO P

119

ANEXO Q 122 


\section{Introdução}

Nos últimos anos ocorreram mudanças nas tecnologias empregadas no setor elétrico, proporcionando redução de tamanho de equipamentos e trazendo novas funcionalidades. Como resultado dessas mudanças, foram mantidos ou até mesmo melhorados os níveis de confiabilidade dos equipamentos com aumento significativo da disponibilidade dos mesmos (RUSH, 2010).

Para adequar e padronizar os novos conceitos aplicados nos projetos de automação, operação e a manutenção das subestações de energia elétrica, a International Electrotechnical Commission (IEC), criou a norma 61850 Communication networks and systems for power utility automation. Sua ampla utilização pelos principais fabricantes de Intelligent Electronic Devices (IED), fez surgir novas possibilidades de atuação integrada dos componentes de proteção, comando e supervisão através da troca de mensagens Generic Object Oriented Substation Events (GOOSE).

A norma IEC 61850 tem sido cada vez mais utilizada pelas empresas do setor de energia elétrica na concepção de novas subestações e no processo de atualização de SEs mais antigas. A possibilidade da troca de mensagens GOOSE no barramento horizontal para funcionalidades de proteção e controle reduz a necessidade da utilização de cabos elétricos para interligação dos IEDs com o objetivo de compartilhar informações (KIMURA, ABBOUD, et al., 2008).

Com a utilização do GOOSE, a dependência de cabos elétricos para sensoriamento de sinais analógicos e digitais entre os IEDs instalados nas subestações é reduzido, pois as informações podem ser facilmente transportadas por mensagens de comunicação. Porém, a utilização do GOOSE em funções críticas como proteção e comando exige cuidado especial na verificação do seu correto funcionamento.

Para comunicação por GOOSE, um arquivo Substation Configuration Description (SCD) é configurado. Devido a particularidades da configuração, muitas delas com o objetivo de tornar a transmissão de mensagens ágil e não prejudicar o desempenho do IED, não é prevista uma forma de verificar se o dispositivo está enviando corretamente as informações previstas no projeto inicial, conforme os datasets (conjunto de dados) dos arquivos de configurações. 
Contudo, a anterior interligação elétrica possibilitava analisar os pontos fisicamente utilizando equipamentos simples de teste de continuidade ou medição caso houvesse necessidade. Para o modelo IEC 61850, o diagnóstico de possíveis falhas envolvendo as mensagens GOOSE requer mão de obra especializada e a utilização de diversos recursos de softwares para conclusão.

Para que os equipamentos inteligentes possam atuar corretamente em subestações configuradas de acordo com a norma IEC 61850, se faz necessário o uso de mão de obra especializada, documentos padronizados e ferramentas que possibilitem aos usuários analisarem amigavelmente as mensagens GOOSE trafegadas. Como não é previsto na norma IEC 61850 uma forma de garantir o correto funcionamento dos IEDs para publicação GOOSE, algumas ferramentas disponibilizadas no mercado são de uso específico para alguns fabricantes, não sendo possível a utilização em ambientes heterogêneos. A metodologia aqui proposta vem ao encontro de atender uma parte desse novo cenário, pois visa propor uma ferramenta única que possibilita documentar, auditar e identificar possíveis falhas nas mensagens GOOSE publicadas no barramento horizontal independente do fabricante.

\subsection{Estrutura do trabalho}

A estrutura deste trabalho é composta por sete capítulos incluindo este primeiro introdutório. Também neste primeiro capítulo, algumas pesquisas utilizadas como referências são comentadas, indicando o atual momento do estado da arte para o tema.

O segundo capítulo aborda os detalhes da inovação tecnológica dos sistemas de proteção e automação das subestações ao longo dos anos. Neste capítulo, também são comentados os componentes que formam um sistema elétrico de potência.

No terceiro capítulo são apresentados os conceitos da norma IEC 61850, sendo o foco específico nos capítulos 6, 7 e 8 que, contém as principais informações da metodologia elaborada neste trabalho.

No quarto capítulo é apresentada a proposta para metodologia de auditoria das mensagens GOOSE. Apresentam-se também o arquivo auxiliar elaborado como referência da configuração definida no projeto inicial e o aplicativo auditor desenvolvido para o automatismo do processo. 
No quinto capítulo a arquitetura física e lógica utilizada durante a pesquisa é apresentada. Também neste capítulo são detalhadas as configurações parametrizadas nos dispositivos.

O sexto capítulo apresenta os ensaios realizados e os resultados obtidos com o aplicativo desenvolvido, produto deste trabalho, que são a auditoria das mensagens GOOSE e a apresentação dos atributos de acordo com a tradução definida pelo usuário.

Uma conclusão é apresentada no sétimo e último capítulo, mostrando que é possível auditar as mensagens GOOSE em rede IEC 61850 e diagnosticar divergência com base no projeto inicial.

\subsection{Estado da Arte}

A norma IEC 61850 é um tema bastante abordado em pesquisas científicas da área de engenharia elétrica e automação. Ao pesquisar sobre o tema, percebe-se que os benefícios da utilização da norma IEC 68150 podem ser observados em diversos campos da sua aplicação, desde a infraestrutura de implantação quanto na velocidade de atuação dos disparos e monitoramento em tempo real do sistema. Acrescenta-se também o surgimento de um novo perfil profissional para atuar nos ambientes onde a norma é inserida.

Na pesquisa realizada por Vicente (VICENTE e SENGER, 2011), é proposta a troca de informações entre agentes de subestações compartilhadas de transmissão e distribuição de energia elétrica utilizando de recursos da norma IEC 61850. O trabalho visa a substituição de sinais elétricos por sinais lógicos para comunicação dos equipamentos compartilhados.

No trabalho de Netto (NETTO, 2012), foi pesquisado um parâmetro de dimensionamento para monitoramento do desempenho de mensagens GOOSE do padrão IEC 61850. O autor destaca as mudanças que ocorreram nas subestações com a implementação da norma IEC61850. Através desse processo de digitalização, os sinais que antes eram enviados através de contatos elétricos físicos, passaram a ser enviados por sinais lógicos; consequentemente, a confiabilidade do sistema de proteção passou a depender da rede de comunicação de dados. Diante disso o autor propõe o uso de um serviço de priorização de pacotes Quality of Service (QoS) e a 
ocupação da banda dos IEDs para determinar um parâmetro que garanta o desempenho das mensagens GOOSE em uma rede IEC 61850.

No trabalho de Araujo (ARAUJO, CAMPELLO e GUALTIERI, 2011), foi pesquisado, uma aplicação da norma IEC 61850-8-1 nas redes de proteção do sistema elétrico. A autora aborda uma aplicação de auditoria para ser responsável por monitorar a rede de proteção e garantir a consistência da rede. Com a aplicação, uma melhor compreensão do que ocorre na rede, para permitir a identificação de problemas, como, por exemplo, relé não atualizado, é discutida. Além disso, a autora destaca que a auditoria de mensagens GOOSE é de fundamental importância para a análise dos telegramas e compreensão dos estados de cada relé e da subestação. Segundo a autora, ela facilita a combinação de informações para fornecer uma análise muito mais completa da rede.

No trabalho de Souza, (SOUZA e MARCOS, 2012), foi apresentado uma proposta de um sistema de monitoramento e validações de comunicação nas redes de subestações de energia. $O$ autor defende a ideia de que, em redes que seguem os padrões da norma IEC 61850, seja possível prever mecanismos que realizem o controle dos telegramas GOOSE, garantindo dessa forma a integridade e periodicidade dentro dos parâmetros definidos em norma. O objetivo do trabalho foi desenvolver um software que pudesse ser executado em computadores, utilizando qualquer sistema operacional, para realizar auditoria das mensagens GOOSE e controle da largura de banda de rede.

Entre os trabalhos pesquisados, os trabalhos de Araujo (ARAUJO, CAMPELLO e GUALTIERI, 2011) e Souza (SOUZA e MARCOS, 2012), são os mais semelhantes à metodologia apresentada nessa pesquisa. A diferença é que a metodologia aqui apresentada visa a criação de um arquivo auxiliar utilizado para documentar as mensagens GOOSE publicadas e assinadas pelos IEDs. Também é proposto, nesse arquivo a inserção da tradução dos atributos contidos nas mensagens GOOSE para facilitar interpretação dos dados pelo usuário. Outra diferença entre os trabalhos pesquisados está na linguagem de programação utilizada para o desenvolvimento do software auditor, para os trabalhos anteriores foi utilizado a linguagem de programação JAVA e para o trabalho aqui proposto foi utilizado a linguagem Microsoft $\operatorname{dotNET~C\# .~}$ 


\section{SISTEMA ELÉTRICO DE POTÊNCIA}

\subsection{Subestação de Energia}

As SEs (Subestações de Energia Elétrica) são instalações que abrigam e conectam diversos equipamentos para garantir a transmissão, distribuição, proteção e controle de energia elétrica. É função de uma SE o direcionamento e o controle do fluxo energético, a elevação ou diminuição dos níveis de tensão, e a entrega de energia para os consumidores residenciais e industriais.

As SEs são pontos críticos do SEP (Sistema Elétrico de Potência). Ações e comandos executados devem ser coordenados por meio de programas, funções lógicas e filosofias de operação, em sintonia com informações disponibilizadas por sistemas de medição e proteção. Para isto, são utilizados dispositivos de manobras, como disjuntores e chaves, para medição, transformadores de corrente (TC) e de potencial (TP) são utilizados. (DUARTE, 2012)

Os sistemas de potência, devido aos seus requisitos de alta confiabilidade, alta disponibilidade e rapidez nas respostas a ocorrências, incorporam de forma bastante cautelosa o progresso tecnológico verificado, por exemplo, nas áreas de telecomunicação e computação (VICENTE e SENGER, 2011). A norma IEC 61850, desde sua elaboração inicial em 2002, tem sido referência no processo de modernização da concepção dos projetos e na forma de operação das subestações de energia elétrica, apesar de ainda enfrentar resistência por parte dos setores mais conservadores.

\subsection{Dispositivos Eletrônicos Inteligentes de Proteção}

Inicialmente, equipamentos com tecnologia eletromecânica eram utilizados para operação e proteção dos sistemas de geração, transmissão e distribuição de energia elétrica de todos os portes. Como esses equipamentos disponibilizavam poucas informações (como sinalizações em quadros de lâmpadas e bandeirolas), e não existia um meio de comunicação que permitisse o acesso remoto, a integração entre instalações era bastante reduzida.

Os relés estáticos começaram a substituir os relés eletromecânicos a partir da década de 60. Componentes eletrônicos foram inseridos na construção desses 
equipamentos e todas as funcionalidades dos relés eletromecânicos puderam ser adicionadas aos dispositivos estáticos (JARDINI, 1997).

Estes dispositivos ainda estão em uso, porém foram descontinuados pelos fabricantes e estão sendo substituídos pelo setor elétrico após os primeiros relés digitais surgirem com a chegada dos microprocessadores. Os relés estáticos utilizam em seus algoritmos as premissas dinâmicas dos relés eletromecânicos integrados à evolução da eletrônica digital (VICENTE e SENGER, 2011).

O avanço tecnológico permitiu que os IEDs pudessem executar diversas funções, como por exemplo, aquisição de dados na rede, múltiplas funções de proteção, automação, controle, comunicação e até gerar arquivos de oscilografias (DUARTE, 2012).

Atualmente os IEDs, como também são conhecidos os relés digitais, estão consolidados no setor elétrico, sendo instalados tanto em projetos de novas subestações de energia elétrica como em projetos de substituição onde antigos relés eletromecânicos e estáticos são substituídos por dispositivos modernos (VICENTE e SENGER, 2011).

Normalmente a troca de informações entre os IEDs em projetos de subestações de energia elétrica anteriores à norma IEC 61850 é realizado através de cabos que interligam os contatos de entradas e saídas dos equipamentos instalados no ambiente e, dependendo do número de dispositivos e variáveis supervisionadas, a instalação dos cabos pode representar uma parcela considerável do custo do projeto (RUSH, 2010).

O rompimento de cabos elétricos de comunicação e o desgaste natural dos contatos dos equipamentos são exemplos comuns de problemas em uma subestação de energia pré-IEC-61850. Apesar disso, realizar análise dos problemas neste ambiente é menos complexo se comparado à subestações seguindo as premissas da IEC 61850, pois a utilização de equipamentos específicos que possibilitam identificar: continuidade, valores de corrente e tensão, podem ser suficientes para que um diagnóstico primário do problema seja realizado

A Figura 1 mostra a quantidade de cabos utilizados para troca de informações entre IEDs quando não realizada por mensagens GOOSE. 
Figura 1 - Quantidade de cabos conectados no relé

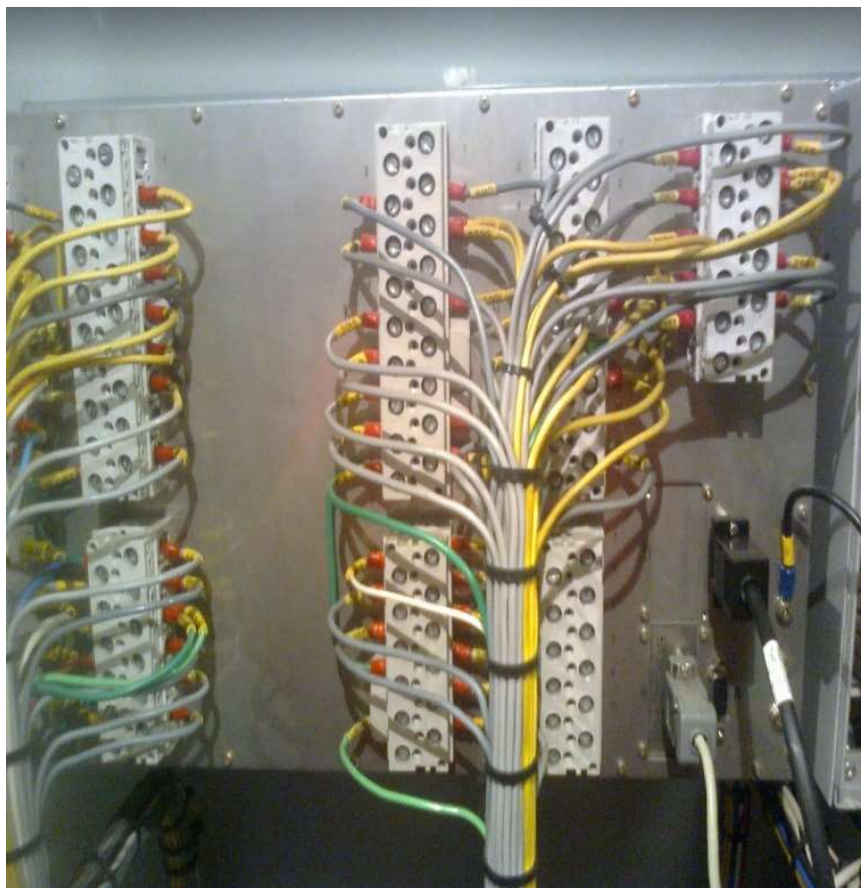

Fonte: $\mathrm{O}$ autor

A Figura 2 contém a imagem de um IED integrado com IEC-61850. Observando a imagem é possível afirmar que para troca de informações entre os IEDs, apenas a conexão do dispositivo na rede é necessária. A porta de comunicação $B$ está conectada na rede através de um cordão de fibra óptica.

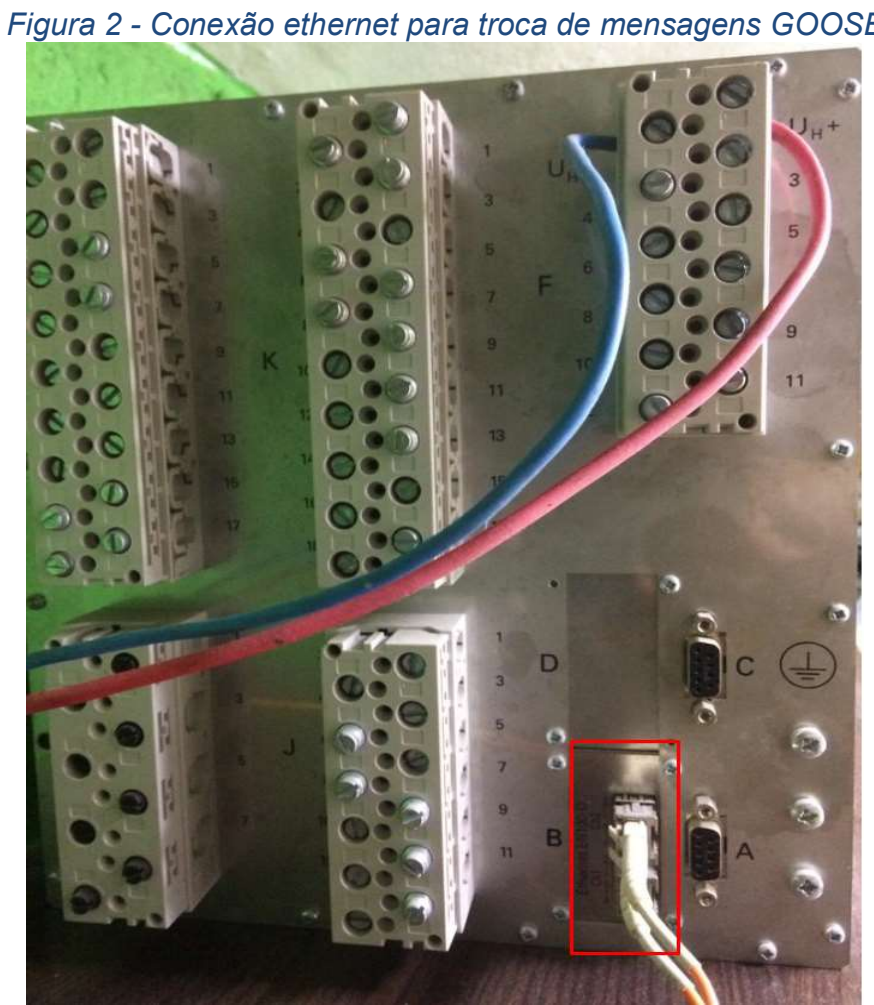

Fonte: $\mathrm{O}$ autor 


\subsection{Automação de Sistemas Elétricos}

"O desenvolvimento da automação elétrica nas subestações está diretamente relacionado ao desenvolvimento dos relés digitais. Muitas aplicações deixaram de trabalhar isoladas e foram incorporadas aos demais sistemas das subestações, através de rede de comunicação ou através de funções agregadas aos relés de proteção". (VICENTE e SENGER, 2011)

Os sistemas de automação de sistemas elétricos são conjuntos formados por hardware e software que possibilitam a visão completa dos equipamentos de energia e dos demais sistemas da operação, controlando sistemas elétricos cuja abrangência geográfica atende a pequenas instalações ou grande áreas. Uma das funções básicas dos sistemas é o monitoramento de todas as operações e a sinalização imediata caso ocorra qualquer evento divergente do esperado para a rede supervisionada. A utilização de computadores para o controle de redes elétricas vem sendo aplicado desde o início dos anos 1970. (RUSH, 2010)

\subsection{Sistemas de Supervisão e Controle}

SSCs (Sistema de Supervisão e Controle) são sistemas independentes e integrados, são responsáveis por controlar as SEs e/ou processos, através de interfaces com os dispositivos de campo. Os SSCs são responsáveis por promover a interface entre os sistemas de controle, os usuários e outros sistemas, bem como realizar operações como registro de dados e exibição de alarmes. No início, as primeiras aplicações dos sistemas SCADA (Supervisory Control and Data Acquisition) eram instaladas nos centros de comando das companhias, centralizando assim, toda a operação e controle das subestações. Atualmente, com a redução dos custos e maior capacidade de processamento de informação pelos equipamentos e softwares, viabilizou-se a implantação desses sistemas também na forma distribuída, proporcionando o controle e automação local. (RUSH, 2010)

A possibilidade de operar remotamente SEs a partir do COS (Centro de Operação do Sistema) tem proporcionado para as empresas a alternativa de não alocar recursos humanos, como por exemplo, operadores, dentro de subestações de energia, que podem funcionar de forma teleassistida, sendo supervisionada e comandadas remotamente. A SE supervisionada remotamente e sem operadores locais recebe o nome de Subestação Desassistida. Conforme a Resolução Normativa 
$\mathrm{n}^{\circ}$ 864, (MME e ANEEL, 2019), as SEs desassistidas também estão sujeitas a penalidades de PVI (Parcela Variável por Indisponibilidade) se houver impossibilidade de utilização de seus equipamentos para manobra ou operação enquanto ela permanecer energizada, assim, os meios de comunicações utilizados para operar essas SEs podem ser classificados como críticos.

\subsection{Protocolos de Comunicação}

O modelo de referência OSI (Open Systems Interconnection) se baseia em uma proposta desenvolvida pela ISO (International Standards Organization) como um primeiro passo em direção à padronização internacional dos protocolos usados nas várias camadas. Protocolo é um conjunto de regras que controla o formato e o significado dos pacotes ou mensagens trocadas pelas entidades pares contidos em uma camada.

O modelo OSI é constituído por sete camadas e a relação entre elas é apresentada na Figura 3.

A primeira camada, denominada camada física, é o núcleo das redes de computadores. Esta camada é responsável por definir os meios de transmissão de dados e sua largura de banda. Os meios podem ser definidos como: guiados; par trançados, coaxial e a fibra óptica, e não guiados; rádio, as micro-ondas, os raios infravermelhos, os raios laser através do ar e os satélites.

A segunda camada, camada de enlace de dados, tem a função de receber os sinais originados da camada física, organizá-los e entregá-los à camada de rede. A apresentação dos dados da camada de enlace pode utilizar vários níveis de confiabilidade, sendo estes níveis desde o serviço sem confirmação de resposta até com a confirmação. Esta camada possui funções específicas para detectar erros, que podem ser utilizados para anular ou corrigir o quadro danificado. Uma das funções da camada de enlace é o controle de fluxo, utilizado para que um emissor com maior capacidade de transmissão não oprima um emissor com capacidade inferior.

A terceira camada do modelo OSI é chamada de camada de rede. A camada recebe os pacotes ordenados da camada anterior, camada de enlace, e sua principal função é rotear os pacotes da origem até o destino. Existem diversos protocolos de roteamento utilizados para essa função, alguns desses protocolos tem a função de identificar de forma dinâmica o caminho mais curto para a rede destino. 
A quarta camada do modelo OSI é chamada de camada de transporte. A função mais importante desta camada é garantir a confiabilidade do tráfego de dados entre o emissor e o receptor. Os protocolos desta camada são capazes de realizar o gerenciamento da conexão em redes não confiáveis, utilizando recursos de handshakes para esta função. Os protocolos mais importantes para esta camada são: User Datagram Protocol (UDP); o destinatário não necessita confirmar o recebimento de mensagens para o emissor para a próxima mensagem seja enviada, e o Transmission Control Protocol (TCP); o emissor requer confirmação do destinatário para o recebimento da mensagem, só então a próxima mensagem é enviada.

A camada de sessão é a quinta camada do modelo OSI. A função desta camada é permitir que dispositivos conectados às redes estabeleçam sessões de comunicação entre si através das portas de serviços disponíveis. Esta camada direciona os dados para os serviços específicos da camada de apresentação.

A sexta camada do modelo OSI é a camada de apresentação. Diferente das camadas abaixo, que são responsáveis pela movimentação dos dados, esta camada tem a função de interpretar o conteúdo do bloco de dado e disponibilizá-lo à camada de aplicação para que possa ser transformado em informação.

A sétima e última camada do modelo OSI é a camada de aplicação; esta camada contém os protocolos necessários para formatar os dados recebidos e apresentá-los em forma de informação através das aplicações e programas específicos de cada protocolo. 
Figura 3 - Modelo de referência OSI/ISO

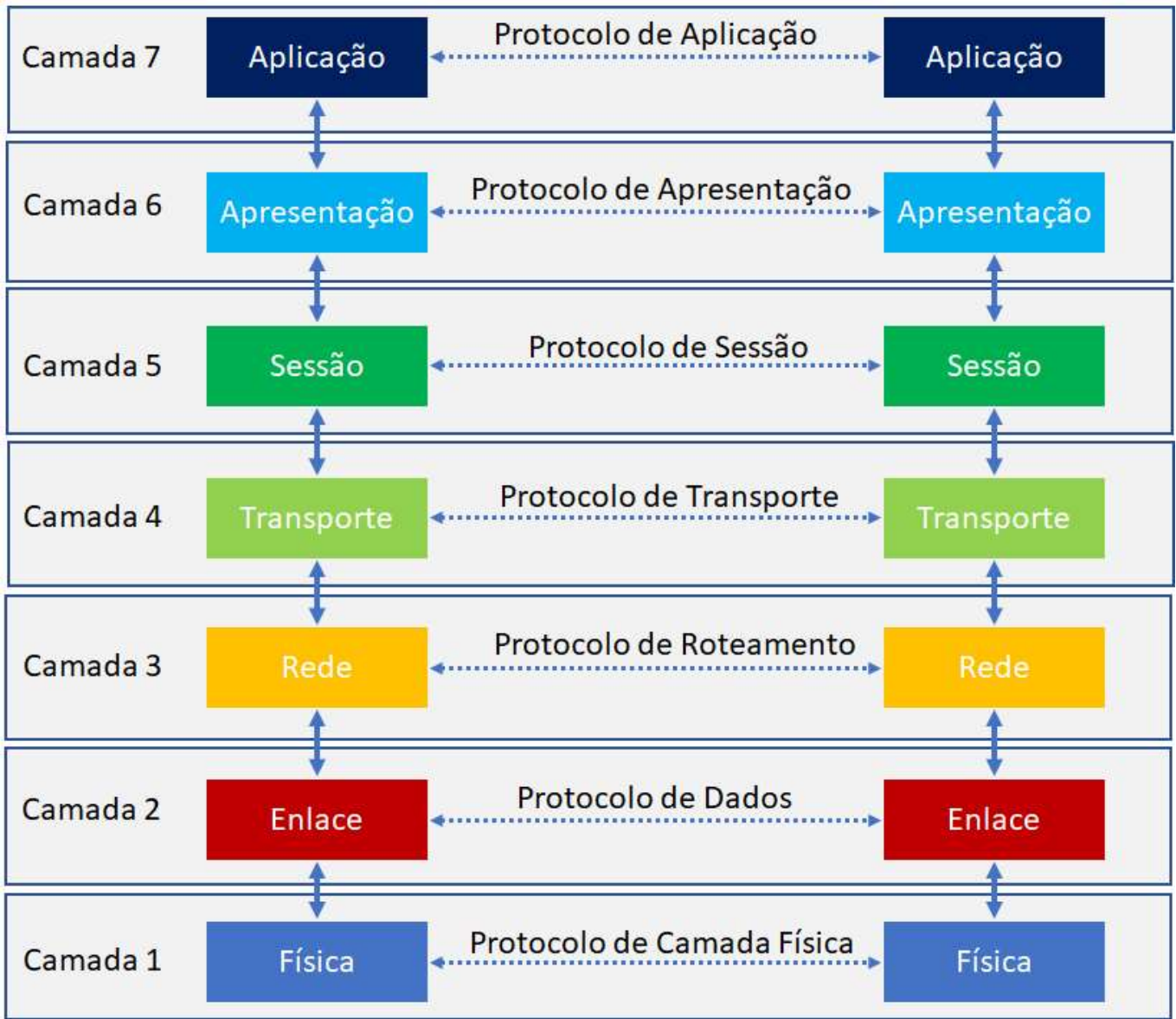

Fonte: Adaptado de (TANENBAUM, 1997)

A Figura 3 ilustra a relação das 7 camadas do modelo OSI. A camada de rede $\mathrm{n}$ de uma máquina se comunica com a camada $\mathrm{n}$ da outra máquina. Portanto, protocolo, segundo (TANENBAUM, 1997), é um conjunto de regras que controla o formato e o significado dos quadros, pacotes ou mensagens trocadas pelos pares de entidades contidos em uma camada. Basicamente são definidos por um conjunto de: (VICENTE e SENGER, 2011)

a) formato de mensagens;

b) serviços;

C) procedimentos;

d) endereçamento;

e) convenção de nomes.

Com os novos recursos dos equipamentos instalados nas subestações, resultado do avanço tecnológico constante, novos protocolos de comunicação foram inseridos nos IEDs. 
Antes do desenvolvimento dos protocolos abertos, como, por exemplo, o Distributed Network Protocol 3 (DNP3), os sistemas existentes nas subestações trabalhavam de forma isolada, pois cada fabricante desenvolvia protocolos específicos de comunicação para seus equipamentos e sistemas, dificultando a integração entre os sistemas de fabricantes diferentes.

Algumas iniciativas para padronizar a comunicação entre os equipamentos e os sistemas no setor elétrico começaram a ser idealizadas no início da década de 90 . A Utility Communications Architecture (UCA) surgiu como um framework para o conjunto de requisitos de comunicação para serviços públicos cujo objetivo foi consolidar as comunicações entres os departamentos de planejamento, supervisão, medição, proteção e controle (ADAMIAK, BAIGENT, et al., 2002). O processo começou com a criação da definição de requisitos de comunicação para as várias funções dentro de uma subestação. Os requisitos funcionais especificados foram seguidos por uma implementação e avaliação inicial que definiu o padrão de uma estrutura de comunicação para a subestação. A Figura 4 apresenta a estrutura de comunicação UCA. O objetivo na definição do padrão da subestação era implementar uma rede ponto a ponto de alta velocidade, conectável, usando o maior número de protocolos possível. Além disso, o objetivo da interoperabilidade de dados do usuário exigia a definição de nomes padronizados para objetos de dados comumente usados.

O padrão desenvolvido utiliza Ethernet para os processos físico e camadas do Data Link. Para camada de rede, embora o objetivo original foi permanecer dentro dos padrões da ISO, a IEC selecionou o TCP / IP como o protocolo de rede obrigatório para comunicações interna e externa da subestação e as camadas de rede OSI como opcional (ADAMIAK, BAIGENT, et al., 2002). Para a camada de aplicação ou serviços, - Manufactory Message Specification (MMS) foi escolhido; sua capacidade de manipular objetos lógicos o diferencia de todos os outros padrões existentes. Atualmente a UCA encontra-se na versão 2.0 (UCA2.0).

Em 1997 foi criado um comitê formado pelo Electric Power Research Institute (EPRI), Electrical and Electronics Engineers (IEEE) e IEC Technical Committee 57 para criar um padrão internacional resultando na atual norma IEC-61850 (VICENTE e SENGER, 2011). 
Figura 4 - Padrão de comunicação UCA

\begin{tabular}{|c|c|c|}
\hline & & Modelo de Camadas \\
\hline \multicolumn{2}{|c|}{$\begin{array}{l}\text { General Model For Substation and Field } \\
\text { Equipmaent - including GOOSE }\end{array}$} & Dados de Usuário \\
\hline \multicolumn{2}{|c|}{ Manufacturing Messaging Specification } & Aplicação \\
\hline $\mathrm{TCP} / \mathrm{IP}$ & ISO & Rede \\
\hline \multicolumn{2}{|c|}{ Ethernet } & Física \\
\hline
\end{tabular}

Fonte: Adaptado de (ADAMIAK, BAIGENT, et al., 2002) 


\section{A Norma IEC 61850}

\subsection{Origem da IEC 61850}

A norma IEC 61850 foi desenvolvida com o objetivo de melhorar a interoperabilidade entre os equipamentos instalados em subestações de energia (CLAVEL, SAVARY, et al., 2014). A evolução contínua da norma tem ocorrido através da colaboração conjunta de fabricantes, instituições de pesquisas e órgãos normativos internacionais (VICENTE e SENGER, 2011),

A norma IEC 61850 teve sua primeira versão publicada em 2003, introduzindo princípios de interoperabilidade, quando dois dispositivos ou mais, independentes do fabricante, trocam informações e usam-nas para sua própria funcionalidade (DUARTE, 2012).

A estrutura da IEC 61850 é completamente diferente se comparada a modelos clássicos de protocolo de comunicação, como DNP3, por exemplo, e muda totalmente a maneira de organizar um projeto elétrico de subestação. Comparando ao DNP3, que é apenas um protocolo de comunicação, IEC 61850 é um padrão completo que define, entre outros:

a) modelagem de dados: como descrever os dispositivos em uma subestação elétrica;

b) protocolos de comunicação: como é realizado a troca de informação entre os dispositivos e sistemas.

Nos projetos de subestação de energia elétrica, seguindo os conceitos da norma IEC 61850, a estrutura de comunicação de dados se torna tão importante quanto o projeto elétrico. Consequentemente, para a validação de uma configuração, o Teste de Aceitação de Fábrica (TAF) e o Teste de Aceitação de Campo (TAC) devem ser reconsiderados.

Na Tabela 1 estão apresentadas as dez partes que constituem a norma IEC 61850 em sua primeira versão. A pesquisa contida neste trabalho foi realizada especificamente nas partes 61850-6, 61850-7 e 61850-8.

Tabela 1 - Partes da Norma IEC 61850 versão 1

\begin{tabular}{|l|l|}
\hline Parte & Descrição \\
\hline 1 & Introdução e visão global \\
\hline
\end{tabular}




\begin{tabular}{|l|l|}
\hline Parte & Descrição \\
\hline 2 & Glossário \\
\hline 3 & Requisitos gerais \\
\hline 4 & Gerenciamento do sistema e projeto \\
\hline 5 & Requisitos de comunicação para funções e modelos de dispositivos \\
\hline 6 & $\begin{array}{l}\text { Configuração da linguagem de descrição para comunicação em subestações com } \\
\text { IEDs }\end{array}$ \\
\hline 7 & Estruturas de comunicação básicas para subestações e alimentadores \\
\hline 7.1 & Princípios e modelos \\
\hline 7.2 & Interface do Serviço de Comunicação Abstrata (ACSI) \\
\hline 7.3 & Classes de dados Comuns (CDC) \\
\hline 7.4 & Classes de dados e nós lógicos compatíveis \\
\hline 8 & Serviço de mapeamento de comunicação específico \\
\hline 8.1 & Mapeamento para MMS (ISSO/IEC 9506 - Partes 1 e 2) e ISSO/IEC 8802-3 \\
\hline 9.1 & $\begin{array}{l}\text { Mapeamento para serviço de comunicação específico (SCSM) - Valores } \\
\text { amostrados sobre enlace serial unidirecional ponto a ponto }\end{array}$ \\
\hline 9.2 & $\begin{array}{l}\text { Mapeamento para serviço de comunicação específico (SCSM) - Valores } \\
\text { amostrados sobre ISSO/IEC 8802-3 }\end{array}$ \\
\hline 10 & Testes de conformidade \\
\hline
\end{tabular}

Fonte: O autor

\subsection{Modelagem de Objetos de Dados}

A modelagem da comunicação orientada a objeto é a base da arquitetura IEC 61850. Diferente do utilizado em outros protocolos, a identificação dos dispositivos do sistema elétrico e as funções de proteção são feitas por um dicionário de nomes e utiliza uma estrutura hierárquica de objetos;

a) Dispositivo físico (PD, do inglês physical device) - destinado a equipamento que executa uma ou mais funções com seu endereço de rede. Exemplo de dispositivos físicos: disjuntores, chaves seccionadoras, relés de proteção, transformador de corrente, transformador de tensão etc. 
b) Dispositivo lógico (LD, de logical device) -dentro de um dispositivo físico, identifica um agrupamento de dados e serviços associados a alguma função do sistema de potência. Por exemplo: controle, medição, etc.

c) Nós lógicos (LN, logical nodes) - dentro do dispositivo lógico representam os objetos do sistema elétrico ou funções de proteção. Por exemplo: PDIF - proteção diferencial e XCBR - disjuntor;

d) Objetos de dados (DO, data objects) - dentro do nó lógico, carregam informações sobre o tipo de ponto, podendo ser um ponto genérico ou outro, por exemplo, a posição ou estado de um disjuntor.

e) Atributos de dados (DA, data attibutes) - cada DO possui uma série de atributos associados a ele, os DA representam o valor do ponto ou sua qualidade, por exemplo, valores de posição do disjuntor e sua qualidade, valores de corrente ou tensão. (COMACCIO, SILVA e COSTA, 2017)

Por exemplo, para o LN\$XCBR, o Logical Node for Circuit Breack (XCBR) representa o disjuntor com os dados POS (posição), para a medição LN\$MMUX, o Logical Node for Measurement (MMXU) representa a potência, tensões, correntes e impedâncias em um sistema trifásico e oferece centenas de valores: (IEC61850-7-4, 2010)
a) valores de medida;
b) valores de configuração;
c) descrição, e;
d) valores de substituição.

A Figura 5 apresenta a estrutura de dados para um disjuntor identificado pelo Logical Node LN\$CXBR. 
Figura 5 - Estrutura de dados definida pela norma

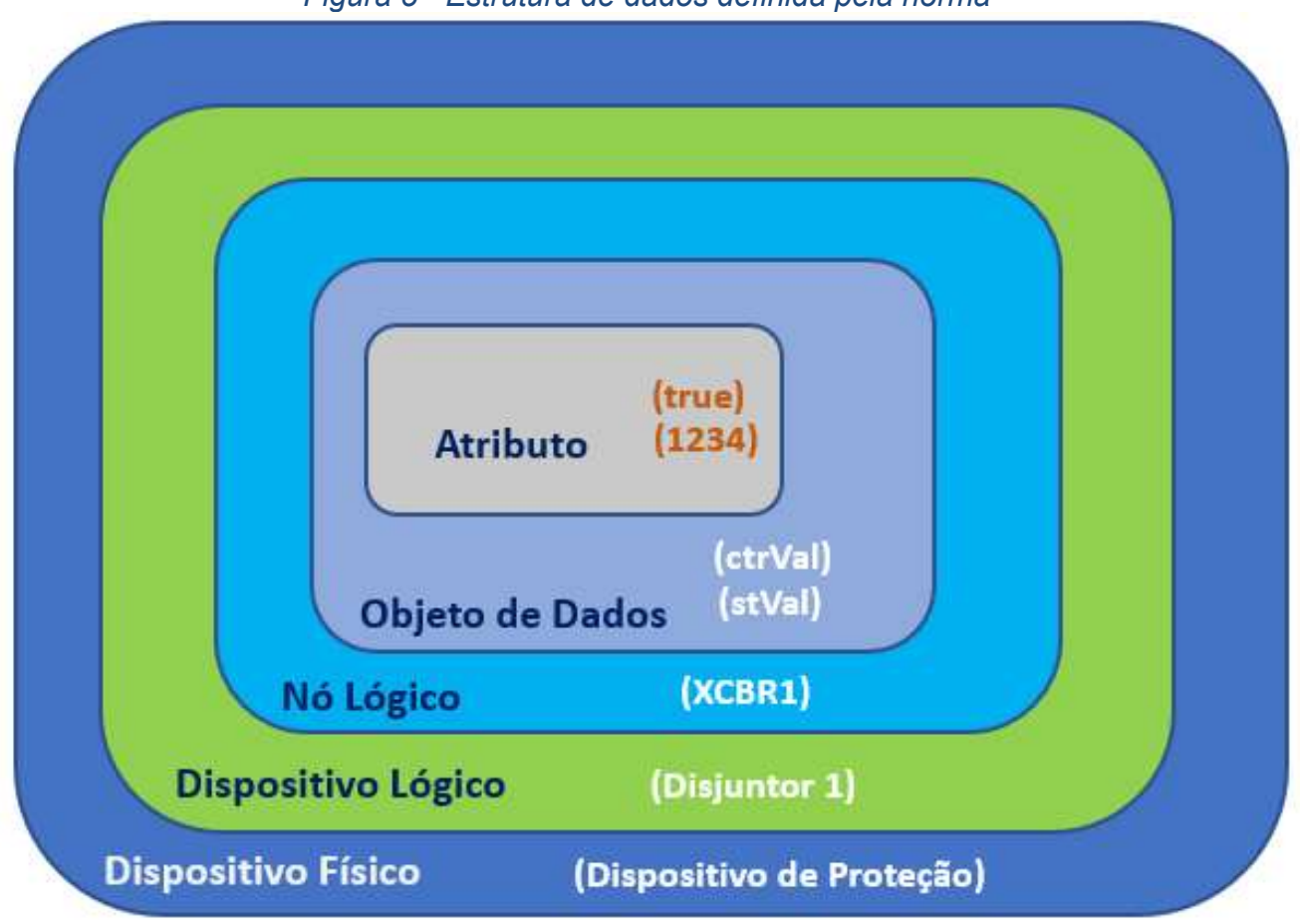

Fonte: Adaptado de (CLAVEL, SAVARY, et al., 2014)

\subsection{Serviços de Comunicação}

A Figura 6 descreve uma arquitetura de rede IEC 61850. O sistema SCADA está conectado aos IEDs através do barramento de estação. A comunicação vertical entre o SCADA e os IEDs é realizada através do protocolo MMS, serviço baseado na camada 3 de comunicação TCP/IP com menores requisitos de tempo. O protocolo MMS permite realizar as seguintes ações nos dispositivos: envio de comandos, leitura dos dados, gravação de parâmetros e disponibilização de eventos por ações não solicitadas. (IEC-61850-8-1, 2011)

Os datagramas GOOSE informam estados e medições, e são mensagens publicadas e assinadas livremente pelos demais dispositivos.

A Figura 7 apresenta a relação dos protocolos utilizados pela norma IEC 61850 e o modelo OSI. AS mensagens GOOSE são transmitidas diretamente na camada de Data Link, por meio de datagramas e são usadas para transmitir informações críticas de proteção.

A Figura 7 mostra também outro tipo de mensagem chamado de Sampled Value (SV). Os valores amostrados de sinais analógicos de medições, por exemplo, são digitalizados e transmitidos via rede de comunicação na camada 2 do modelo OSI. Funções críticas de tempo, como por exemplo, valores de correntes e tensões para 
relés de proteção, são transmitidos através das mensagens SV. O protocolo MMS, como pode ser observado na Figura 7 , utiliza as sete camadas do modelo de referência OSI para ser transmitido.

Figura 6 - Comunicação em uma arquitetura IEC-61850

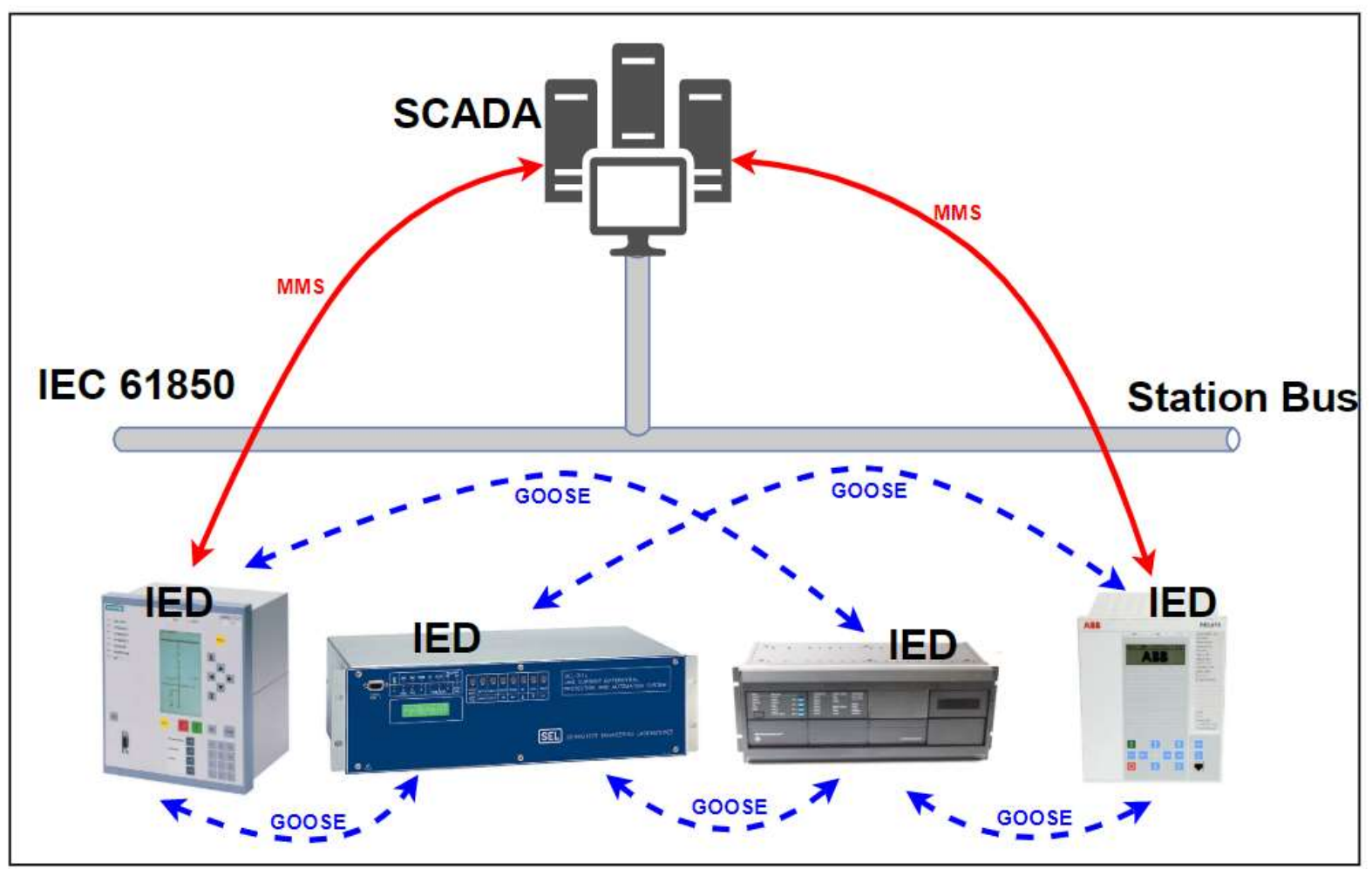

Fonte: $\mathrm{O}$ autor 
Figura 7 - Serviços de comunicação da norma IEC-61850 no modelo OSI

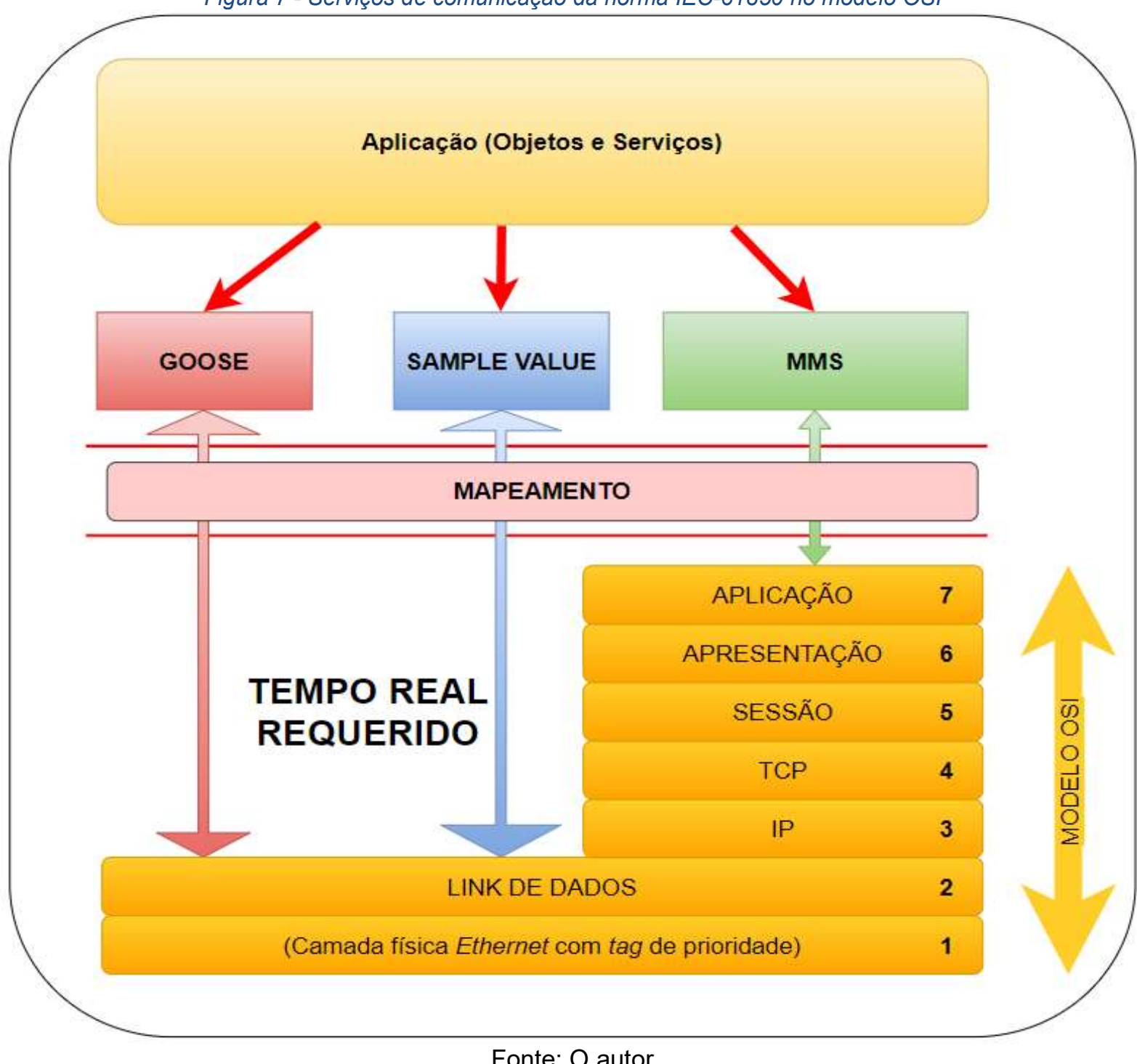

Fonte: $\mathrm{O}$ autor

\subsection{Mensagens em tempo real GOOSE}

O pacote de GOOSE é detalhado na parte 8-1 da norma IEC 61850. Esta parte da norma aborda a estrutura básica de informação e comunicação (IEC-61850-8-1, 2011).

Para fornecer serviços avançados para subestações de energia elétrica, a norma IEC 61850 permite que mensagens críticas entre equipamentos sejam trocadas em tempo real através do barramento de processos e de estação. São alguns exemplos de mensagens críticas:

- Intertravamento;

- transferência de carga;

- transferência automática de fonte. 
Como apresentado na Figura 7 as mensagens GOOSE são transmitidas diretamente na camada 2 do modelo OSI. As mensagens são enviadas por uma transmissão em multicast e possuem alta prioridade na rede. Com a utilização das mensagens a necessidade de uso de cabos elétricos é bastante reduzida. (KIMURA, ABBOUD, et al., 2008)

As mensagens GOOSE são publicadas periodicamente como forma de verificação do correto funcionamento do equipamento publicador e também garantindo que todos os IEDs, incluindo os recém-inseridos na rede, tenham informações atualizadas. As mensagens GOOSE usam uma sequência específica de envio como pode ser observada na Figura 8.

Onde: (VICENTE e SENGER, 2011)

a) A: retransmissão do GOOSE em condições estáveis;

b) X: retransmissão do GOOSE interrompida por um evento;

c) B: retransmissão do evento em períodos curtos;

d) C e D: retransmissão do evento em períodos mais longos até atingir a estabilidade.

Figura 8 - Frequência da transmissão do GOOSE

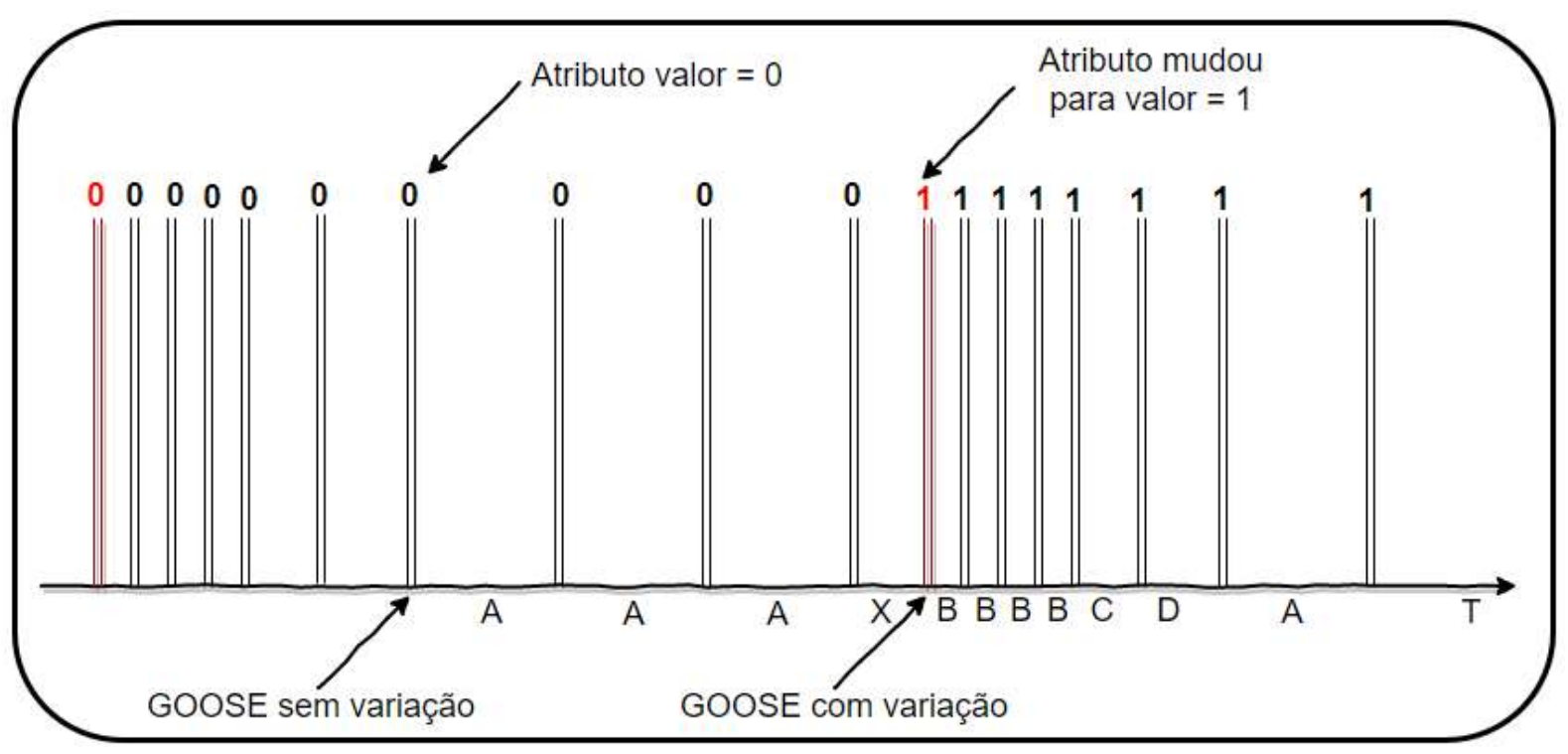

Fonte: Adaptado de (IEC-61850-8-1, 2011)

Os datasets (conjuntos de dados) usados na comunicação GOOSE podem ser compostos por dados analógicos, binários ou valores inteiros. A Figura 9 ilustra 0 processo de publicação de uma mensagem GOOSE. Os vários dados são agrupados 
no dataset, posteriormente estruturado no IED publicador e por fim transmitido em multicast na rede. (VICENTE e SENGER, 2011)

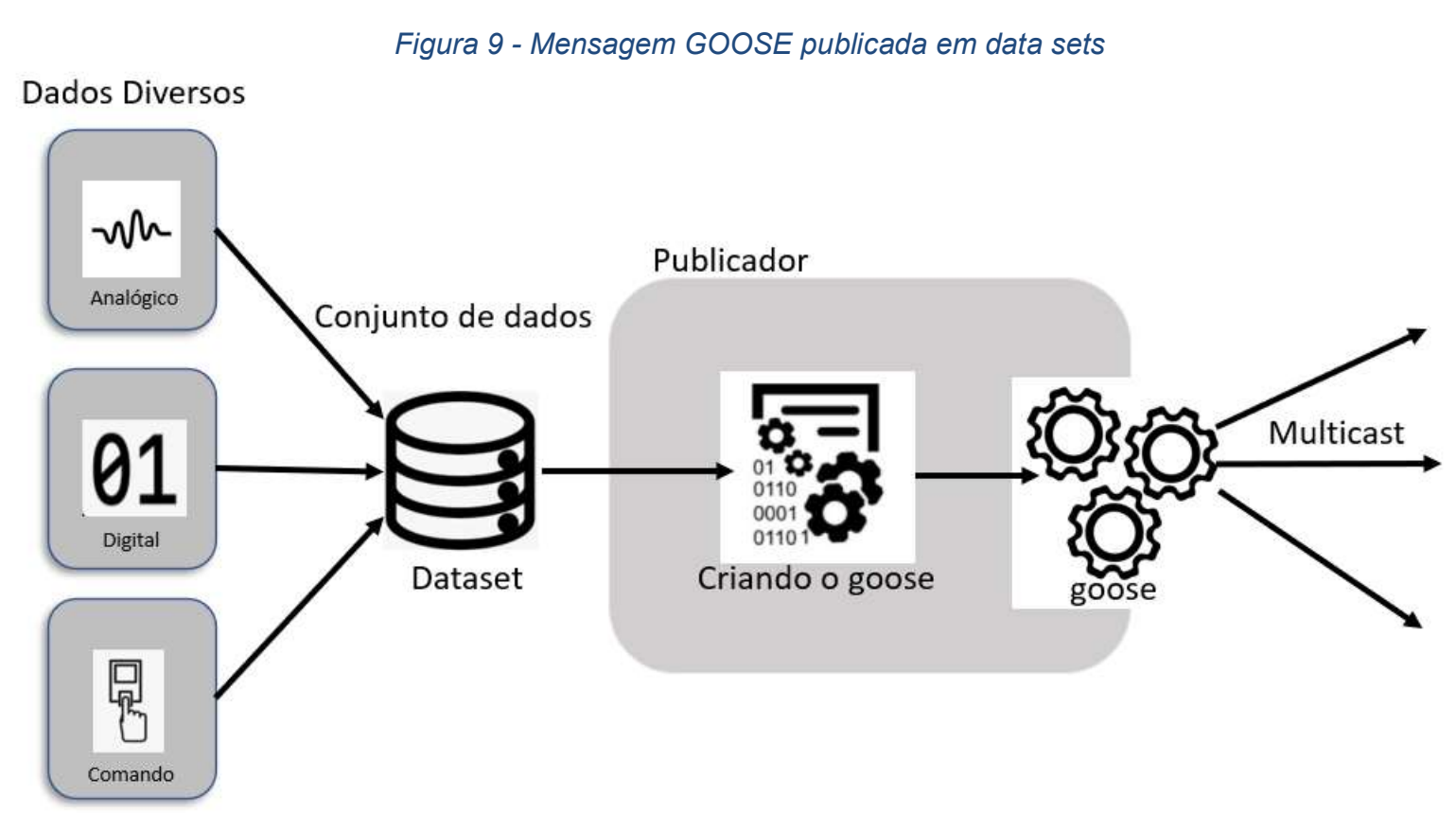

Fonte: Adaptado de (VICENTE e SENGER, 2011)

As mensagens GOOSE são transmitidas através dos frames Ethernet IEEE 802.3. A Tabela 2 mostra uma estrutura do quadro padrão Ethernet 802.3 definido pelo IEEE. (TANENBAUM, 1997)

Cada quadro começa com um preâmbulo de 7 bytes, cada um contendo o padrão de bit 10101010. Em seguida, vem um byte de início de quadro, contendo a sequência de bit 10101011 para sinalizar o início do quadro propriamente dito.

Os quadros seguintes contêm dois endereços de MAC de 2 a 6 bytes cada, uma para o destino e um para a origem. O campo comprimento informa quantos bytes existem no campo de dados, de um mínimo de 0 a um máximo de 1500. Apesar de válido, um campo de dados de 0 bytes causa problemas. O padrão Ethernet exige que os quadros válidos tenham pelo menos 64 bytes, então, se a parte de dados de um quadro for menor que 64 bytes, o campo padding será usado para preencher o quadro até o tamanho mínimo.

O campo final do padrão Ethernet IEEE 802.3 é o checksum. Este campo verifica a integridade do quadro. 
Tabela 2 - Estrutura padrão IEEE 802.3, para transmissão de GOOSE

\begin{tabular}{lll}
\hline Bytes & Identificação & Sequência binária padrão \\
\hline 7 & Preâmbulo & AA \\
\hline 1 & Delimitador & AB \\
\hline 2 a 6 & MAC GOOSE de destino & Depende da configuração \\
\hline 2 a 6 & MAC GOOSE de origem & Depende do fabricante \\
\hline 2 & Comprimento & \\
\hline 0 a 1500 & Dados & \\
\hline 0 a 46 & padding & \\
\hline 4 & checksum & \\
\hline
\end{tabular}

Fonte: $\mathrm{O}$ autor

Alguns modelos de switches gerenciados possibilitam a configuração de VLANs (Virtual Local Area Network), redes virtualizadas configuradas em uma mesma estrutura física, porém separadas de forma lógica.

Cada frame GOOSE publicado contém informação de VLAN ID, prioridade definida pela norma 802.1 Q, e um endereço MAC (Media Access Control) Multicast, que permite que uma mesma mensagem GOOSE possa ser assinada por mais de um dispositivo na rede. O MAC Multicast é um endereço hexadecimal composto de seis bytes com as seguintes recomendações pela norma:

a) os três primeiros bytes são definidos pela IEEE como 01-0C-CD;

b) o quarto byte deve ser 01 para GOOSE, 02 para Generic Substation Status Event (GSSE) e 04 para SV;

c) os dois últimos bytes devem estar na faixa 00-00, 01-FF.

A estrutura da mensagem GOOSE é padronizada pelo Abstract Syntax Notation One (ASN.1). Um exemplo da sequência definida pela ASN.1 para as mensagens GOOSE é ilustrada na Figura 10. Observa-se que a estrutura do GOOSE definida pela ASN.1 é constituída por doze variáveis. (IEC-61850-8-1, 2011) 
Figura 10 - ANS.1 referência GOOSE

IECGoosePdu : : = SEQ
goocbRef
timeAllowedtoLive
datSet
goID
T
stNum
sqNum
simulation
confRev
ndsCom
numDatSetEntries
allData
\}

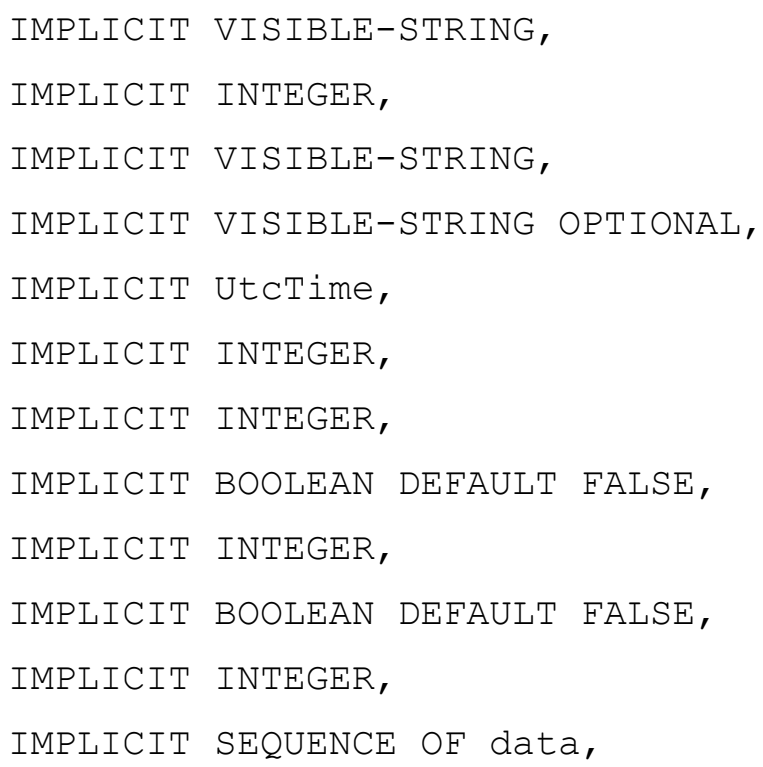

Fonte: Adaptado de (IEC-61850-8-1, 2011)

$\mathrm{Na}$ Tabela 3, é apresentada a estrutura do formato da mensagem GOOSE definida pela ASN.1 e transmitida no padrão Ethernet IEEE 802.3. Alguns valores de sequência hexadecimal padronizado são apresentados. Esses valorem indicam o início de blocos específicos (IEC-61850-8-1, 2011).

\begin{tabular}{llll}
\hline Bloco & Bytes & Identificação & $\begin{array}{l}\text { Sequência } \\
\text { hexadecimal } \\
\text { padrão }\end{array}$ \\
\hline 6 & 2 & APPID & 61 \\
\hline 8 & 1 & GOOSE PDU & 80 \\
\hline 9 & 1 & Tamanho do PDU & 81 \\
\hline 10 & 1 & Quadro de Controle de Referência & \\
\hline 12 & 1 & Quadro de Referência do tempo de vida do pacote & 81 \\
\hline 14 & $\mathrm{X}$ & GoOSE & 83 \\
\hline 15 & 1 & Quado do tempo de vida do pacote GOOSE de Referência da Identificação do dataset & 82 \\
\hline 17 & $\mathrm{X}$ & Quadro com a informação de identificação do dataset \\
\hline 18 & 1 & Quadro de Referência do GOOSE ID & 83 \\
\hline \multicolumn{4}{l}{}
\end{tabular}


Bloco Bytes Identificação hexadecimal padrão

\begin{tabular}{|c|c|c|c|}
\hline 20 & $\mathrm{X}$ & Quadro com a informação de GOOSE ID & \\
\hline 21 & 1 & $\begin{array}{l}\text { Quadro de Referência da Estampa de Tempo do } \\
\text { GOOSE }\end{array}$ & 84 \\
\hline 23 & $X$ & $\begin{array}{l}\text { Dado da Estampa de Tempo do PDU no formato } \\
\text { epoch. }\end{array}$ & \\
\hline 24 & 1 & $\begin{array}{l}\text { Quadro de referência do número de estado do } \\
\text { GOOSE }\end{array}$ & 85 \\
\hline 26 & $\mathrm{X}$ & Dado do número de estado do GOOSE & \\
\hline 27 & 1 & $\begin{array}{l}\text { Quadro de referência do número sequencial do } \\
\text { GOOSE }\end{array}$ & 86 \\
\hline 29 & $\mathrm{X}$ & Dado do número sequencial do GOOSE & \\
\hline 30 & 1 & Quadro de referência do estado do IED & 87 \\
\hline 32 & 1 & Quadro com a informação do estado do IED & \\
\hline 33 & 1 & $\begin{array}{l}\text { Quadro de referência da identificação da revisão do } \\
\text { GOOSE }\end{array}$ & 88 \\
\hline 35 & $\mathrm{X}$ & Dado de identificação da revisão do GOOSE & \\
\hline 36 & 1 & $\begin{array}{l}\text { Quadro de referência da informação da necessidade } \\
\text { de revisão do GOOSE }\end{array}$ & 89 \\
\hline 38 & 1 & $\begin{array}{l}\text { Dado com a informação da necessidade de revisão } \\
\text { do GOOSE }\end{array}$ & \\
\hline 39 & 1 & $\begin{array}{l}\text { Quadro de referência dos dados de atributos do } \\
\text { GOOSE }\end{array}$ & $8 \mathrm{~A}$ \\
\hline 41 & $x X$ & $\begin{array}{l}\text { Quadro com a informação da quantidade de atributos } \\
\text { contido no pacote GOOSE }\end{array}$ & \\
\hline 42 & 1 & Quadro de referência do início dos atributos & $A B$ \\
\hline 43 & $\mathrm{XX}$ & Quadro com o datagrama GOOSE transmitido & \\
\hline 44 & 0 a 46 & padding & \\
\hline 45 & 4 & checksum & \\
\hline
\end{tabular}




\subsection{Arquivos de descrição da configuração}

A norma IEC-61850-6 especifica uma linguagem de descrição para configuração de IEDs, denominada Substation Configuration Description Language (SCL). O SCL tem como um dos principais objetivos a padronização da nomenclatura utilizada através de um modelo único de descrição de dados. A configuração do SCL é baseada em eXtensible Modeling Language (XML), linguagem utilizada no auxílio da troca de dados de configuração do banco de dados entre ferramentas diferentes. Um arquivo SCL possui em sua configuração dados gerais da subestação, dos equipamentos de manobra, das funcionalidades utilizadas dos IEDs e serviços de comunicação de dados. (NETTO, 2012)

Na IEC-61850-6 são definidos cinco diferentes tipos de arquivos SCL utilizados na fase de projetos para compor a arquitetura da subestação (VICENTE e SENGER, 2011). A Tabela 4 apresenta um resumo dos arquivos SCL.

Tabela 4 - Arquivos SCL

\begin{tabular}{|c|c|}
\hline Arquivo & Descrição \\
\hline $\begin{array}{l}\text { System Specification Description } \\
\text { (SSD) }\end{array}$ & $\begin{array}{l}\text { Descreve o diagrama e a funcionalidade da } \\
\text { automação da subestação associado aos nós lógicos }\end{array}$ \\
\hline SCD & $\begin{array}{l}\text { Descreve a configuração completa da subestação } \\
\text { incluindo a rede de comunicação e a informação } \\
\text { sobre o fluxo de dados de comunicação }\end{array}$ \\
\hline IED Capability Description (ICD) & $\begin{array}{l}\text { Descreve as capacidades e pré-configurações dos } \\
\text { IEDs }\end{array}$ \\
\hline $\begin{array}{l}\text { Configuration IED Description } \\
\text { (CID) }\end{array}$ & $\begin{array}{l}\text { Descrição da configuração de um IED específico, ou } \\
\text { seja, dos dados que serão fornecidos pelos nós } \\
\text { lógicos de cada IED }\end{array}$ \\
\hline Instantiated IED Description (IID) & $\begin{array}{l}\text { Descrição da configuração e recursos específicos de } \\
\text { um IED no projeto. É usado como formato de troca } \\
\text { de dados do configurador de IED para o configurador } \\
\text { do sistema. }\end{array}$ \\
\hline
\end{tabular}

Fonte: $\mathrm{O}$ autor

A Figura 11 apresenta a relação entre os diversos arquivos mencionados. No arquivo ICD são detalhados as características e funcionalidades de um IED. No 
arquivo SSD estão descritos o diagrama unifilar da SE e os LNs necessários. No arquivo SCD estão contidas informações sobre todos os IEDs, dados da configuração das comunicações, e uma descrição da subestação. O arquivo CID, que pode existir em várias instâncias em uma arquitetura de subestação, descreve um único IED criado dentro do projeto, e inclui informações de Header, Communication, IED e DataTypeTemplates específico do equipamento. (VICENTE e SENGER, 2011)

As configurações contidas no arquivo CID são transferidas para o equipamento através do software de configuração do fabricante, e as informações do arquivo IID são importadas pelo configurador do sistema.

Figura 11 - Linguagem de configuração da subestação

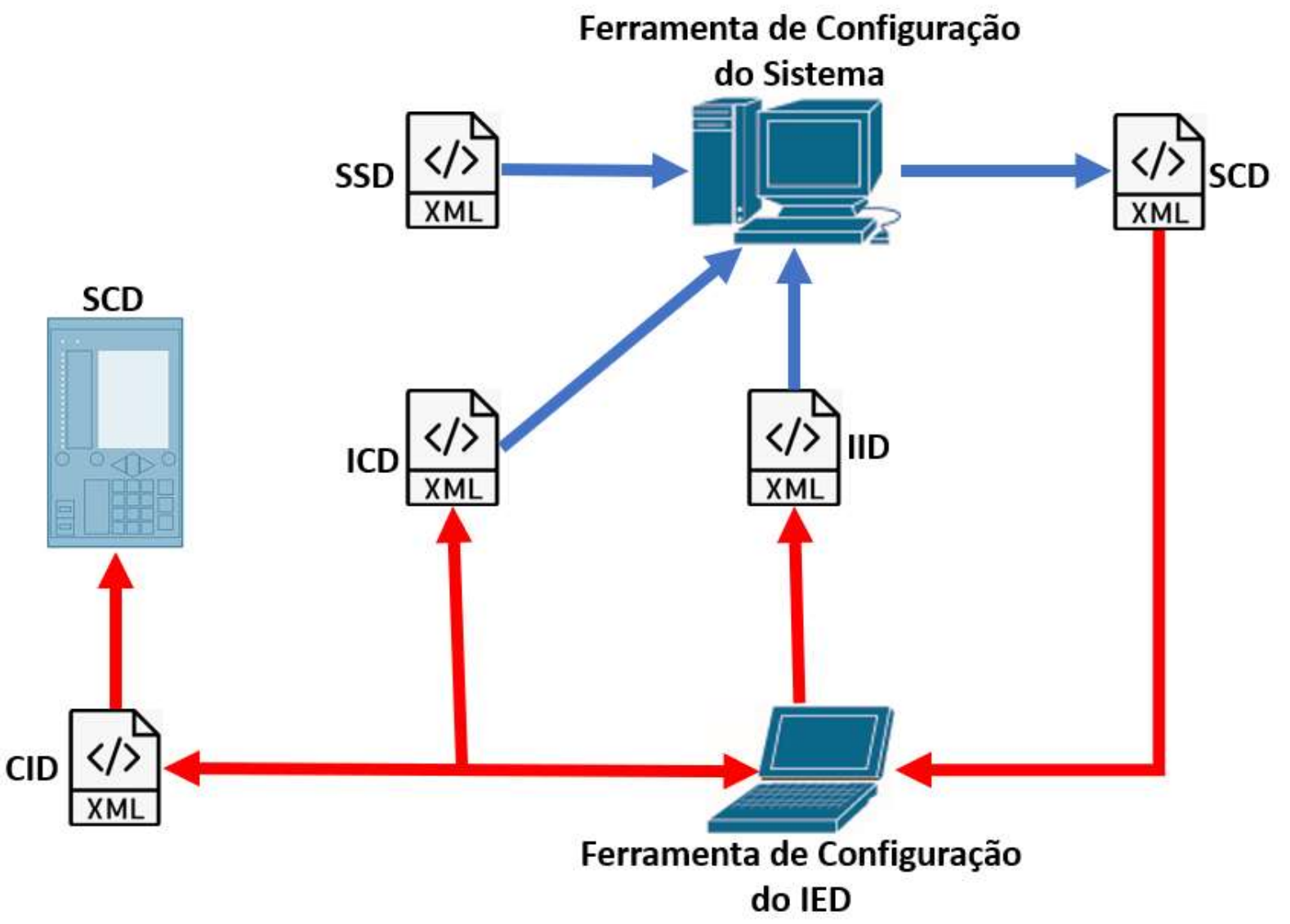

Fonte: Adaptado de (NETTO, 2012)

\subsection{Análise do arquivo SCD}

Como comentado no item anterior, o arquivo SCD contém dados sobre todos os IEDs configurados em uma subestação IEC-61850 e pode ser utilizado como referência base do projeto elétrico, físico, e logico de uma subestação IEC-61850.

A estrutura do arquivo é composta por cinco classes principais: 

a) SCL:
b) Header:
c) Communication:
d) IED:
e) DataTypeTemplates:

$\mathrm{Na}$ Figura 12 uma estrutura de um arquivo SCD contendo dois IEDs é apresentada. O software XML Maker v1.1 foi utilizado para abrir o arquivo. $\mathrm{Na}$ estrutura do SCD é possível identificar a classe principal SCL, Header, Communication, uma classe para o IED1, uma classe para o IED2 e o DataTypeTemplates.

Figura 12 - Estrutura do arquivo SCD

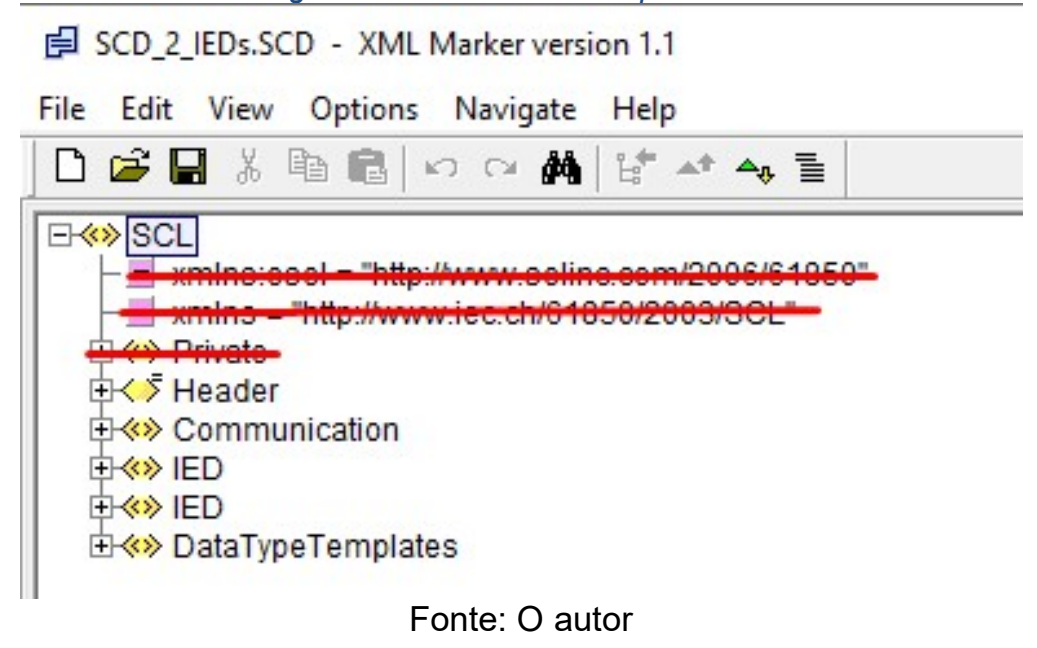

Para as mensagens GOOSE trafegadas vale destacar as seguintes estruturas no arquivo SCD: Figura 13 a Fonte: $O$ autor

Figura 15.

a) SCLIIEDIAccessPoint ServerLLNO\$CFGIGSEControl: o nome do IED, endereço de MAC, dataset publicado e o nome do pacote GOOSE podem ser identificados neste caminho.

b) SCLIIEDIAccessPoint ServerLNO \$CFGIDataSet: listagem dos atributos contidos no dataset.

c) SCLIIEDVAccessPoint ServerLLNO\$CFGInputs; identificação dos atributos externos que devem ser considerados pelo IED. 
Figura 13 - Estrutura do LN GSEControl

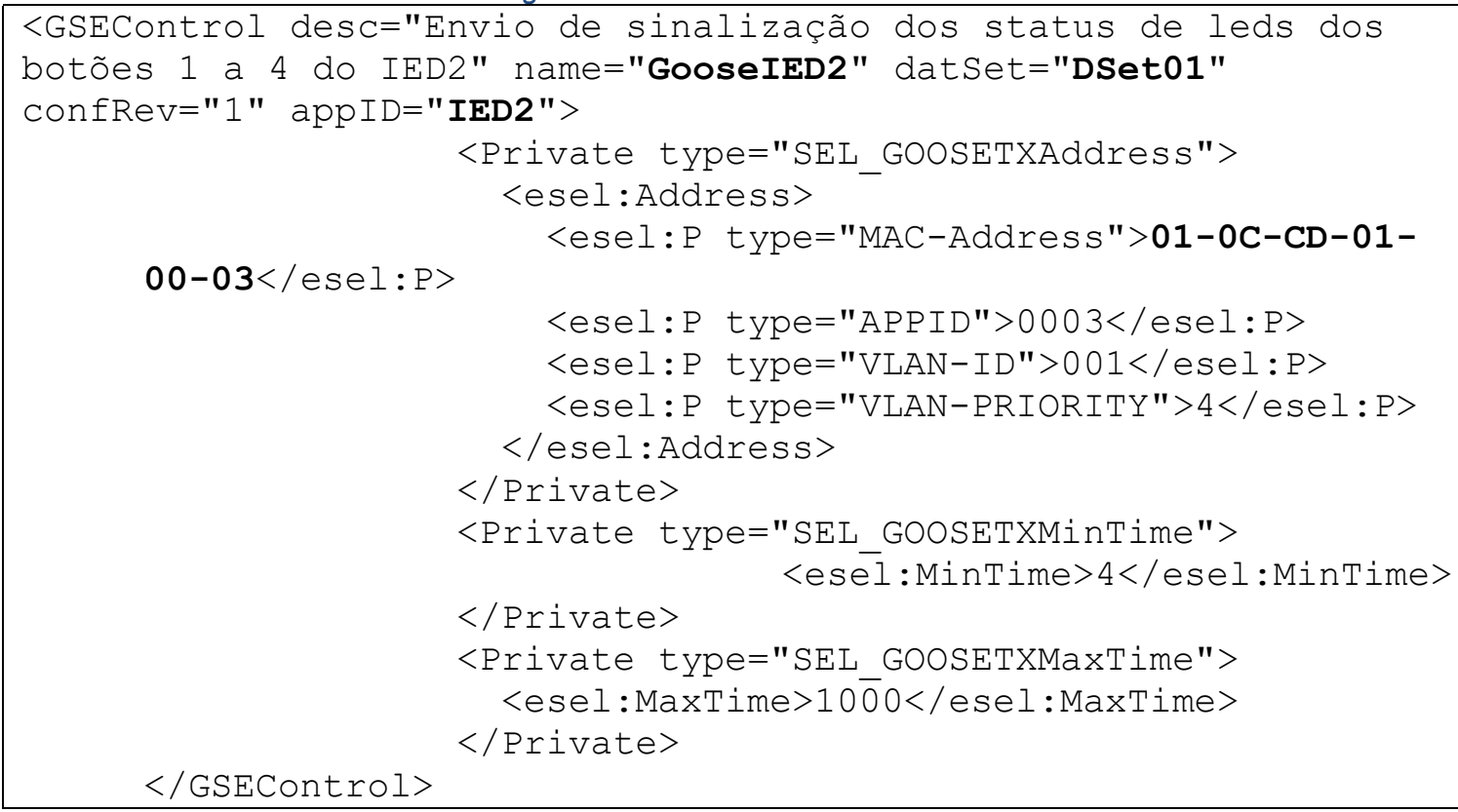

\section{Fonte: $\mathrm{O}$ autor}

Figura 14 - Estrutura da classe DataSet do arquivo SCD

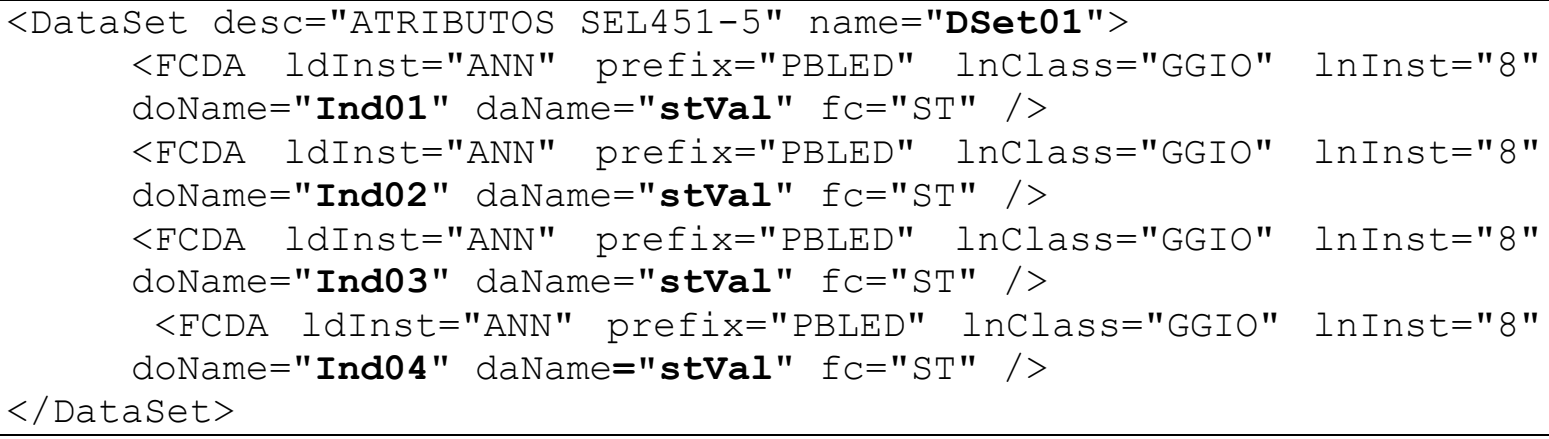

Fonte: O autor

Figura 15 - Estrutura da classe Inputs do arquivo SCD

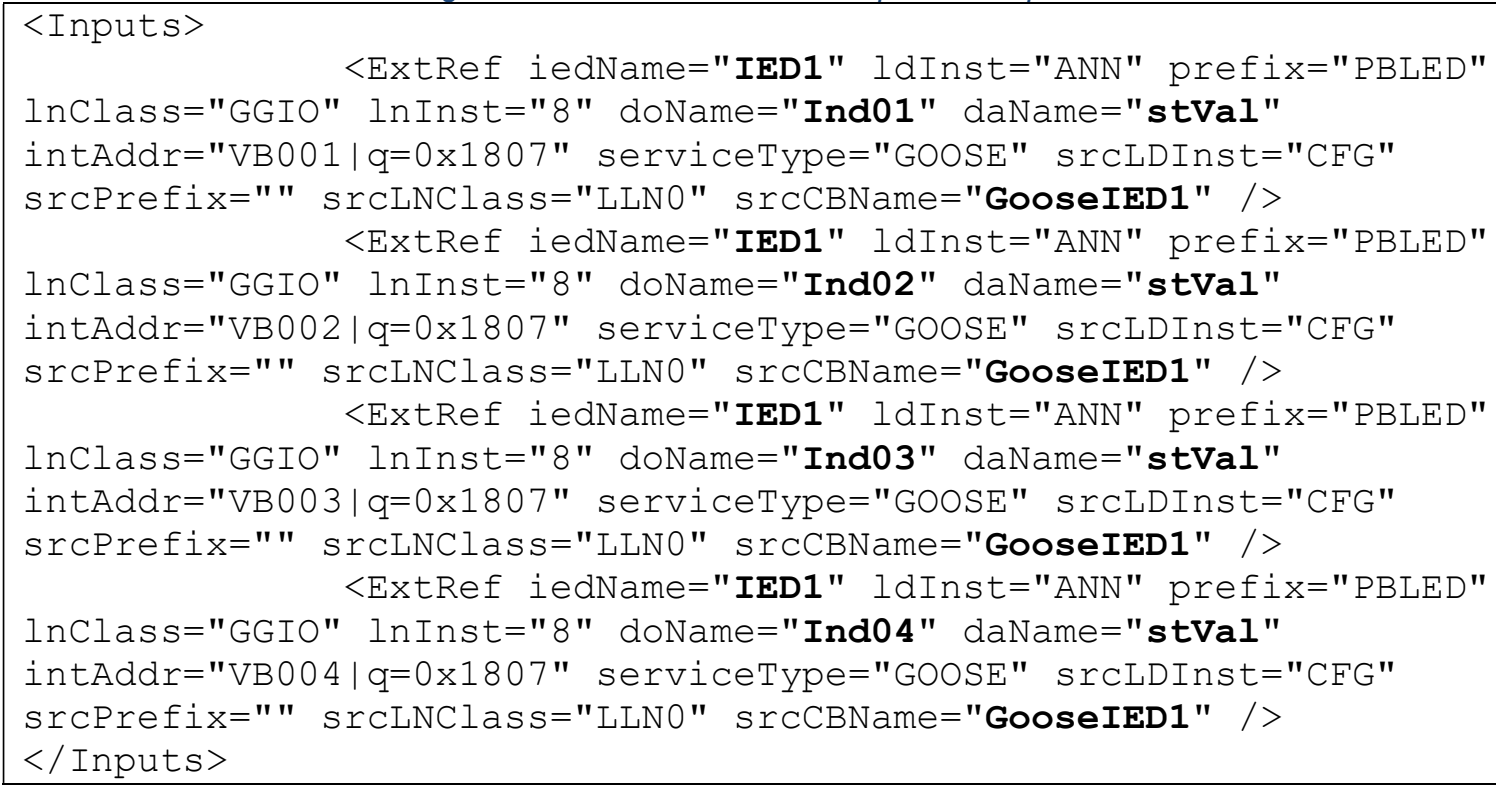




\section{Metodologia de auditoria}

\subsection{Processo de Auditoria das Mensagens GOOSE}

Conforme explicado no item 1.13, as configurações dos datasets são definidos nos IEDs e a publicação do seu conteúdo é realizado através das mensagens GOOSE. As mensagens publicadas e assinadas pelos dispositivos podem ser identificadas dentro do arquivo SCD. Essas informações são compiladas nos sistemas internos dos IEDs e seu conteúdo é transmitido nos blocos GOOSE que são transportados pelo protocolo padrão Ethernet IEEE 802.3, ambos já discutidos no item 1.11.

As informações equivalentes contidas no arquivo SCD e publicadas na mensagem GOOSE foram identificadas e relacionadas.

A Figura 16 ilustra o encapsulamento das informações GOOSE no bloco de dados do quadro Ethernet 802.3. Um arquivo SCD e as classes GSEControl e DataSet com os atributos mais importantes para auditoria são apresentados. Analisando a relação entre o arquivo SCD e o protocolo Ethernet IEEE 802.3, é possível afirmar que a informação de MAC-Address contida na classe GSEControl é inserida no terceiro quadro do protocolo IEEE802.3, as demais informações estão inseridas no sexto quadro do mesmo protocolo. 
Figura 16 - Relacionamento SCD e IEEE802.3

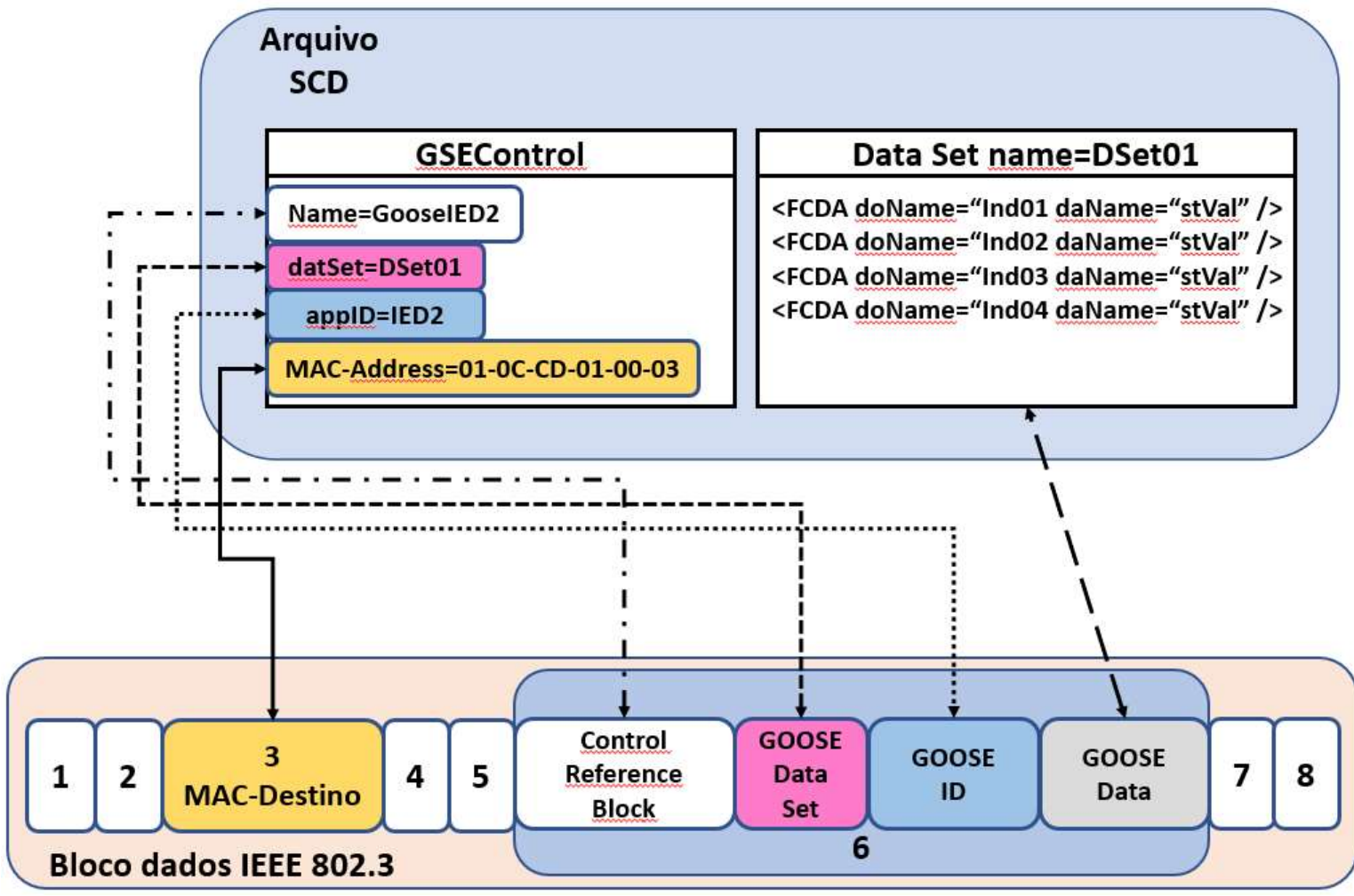

Fonte: $\mathrm{O}$ autor

O diagrama da metodologia desenvolvida é apresentado na Figura 17. Um projeto de SE IEC 61850 é elaborado e, como resultado, os arquivos SCD e CID são gerados. Durante o projeto de configuração dos dispositivos, um arquivo ATG é preenchido e disponibilizado como referência para o processo de auditoria. $\mathrm{O}$ arquivo ATG faz parte da proposta deste trabalho, e será detalhado ao longo deste capítulo.

Com o projeto da subestação finalizado, as configurações do ICD são descarregadas no IED e então os GOOSE são publicados. As mensagens enviadas pelos dispositivos são capturadas pelo software auditor e o conteúdo interno é analisado com base nas configurações dos arquivos SCD e ATG detalhados nos itens 3.6 e 1.16. Se não for identificada divergência na mensagem em relação aos arquivos, os atributos são interpretados e seus valores apresentados para o usuário. 
Figura 17 - Metodologia de auditoria e tradução GOOSE

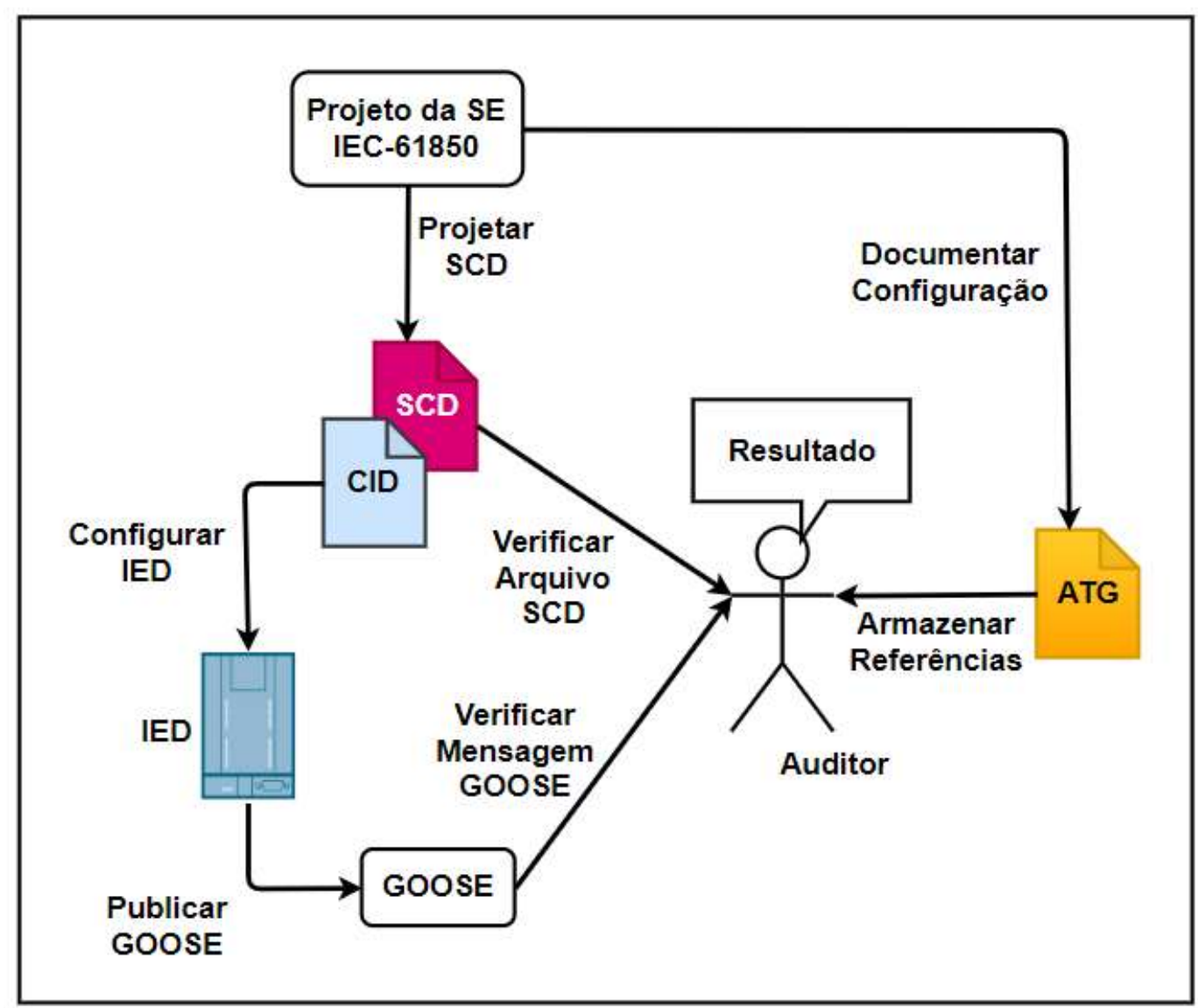

Fonte: $\mathrm{O}$ autor

\subsection{Aplicativo Auditor GOOSE (AAG)}

Foi desenvolvido um software auditor, denominado Aplicativo Auditor GOOSE (AAG), capaz de capturar e interpretar as mensagens GOOSE. O AAG foi desenvolvido para ambiente Windows e utiliza a linguagem de programação dotNET C\#. Este aplicativo foi compilado na Integrated Development Environment (IDE) Visual Studio 2017 da Microsoft.

Para captura das mensagens GOOSE através da plataforma computacional foi instalado o software Winpcap. O programa é desenvolvido para sistemas operacionais Windows para capturar pacotes de dados trafegados em redes de computadores. $O$ Winpcap é uma ferramenta gratuita que pode capturar e enviar pacotes de dados na rede de computadores através das interfaces de rede das plataformas computacionais e ao mesmo tempo realizar filtro e armazenar os pacotes capturados. O Winpcap funciona na camada de drivers e pode acessar as camadas mais baixa de rede com alta eficiência. (LU, SUN e LI, 2010) 
O AAG é constituído por diversas classes e bibliotecas que foram desenvolvidas para garantir o automatismo da metodologia proposta por esta pesquisa. As principais classes e bibliotecas desenvolvidas são apresentadas nos subcapítulos a seguir:

a) Program: classe principal de inicialização do software AAG. O ANEXO A apresenta um trecho do código fonte da classe Program;

b) ThreadValidaRecepçãoGoose classe desenvolvida para gerenciar o tempo de recepção das mensagens GOOSE. Possui um contador em milissegundos que monitora o tempo de recepção da próxima mensagem GOOSE com o mesmo name, AppID e dataset; se, após o tempo configurado não for identificada a recepção de uma nova mensagem o AAG apresenta mensagem de falha para recepção GOOSE.

c) Classe Epoch: Epoch time é um valor inteiro referente ao tempo em milissegundos armazenado desde (1/1/1970 00:00:00.000). (SYMANTEC, 2010) A classe Epoch foi desenvolvida para tratar valores referentes a estampa de tempo no formato epoch. A Figura 18 ilustra a conversão da data (07/12/2019 02:15:00) para a estampa de tempo epoch em segundos (1575695700) e a conversão da data para estampa de tempo em milissegundos (1575695700000).

Figura 18 - Conversão epoch

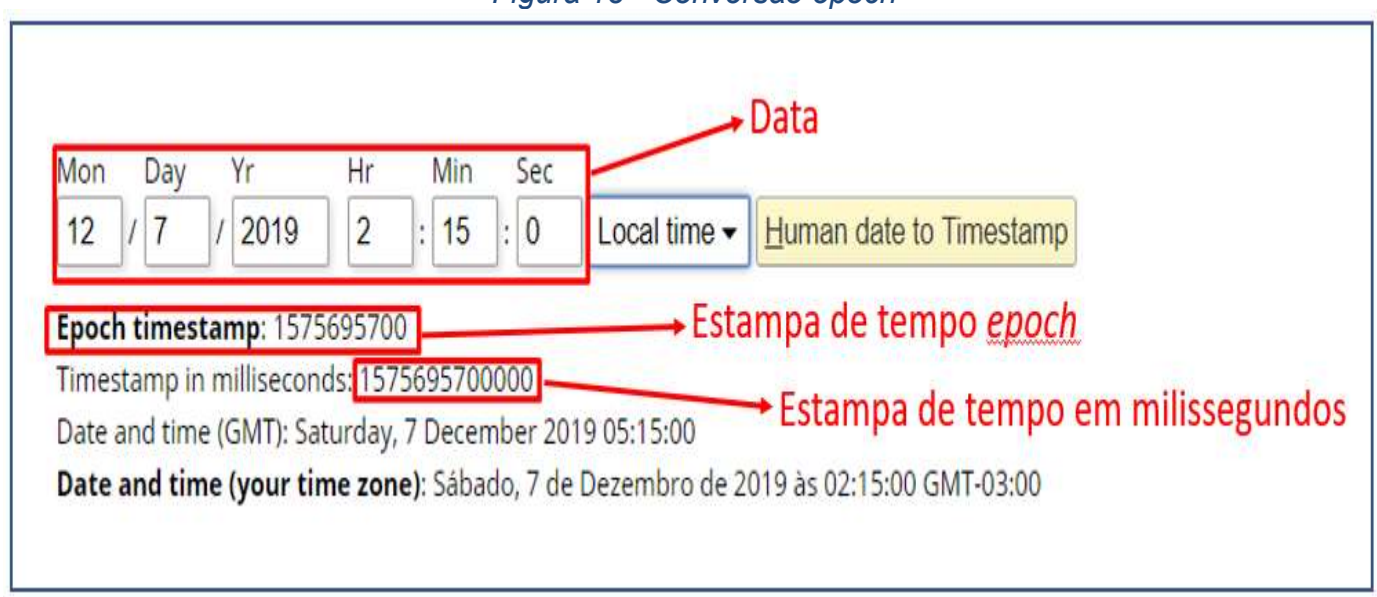

Fonte: $\mathrm{O}$ autor

d) Biblioteca SCD: A biblioteca SCD foi desenvolvida para interpretar a estrutura de classes dos arquivos ATG e SCD. Este conjunto de classes também permite identificar as diversas variáveis utilizadas no processo de 
auditoria. Outra função da biblioteca SCD é criar arquivos específicos para as classes <Header>, <Communication>, <IED> e <DataTypeTemplates> encontradas no arquivo SCD. A Figura 19 apresenta os arquivos que foram gerados a partir da interpretação do arquivo SCD.

Figura 19 - Classes SCD desmembradas

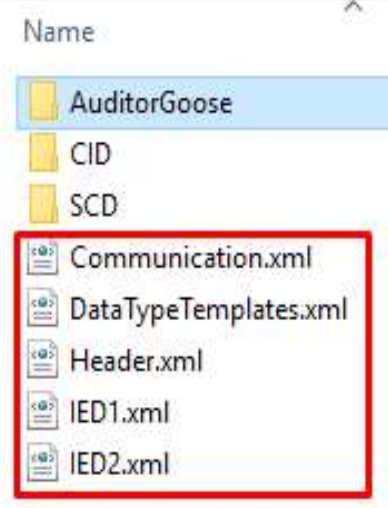

Date modified Type

25/11/2018 15:14 File folder

23/07/2018 23:44 File foider

16/11/2019 11:40 File folder

$06 / 12 / 201923 ; 56$

XML Document

$2 \mathrm{~KB}$

$06 / 12 / 201923: 56$

XML Document

$131 \mathrm{~KB}$

06/12/2019 23:56

XML Document

$1 \mathrm{~KB}$

$06 / 12 / 201923: 56$

XML Document

$811 \mathrm{~KB}$

$06 / 12 / 201923: 56$

XML Document

$1.157 \mathrm{~KB}$

Fonte: O autor

e) Biblioteca GOOSE: A Biblioteca GOOSE é um conjunto de classes desenvolvidas para interpretar de forma individualizada os blocos da mensagem GOOSE.

A Tabela 5 contém as classes desenvolvidas e suas funcionalidades.

Tabela 5 - Classes desenvolvidas

\begin{tabular}{|l|l|l|}
\hline Classe & Descrição & Anexo \\
\hline AppID & $\begin{array}{l}\text { identifica no quadro GOOSE a informação de } \\
\text { APPID }\end{array}$ & Anexo B \\
\hline GooseLength & $\begin{array}{l}\text { identifica o tamanho do pacote GOOSE recebido } \\
\text { pelo AAG }\end{array}$ & Anexo C \\
\hline PDU & $\begin{array}{l}\text { identifica a sinalização do início da mensagem } \\
\text { GOOSE através da informação hexadecimal 61 e } \\
\text { o tamanho da mensagem }\end{array}$ & Anexo D \\
\hline ControlRefBlock & $\begin{array}{l}\text { identifica o quadro Control Reference Block da } \\
\text { mensagem GoOSE através da informação } \\
\text { hexadecimal 80 e extrai a informação contida no } \\
\text { quadro }\end{array}$ & Anexo E \\
\hline Time2LiveAllowed & $\begin{array}{l}\text { identifica a sinalização hexadecimal 81 e extrai a } \\
\text { informação do tempo contido na mensagem. }\end{array}$ & Anexo F \\
\hline
\end{tabular}




\begin{tabular}{|l|l|l|}
\hline Classe & Descrição & Anexo \\
\hline DataSet & $\begin{array}{l}\text { identifica a sinalização hexadecimal 82 e extrai a } \\
\text { informação com o endereço de DATA SET } \\
\text { contido na mensagem }\end{array}$ & Anexo G \\
\hline GooselD & $\begin{array}{l}\text { identifica a sinalização hexadecimal 83 e extrai a } \\
\text { informação do GOOSE ID }\end{array}$ & Anexo H \\
\hline TimeStamp & $\begin{array}{l}\text { identifica a sinalização hexadecimal 84 e extrai a } \\
\text { informação de TIME STAMP }\end{array}$ & Anexo I \\
\hline StateNumber & $\begin{array}{l}\text { identifica a sinalização hexadecimal 85 e extrai a } \\
\text { informação do STATE NUMBER }\end{array}$ & Anexo J \\
\hline SequenceNumber & $\begin{array}{l}\text { identifica a sinalização hexadecimal 86 e extrai a } \\
\text { informação do SEQUENCE NUMBER DATA }\end{array}$ & Anexo K \\
\hline IEDState & $\begin{array}{l}\text { identifica a sinalização hexadecimal 87 e extrai a } \\
\text { informação do IED STATE DATA }\end{array}$ & Anexo L \\
\hline ConfigRevision & $\begin{array}{l}\text { identifica a sinalização hexadecimal 88 e extrai a } \\
\text { informação do ConfRev DATA }\end{array}$ & Anexo M \\
\hline NeedRevision & $\begin{array}{l}\text { identifica a sinalização hexadecimal 89 e extrai a } \\
\text { informação do NdsCom DATA }\end{array}$ & Anexo N \\
\hline identifica a sinalização hexadecimal 8A e extrai a \\
informação do Data Entries
\end{tabular}

O Software Auditor GOOSE desenvolvido neste trabalho pode realizar as seguintes funcionalidades:

- Leitura dos arquivos SCD e ATG;

- Captura dos pacotes de dados inserindo uma identificação de estampa de tempo do horário recebido;

- Verificação dos endereços de MAC dos equipamentos conectados na rede;

- Auditoria do protocolo GOOSE baseado nos arquivos SCD e ATG;

- Tradução dos dados trafegados, apresentando para o usuário o valor do atributo e a respectiva unidade de medida conforme cadastro do ATG; 
- Geração de alarme quando detectada divergência entre o dado trafegado e o informado nos arquivos SCD e ATG;

A Figura 20 apresenta a metodologia, explicada no item 1.14, utilizada pelo AAG para realizar a auditoria das mensagens GOOSE capturadas.

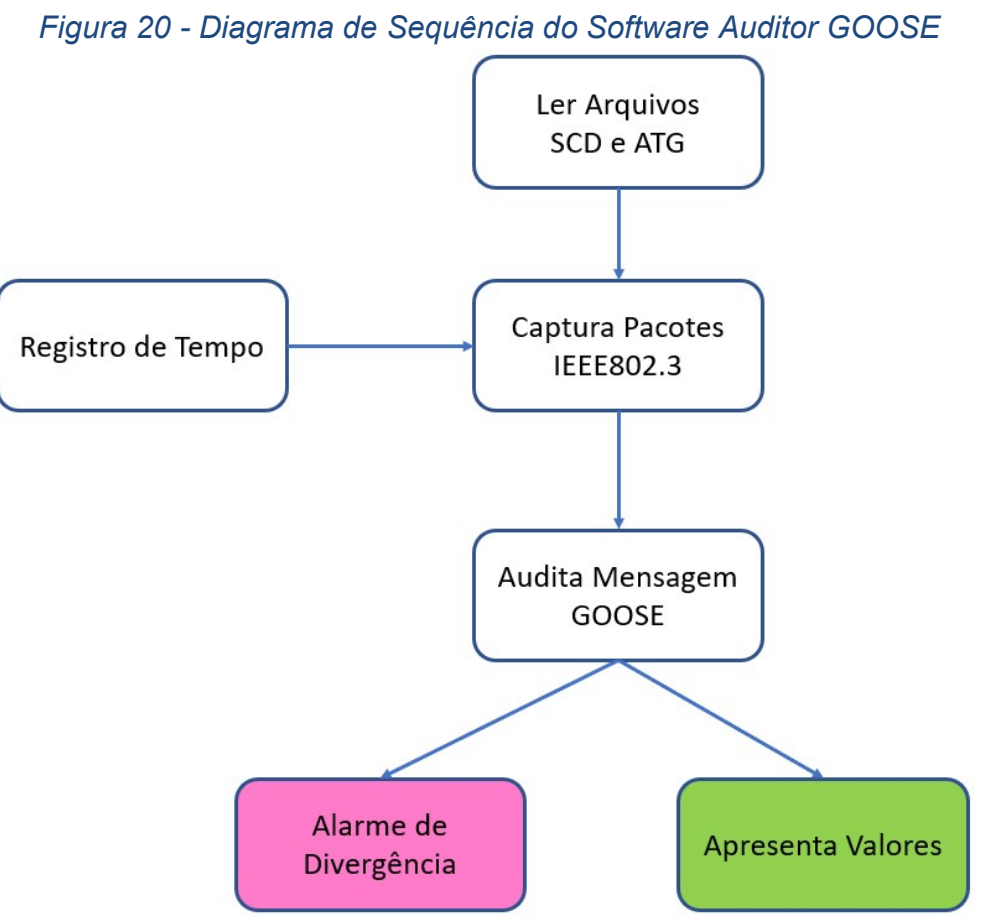

Fonte: $\mathrm{O}$ autor

Com o auxílio do software acSELerator Architect o arquivo SCD_2_IEDs.SCD contendo as configurações IEC61850 do projeto pode ser salvo no diretório c:/Nucleo/IEC61850/SCD da plataforma computacional. O arquivo com as informações dos IEDs utilizados no projeto pode ser analisado como apresentado na Figura 21.

Figura 21 - Estrutura XML do arquivo SCD do projeto

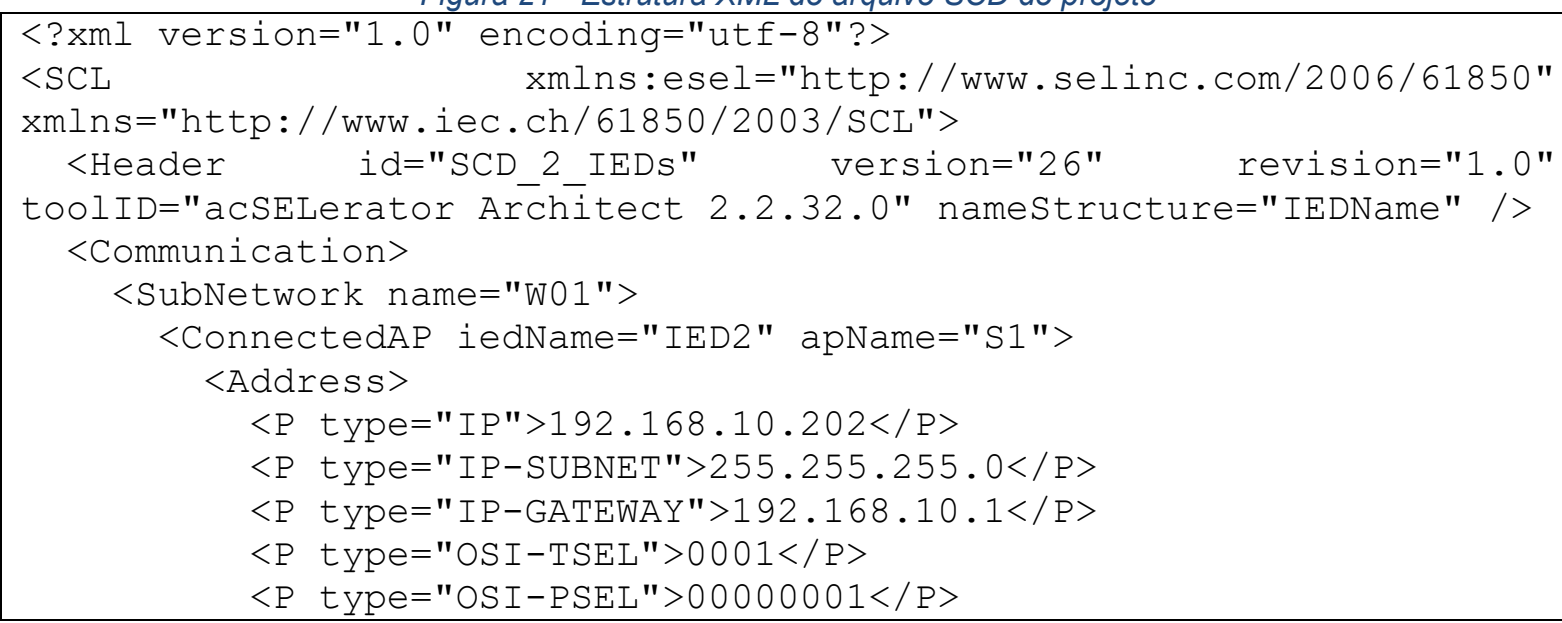




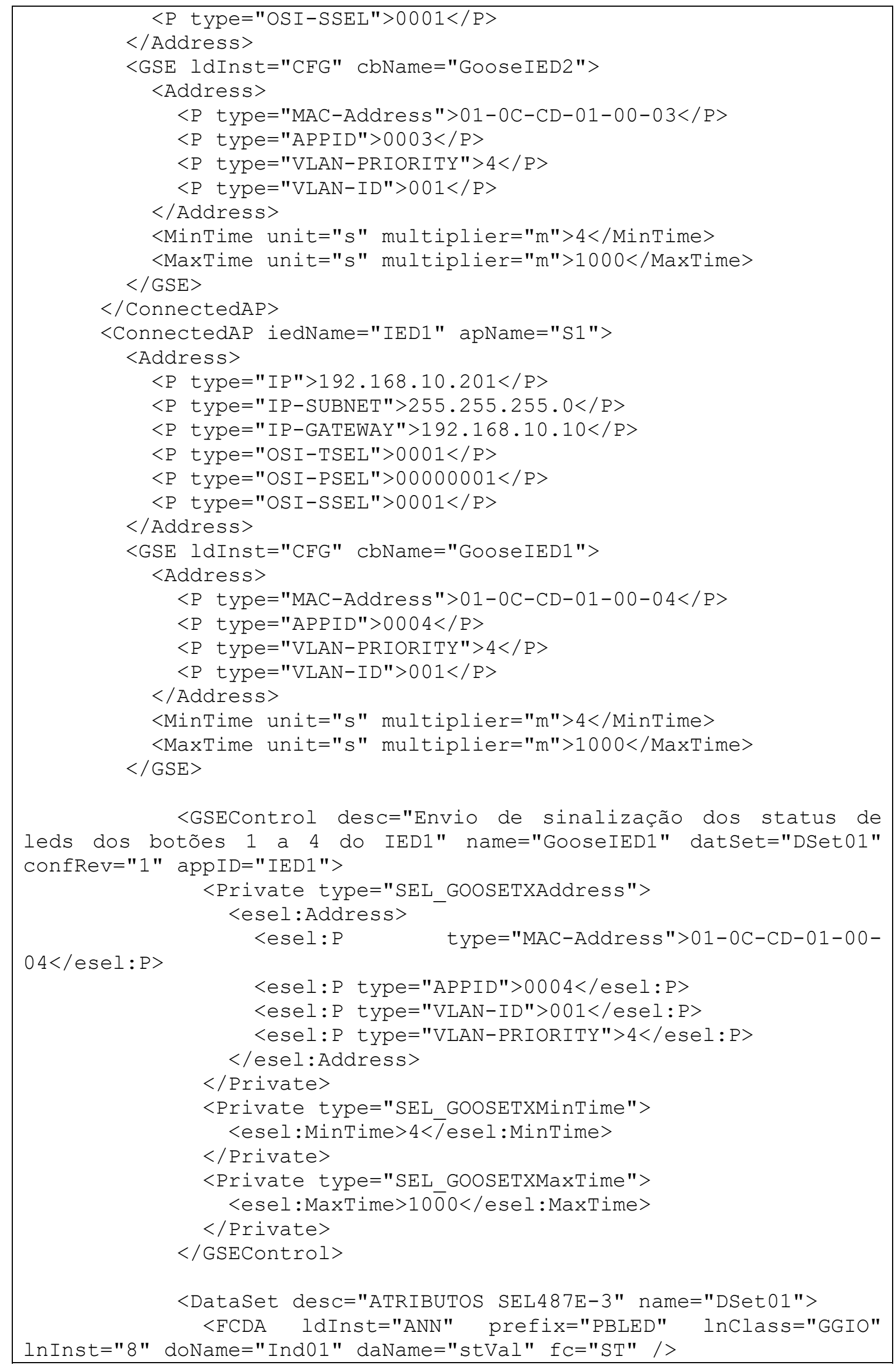




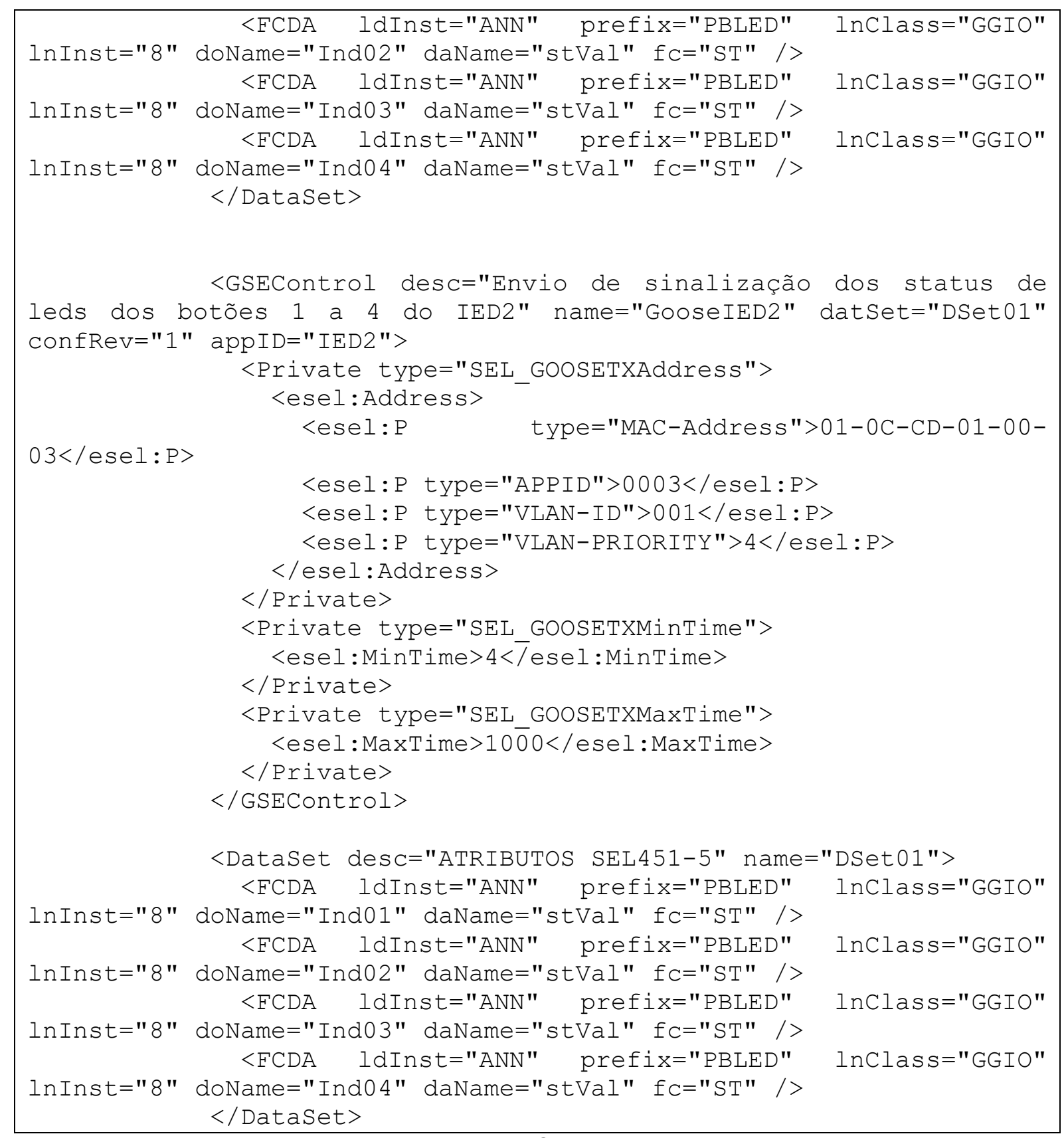

Fonte: $\mathrm{O}$ autor

\subsection{Arquivo de Tradução GOOSE (ATG)}

A metodologia de auditoria das mensagens GOOSE proposta neste trabalho tem como objetivo identificar e informar de forma automática da ocorrência das seguintes falhas:

- Divergência na quantidade de atributos publicados no dataset e informados no projeto inicial;

- Ausência de mensagens GOOSE indicadas no arquivo SCD e ATG; 
- Tráfego de mensagens GOOSE na rede local não informados no projeto inicial;

- Falha de sincronismo de tempo dos IEDs publicadores de mensagens GOOSE.

O ATG foi elaborado e desenvolvido neste trabalho e tem como objetivo garantir a integridade das informações auditáveis do arquivo SCD definidas no projeto inicial. Durante o desenvolvimento do software auditor foi identificado a possibilidade de integrar uma funcionalidade que permitisse a tradução dos atributos e acrescentar as unidades de medidas desses atributos contidos nas mensagens GOOSE visualizadas pelos usuários.

A partir desta motivação foram inseridos no ATG um campo para descrição do atributo de acordo com a tradução do usuário e um campo para descrição da unidade de medida. Outra funcionalidade atribuída ao ATG e desenvolvida durante o projeto foi a possibilidade da inserção de condições da apresentação dos resultados baseado nos valores contidos nos atributos, assim, os usuários podem visualizar o valor contido no atributo como informação sem a necessidade de utilizar softwares para interpretação.

O ATG possui então as seguintes funcionalidades:

- Documentar as informações GOOSE do arquivo SCD declarados no projeto inicial;

- Auxiliar o time técnico na interpretação dos dados GOOSE trafegados na rede;

- Permite ao usuário inserir condições que serão apresentadas como informação de acordo com o valor contido no atributo capturado.

O ATG é escrito utilizando a linguagem XML e possui em sua estrutura interna uma classe para cada dispositivo inserido no processo de auditoria. A estrutura da classe IED do arquivo ATG contém as seguintes subclasses:

- <IED name=" nome_do_ied"> : Identificação para o início dos dados de um IED. O campo name deve ser único para

- <DATASET name="identificação_dataset">: Identificação do dataset publicado pelo IED 
- <ITEM id="posição_dataset">: Identificação do atributo, o id é a posição do atributo dentro do dataset. Para esse item são inseridas as seguintes informações:

a) <LN>: Endereço lógico da informação conforme a norma IEC-61850;

b) <TRANSLATION>: Tradução da informação para o usuário;

c) <UNIT>: Campo utilizado para indicar o tipo de informação do dado

d) <CONVERT>: Classe contendo as possíveis condições interpretadas pelo usuário.

- $\quad$ SUBSCRIBER>: Identificação da classe de registro de GOOSE assinado

- <PUBLISHER name="nome_do_ied">: Identificação do IED que publicará as mensagens que devem ser assinadas.

- <DATASET_P name="nome_do_dataset">: Identificação do dataset que contém os atributos que deverão ser assinados pelo IED

- $\quad<A T T R I B U T E>$ : Posição do atributo no dataset para assinatura

A estrutura do arquivo ATG é apresentada na Figura 22.

Figura 22 - Estrutura do arquivo ATG

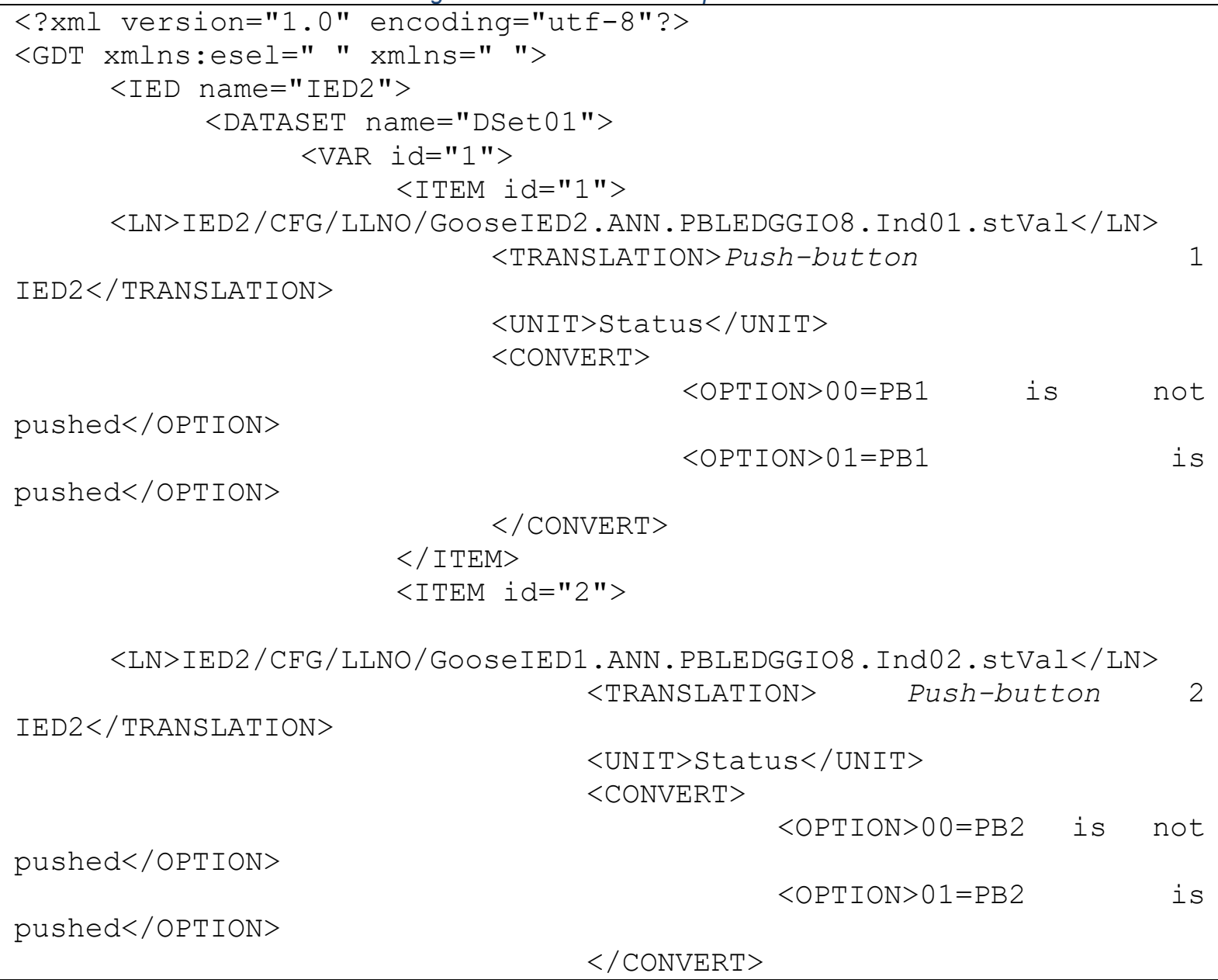

$<\mathrm{LN}>\mathrm{IED} 2$ / CFG / LLNO/GooseIED1. ANN . PBLEDGGIO8. Ind02. stVal</LN> $<$ TRANSLATION $>\quad$ Push-button

pushed $</$ OPTION $>$ $<O P T I O N>00=P B 2$ is not 


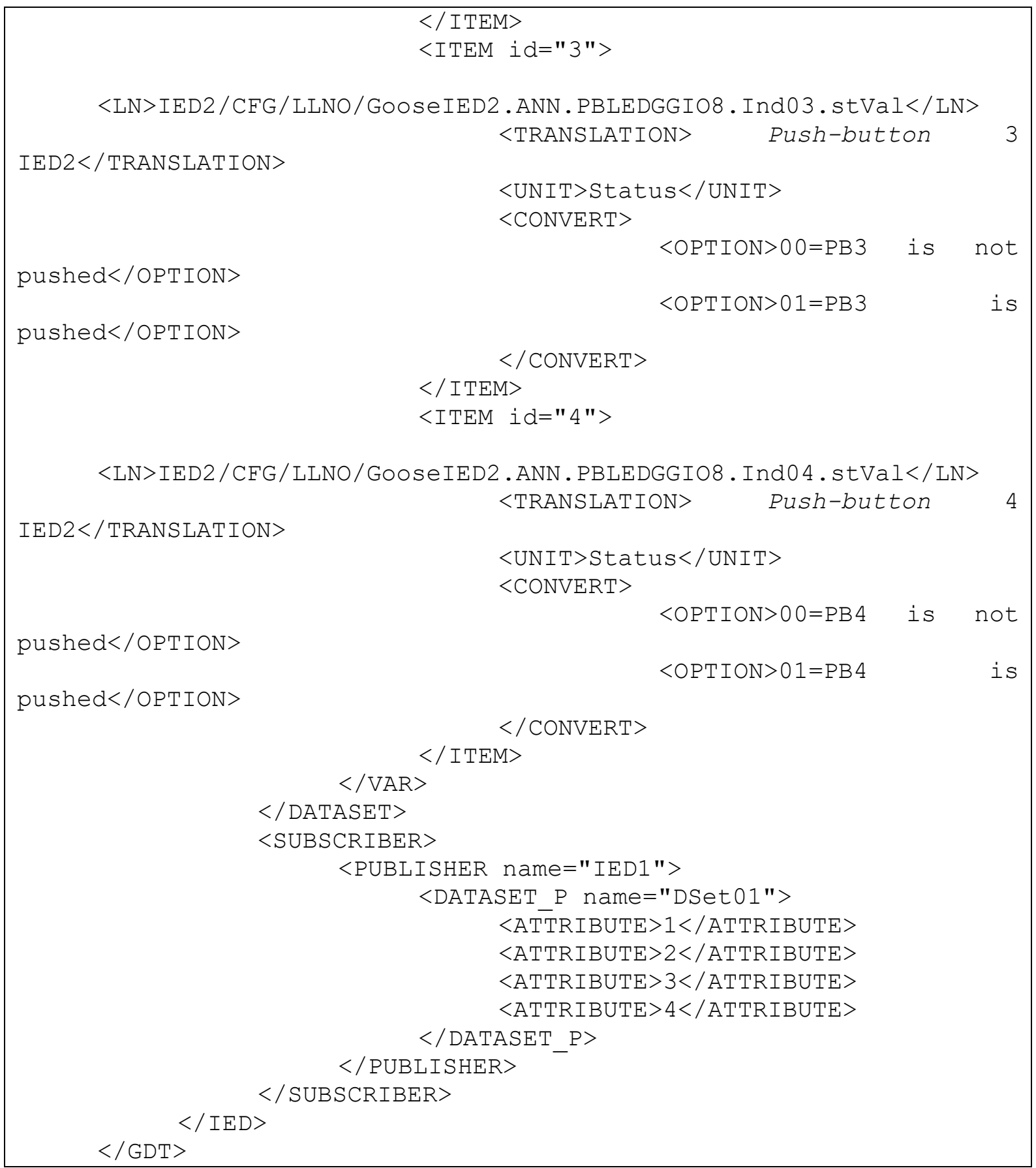

\section{Fonte: $\mathrm{O}$ autor}

O arquivo ATG pode ser configurado com informações relacionadas ao arquivo SCD definido no projeto inicial. A Figura 23 apresenta o arquivo ATG configurado.

Figura 23 - Arquivo ATG configurado no projeto

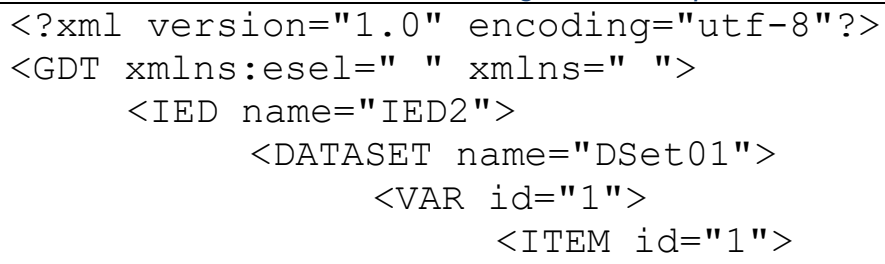


$<\mathrm{LN}>$ IED2 / CFG / LLNO/GooseIED2. ANN . PBLEDGGIO8 . Ind01 . stVal</LN> <TRANSLATION> IED2 push-button 1 status $</$ TRANSLATION $>$ $<$ UNIT $>$ Valor $</$ UNIT $>$ $<$ CONVERT>

pushed $</$ OPTION $>$ $\angle O P T I O N>00=P B 1$ is not pushed $</$ OPTION $>$ $<O P T I O N>01=\mathrm{PB} 1$

$</$ ITEM $>$

$</$ CONVERT $>$

$<$ ITEM id="2">

$<\mathrm{LN}>\mathrm{IED} 2$ / CFG/LLNO/GooseIED2. ANN . PBLEDGGIO8. Ind02. stVal</LN> <TRANSLATION> IED2 push-button 2 status

$</$ TRANSLATION $>$ $<$ UNIT $>$ Valor $</$ UNIT $>$ $<$ CONVERT $>$

pushed $</$ OPTION $>$ $\angle O P T I O N>00=P B 2$ is not pushed $</$ OPTION $>$ $<O P T I O N>01=\mathrm{PB} 2$

$$
\begin{aligned}
& \quad</ \text { CONVERT }> \\
& </ \text { ITEM }> \\
& <\text { ITEM id="3"> }
\end{aligned}
$$

$<\mathrm{LN}>\mathrm{IED} 2 / \mathrm{CFG} / \mathrm{LLNO} / \mathrm{GoO}$ eIED2. ANN . PBLEDGGIO8. Ind03. stVal</LN $>$ <TRANSLATION> IED2 push-button 3 status $</$ TRANSLATION $>$ $<$ UNIT >Valor </UNIT> $<$ CONVERT $>$ $\angle O P T I O N>00=$ PB3 is not

pushed $</$ OPTION $>$ $<O P T I O N>01=$ PB 3

pushed $</$ OPTION $>$

$$
\begin{aligned}
& </ \text { ITEM }> \\
& <\text { ITEM id=" } 4 ">
\end{aligned}
$$$$
</ \text { CONVERT }>
$$

$<\mathrm{LN}>\mathrm{IED} 2 / \mathrm{CFG} / \mathrm{LLNO} / \mathrm{GoO}$ eIED2. ANN . PBLEDGGIO8. Ind0 4 . stVal</LN>

\section{$</$ TRANSLATION $>$} <TRANSLATION> IED2 push-button 4 status $<$ UNIT $>$ Valor $</$ UNIT $>$ $<$ CONVERT $>$

pushed $</$ OPTION $>$ $<O P T I O N>00=P B 4$ is not pushed $</$ OPTION $>$

$$
<O P T I O N>01=\text { PB } 4
$$

$$
</ \text { ITEM }>
$$

$</$ CONVERT $>$

$</ D A T A S E T>$

$<$ SUBSCRIBER $>$

<PUBLISHER name="IED1"> <DATASET_P name="DSet01"> 


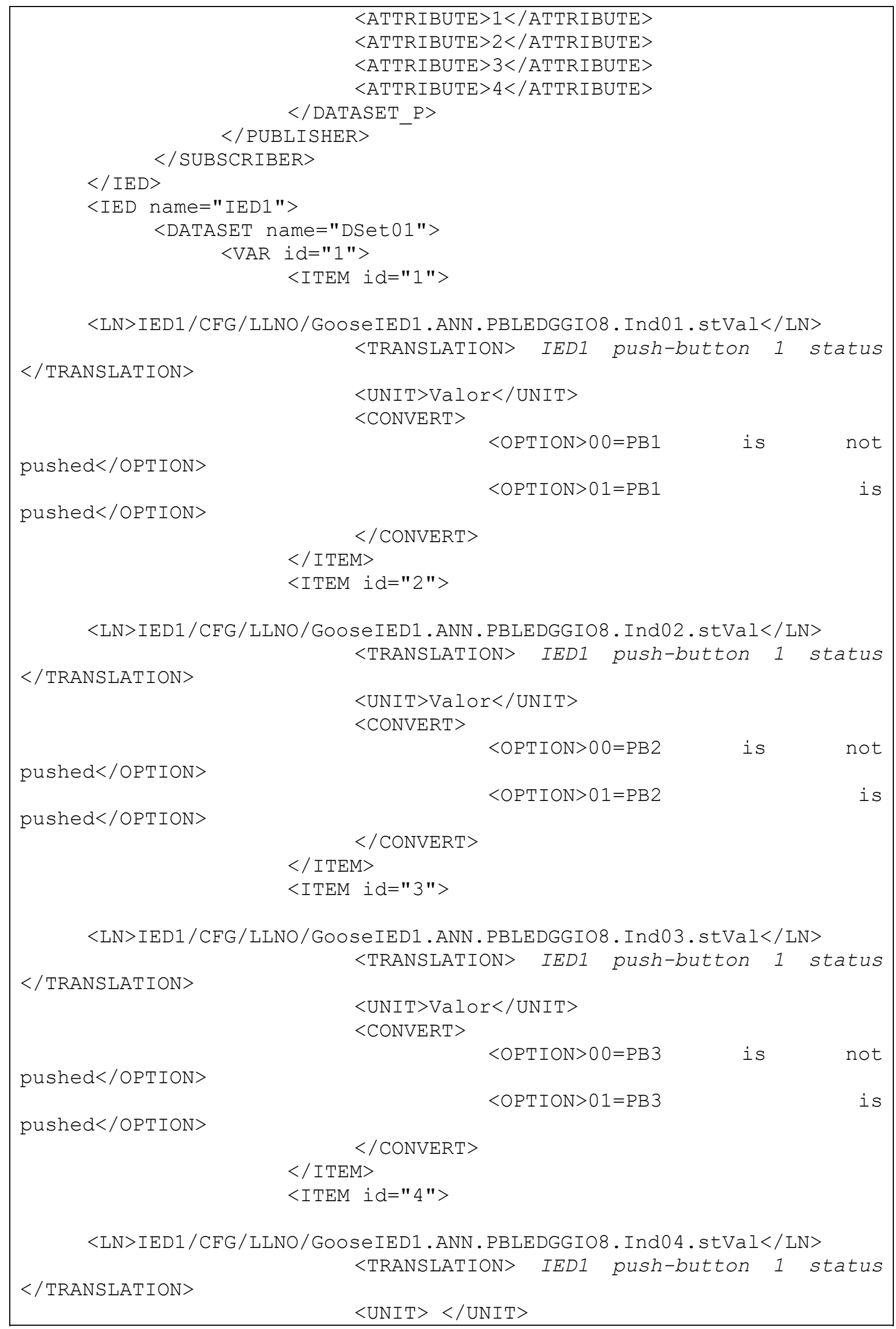




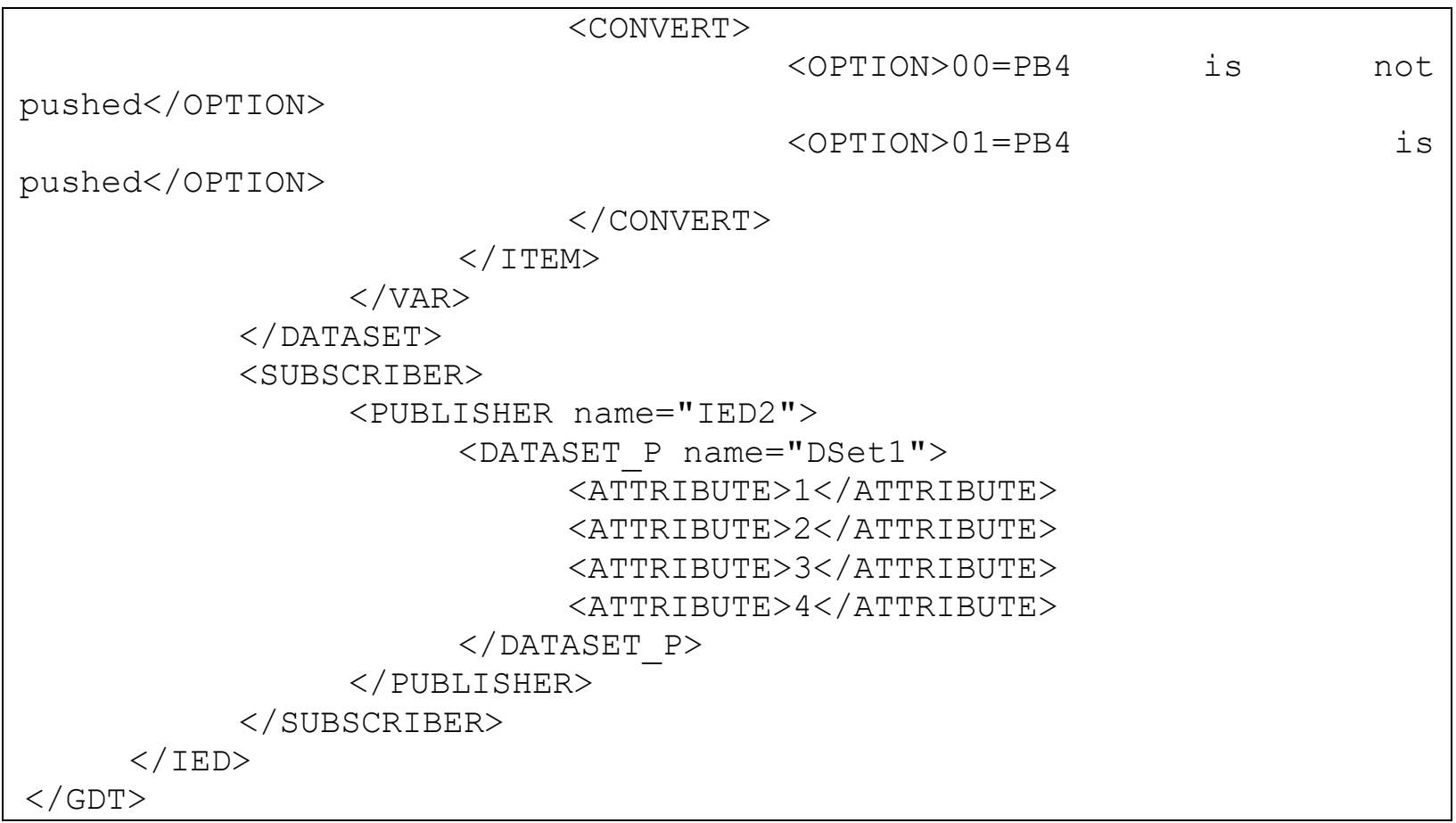

Fonte: O autor

A Figura 24 apresenta a estrutura padrão desenvolvida para o arquivo ATG.

Figura 24 - Esquema Macro do Arquivo ATG

ATG

$<$ IED nome $=$ " " $>$ (Nome do IED)

$<$ Dataset nome $=$ " ">

$<$ Atributo>

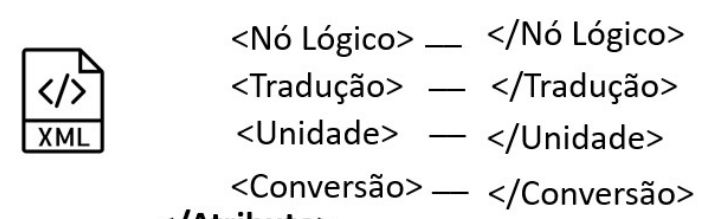
$</$ Atributo $>$

$</$ Dataset $>$

$<$ Subscriber $>$

$<$ Publisher nome $="$ " $>$

$<$ Dataset_P nome $=$ " ">

$<$ Atributo $></$ Atributo $>$

$</$ Dataset_P $>$

$<$ /Publisher $>$

$</$ Subscriber $>$

$</$ IED $>$

Fonte: $\mathrm{O}$ autor

A Tabela 6 contém as principais variáveis configuradas no arquivo ATG para os IEDs em testes com base na interpretação dos dados para o usuário, uma arquitetura de teste é apresentada no capítulo 0 . O campo IED contém a identificação do IED para o software auditor, o campo data set; a identificação do dataset publicado 
pelo dispositivo; nó lógico contém o endereço de nó lógico do atributo publicado pelo equipamento, o campo tradução contém a tradução do nó lógico na visão do usuário, o campo condição contém as possíveis condições de resultado que será apresentada com base no valor do dado contido no atributo capturado pelo software auditor.

Tabela 6 - Tabela de tradução dos atributos publicados

\begin{tabular}{|c|c|c|c|c|}
\hline IED & data set & nó lógico & tradução & condição \\
\hline \multirow{4}{*}{ IED1 } & \multirow{4}{*}{ Dset1 } & $\begin{array}{l}\text { IED1.ANN.PBLEDGGIO8.Ind } \\
\text { 01.stVal }\end{array}$ & IED1 push-button 1 status & $\begin{array}{l}00=\mathrm{PB} 1 \text { is not pushed } \\
01=\mathrm{PB} 1 \text { is pushed }\end{array}$ \\
\hline & & $\begin{array}{l}\text { IED1.ANN.PBLEDGGIO8.Ind } \\
\text { 02.stVal }\end{array}$ & IED1 push-button 2 status & $\begin{array}{l}00=\mathrm{PB} 1 \text { is not pushed } \\
01=\mathrm{PB} 1 \text { is pushed }\end{array}$ \\
\hline & & $\begin{array}{l}\text { IED1.ANN.PBLEDGGIO8.Ind } \\
\text { 03.stVal }\end{array}$ & IED1 push-button 3 status & $\begin{array}{l}00=\mathrm{PB} 1 \text { is not pushed } \\
01=\mathrm{PB} 1 \text { is pushed }\end{array}$ \\
\hline & & $\begin{array}{l}\text { IED1.ANN.PBLEDGGIO8.Ind } \\
\text { 04.stVal }\end{array}$ & IED1 push-button 4 status & $\begin{array}{l}00=P B 1 \text { is not pushed } \\
01=P B 1 \text { is pushed }\end{array}$ \\
\hline \multirow{4}{*}{ IED2 } & \multirow{4}{*}{ Dset1 } & $\begin{array}{l}\text { IED2.ANN.PBLEDGGIO8.Ind } \\
\text { 01.stVal }\end{array}$ & IED2 push-button 1 status & $\begin{array}{l}00=\mathrm{PB} 1 \text { is not pushed } \\
01=\mathrm{PB} 1 \text { is pushed }\end{array}$ \\
\hline & & $\begin{array}{l}\text { IED2.ANN.PBLEDGGIO8.Ind } \\
\text { 02.stVal }\end{array}$ & IED2 push-button 2 status & $\begin{array}{l}00=\mathrm{PB} 1 \text { is not pushed } \\
01=\mathrm{PB} 1 \text { is pushed }\end{array}$ \\
\hline & & $\begin{array}{l}\text { IED2.ANN.PBLEDGGIO8.Ind } \\
\text { 03.stVal }\end{array}$ & IED2 push-button 3 status & $\begin{array}{l}00=P B 1 \text { is not pushed } \\
01=P B 1 \text { is pushed }\end{array}$ \\
\hline & & $\begin{array}{l}\text { IED2.ANN.PBLEDGGIO8.Ind } \\
\text { 04.stVal }\end{array}$ & IED2 push-button 4 status & $\begin{array}{l}00=P B 1 \text { is not pushed } \\
01=P B 1 \text { is pushed }\end{array}$ \\
\hline
\end{tabular}

Fonte: O autor

Com os arquivos SCD e ATG configurados o software auditor pode ser executado. A primeira ação do AAG é identificar no arquivo SCD os parâmetros: Message name, IED ID, dataset e a quantidade de atributos do dataset especificado pelo usuário. A Erro! Autoreferência de indicador não válida. apresenta o resultado da identificação das variáveis realizada pelo software. 
Figura 25 - Identificação de IED e Dataset no SCD

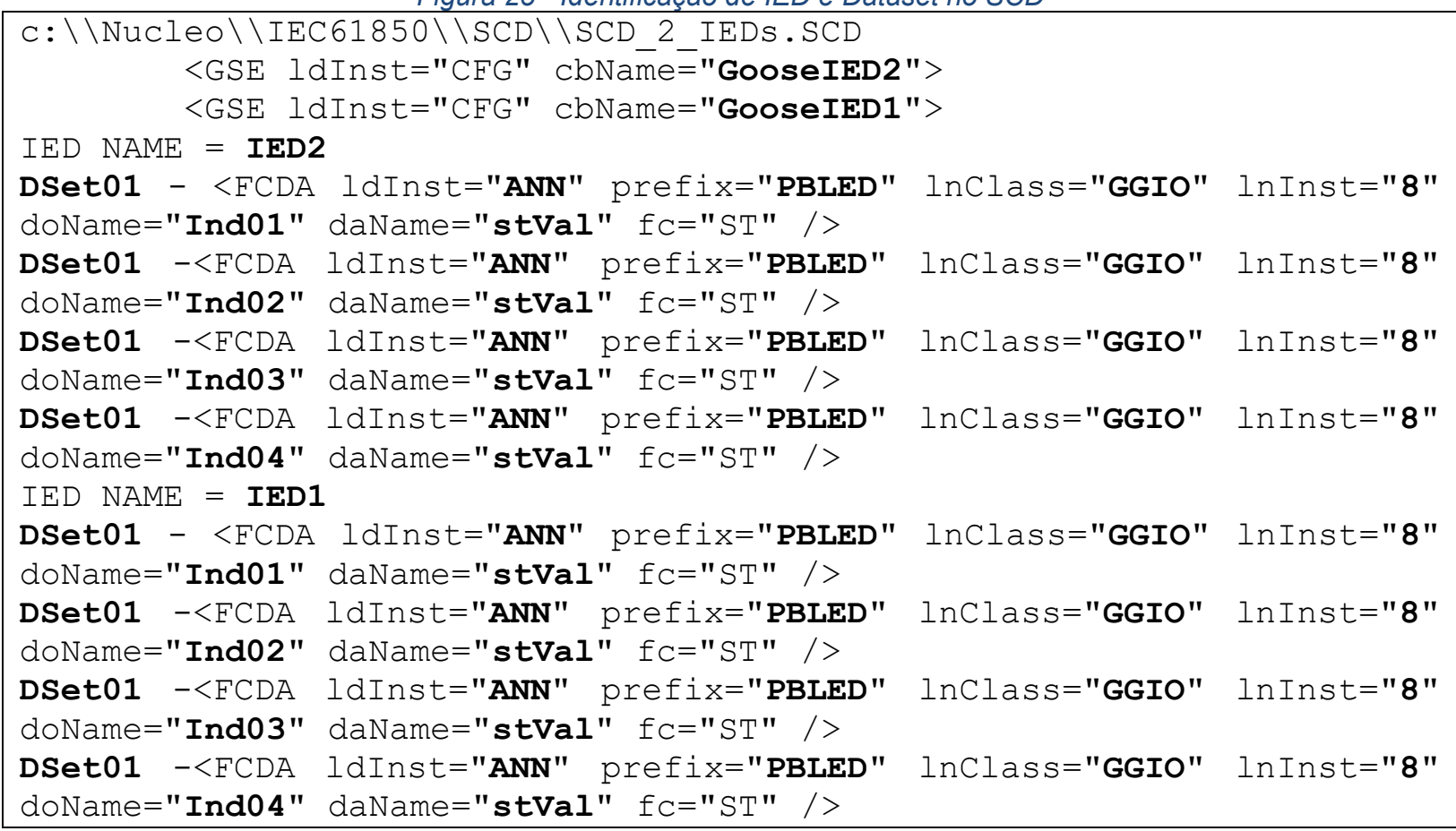
Fonte: O autor

Após o AAG identificar as informações do arquivo SCD, o arquivo ATG é carregado e as informações são comparadas. Não sendo identificadas divergências nos arquivos SCD e ATG, o AAG inicializa a captura dos pacotes trafegados na interface de rede da plataforma computacional, inserindo o valor de timestamp da recepção em todas as mensagens GOOSE identificadas. A próxima ação do AAG é analisar os dados contidos nas mensagens capturas, como mencionado no item 1.15. 


\section{Arquitetura de ensaio}

\subsection{Ambiente de ensaio}

As Figura 26 e Figura 27 apresentam a arquitetura e os equipamentos utilizados no ambiente de laboratório para realização dos ensaios. Na arquitetura preparada, um switch adequado à norma IEC-61850, gerenciável, foi utilizado para simulação de uma LAN contendo os equipamentos utilizados no ensaio. Os IEDs utilizados nos testes foram configurados de tal forma que a troca de mensagens GOOSE pôde ser realizada. Uma plataforma computacional com o software auditor instalado foi conectada ao switch, possibilitando assim, capturar e analisar as mensagens GOOSE publicadas pelos IEDs. Para garantir a mesma estampa de tempo dos dispositivos utilizados no ambiente de teste um Network Time Protocol (NTP) Server, com antena externa, foi configurado e conectado ao switch do ambiente.

Figura 26 - Arquitetura utilizada na pesquisa

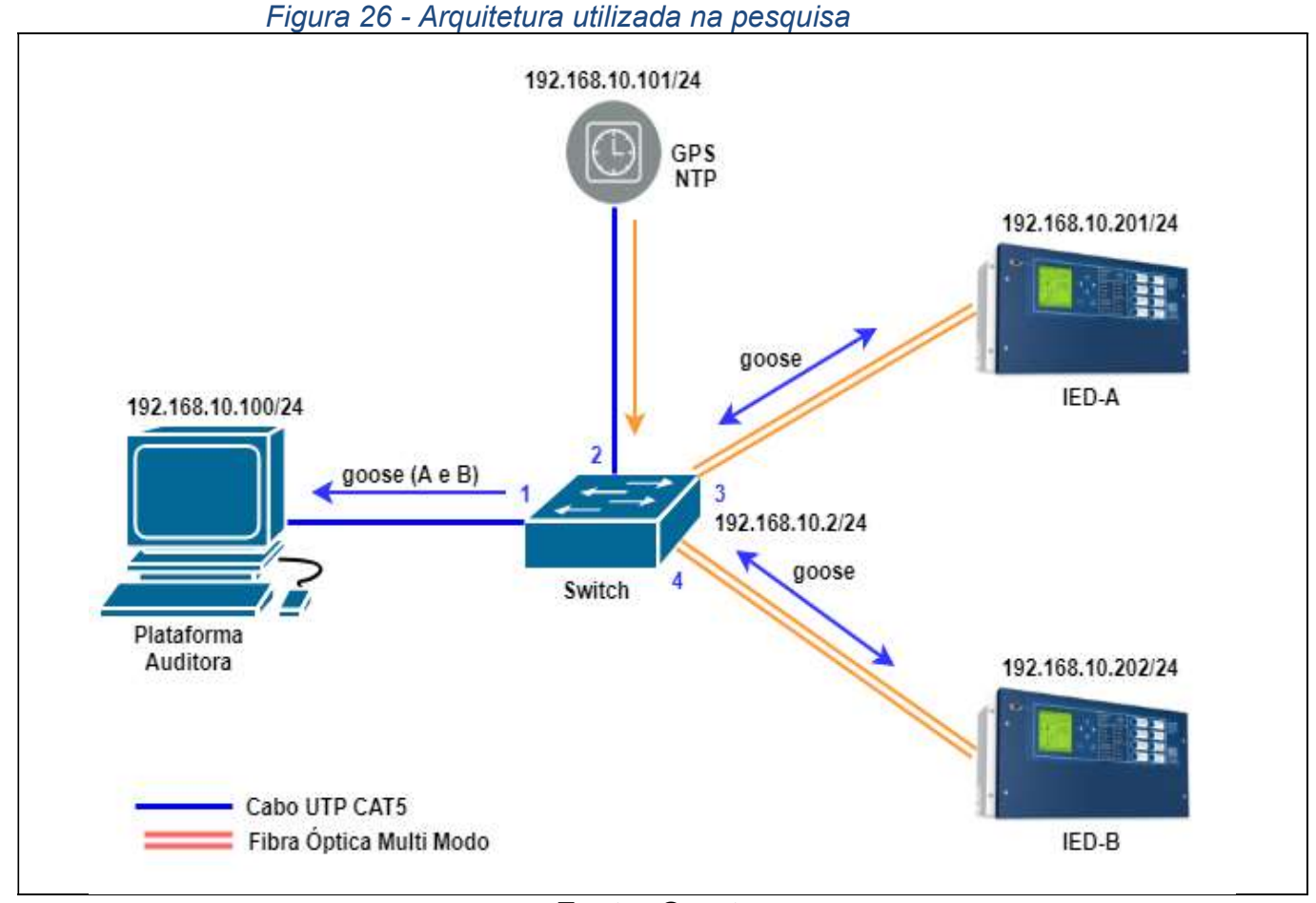

Fonte: $\mathrm{O}$ autor 
Figura 27 - Arquitetura de proposta para avaliação

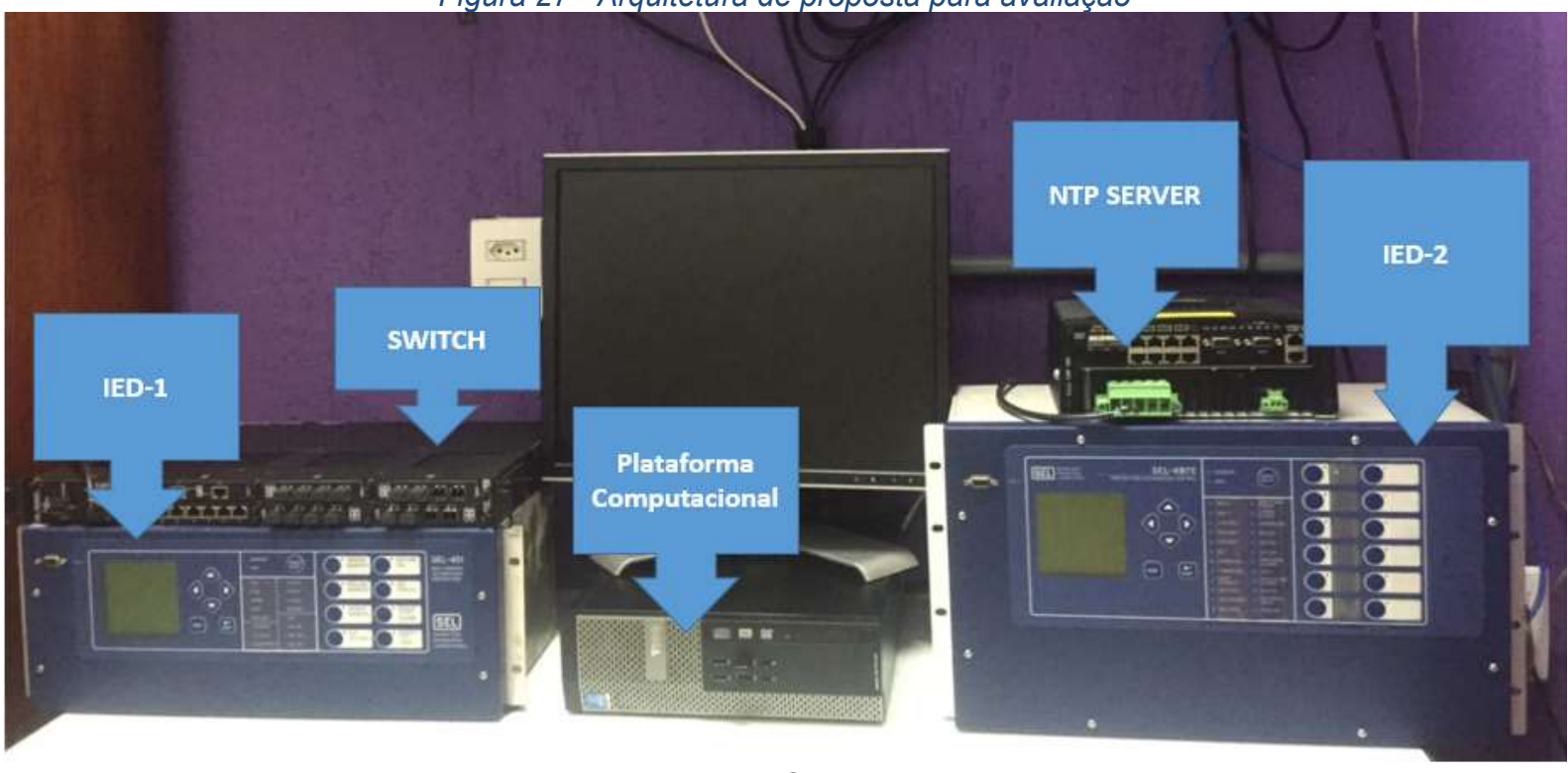

Fonte: $\mathrm{O}$ autor

O laboratório foi montado em um ambiente privado e foi composto pelos seguintes equipamentos:

- um IED da Schweitzer Engineering Laboratories - SEL, modelo 451-X . Part number 04515615XC2X4H224, firmware SEL-451-5-R314-V0Z019012-D20130618;

- um IED da SEL, modelo 487-X, Part number 0487E3X611XXC2, firmware SEL-487E-3R310-V0-Z104101-D2140515;

- um switch Siemens, modelo RX-1501, Part number RX1501-L2-MNTHIP-L2SE-CG01-6TX01-4FX11-4FX11-4FX11-4FX11;

- um roteador Cisco, modelo CGR-1120, com a função NTP Server habilitada.

- dois cabos ópticos com conectores Local Connector - LC para conectar os IEDS ao switch;

- dois cabos unshielded twisted pair (UTP) para conectar a plataforma computacional e o NTP Server ao switch;

- uma plataforma computacional com Windows 10 Professional 64bits.

- uma interface de rede para computador da marca Realtek modelo PCle GBE Family controller,

Os seguintes programas foram instalados na plataforma computacional:

- SEL-5032 acSELerator Architect versão 2.2.32.0: programa da SEL, para configurar a arquitetura dos IEDs em subestações com IEC61850. 
Possibilita a criação e o mapeamento das mensagens GOOSE, utiliza reports pré-definidos, cria e edita bases de dados e lê arquivos SCD, ICD e CID;

- SEL-5030 acSELerator Quickset versão 6.7.6.1: programa da SEL para configurar lógicas e os parâmetros de proteção dos IEDs;

- Wireshark Network Protocol Analyzer versão 3.0.1(v3.0.1-0gea351 cd8): analisador gratuito de protocolos de rede Ethernet mantido por voluntários especialistas em rede ao redor do mundo.

- Google Chrome versão 78.0.39.04.87 64bits: web browser da empresa Google utilizado para configuração do switch.

- Putty versão 0.70: Programa utilizado para acessar e configurar o NTP

Para a arquitetura simplificada implantada no laboratório, cada dispositivo foi configurado com um endereço IPv4 para acesso à configuração de parâmetros. Além dos endereços IPv4 e da máscara de rede, um endereço de gateway também foi configurado. A configuração detalhada é apresentada na Figura 28.

Figura 28 - Endereços IPV4 e MACs configurados no ambiente de teste

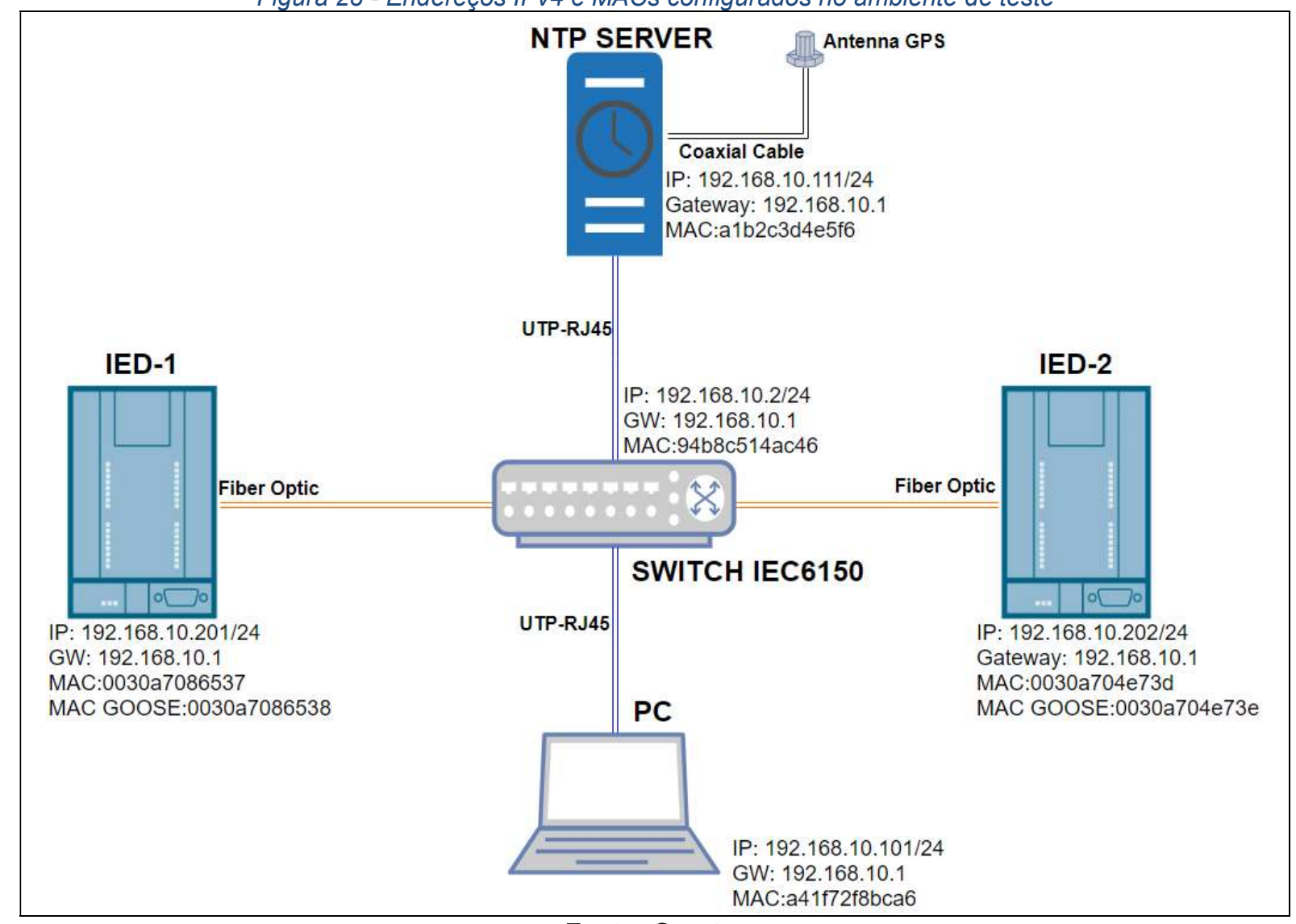

Fonte: $\mathrm{O}$ autor 


\subsection{Configuração do ambiente de ensaio}

Para a arquitetura simplificada elaborada em laboratório, foram inseridos endereços IPs diferentes para os devices de forma a possibilitar o acesso para configuração. Além dos IPs, e das sub redes, foi configurado o endereço do servidor de tempo para garantir a validação de detecção de falha de sincronismo através da estampa de tempo da mensagem GOOSE.

\subsubsection{Configuração da interface de rede do PC}

Uma forma de integrar a plataforma computacional a rede de comunicação do ambiente de teste, foi utilizar uma placa de rede padrão ethernet do modelo Realtek PCle GbE Family Controller configurado com um endereço IPv4 fixo, no mesmo intervalo permitido aos IEDs. A Figura 29 apresenta a descrição do modelo da placa de rede que foi instalada para captura de dados e a Figura 30 o endereço IPv4 configurado na plataforma computacional. Após a configuração da interface de rede do computador foi possível acessar os dispositivos para as configurações iniciais através dos aplicativos utilizando endereço IPv4.

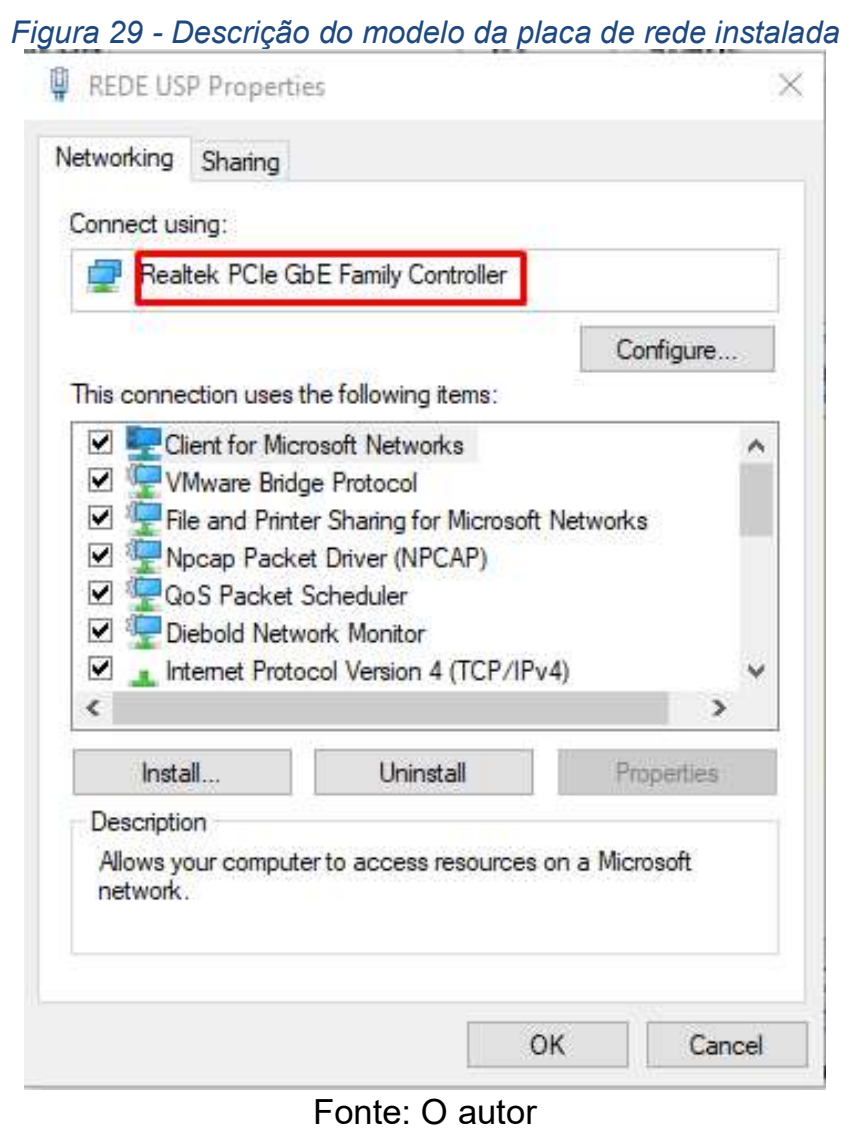




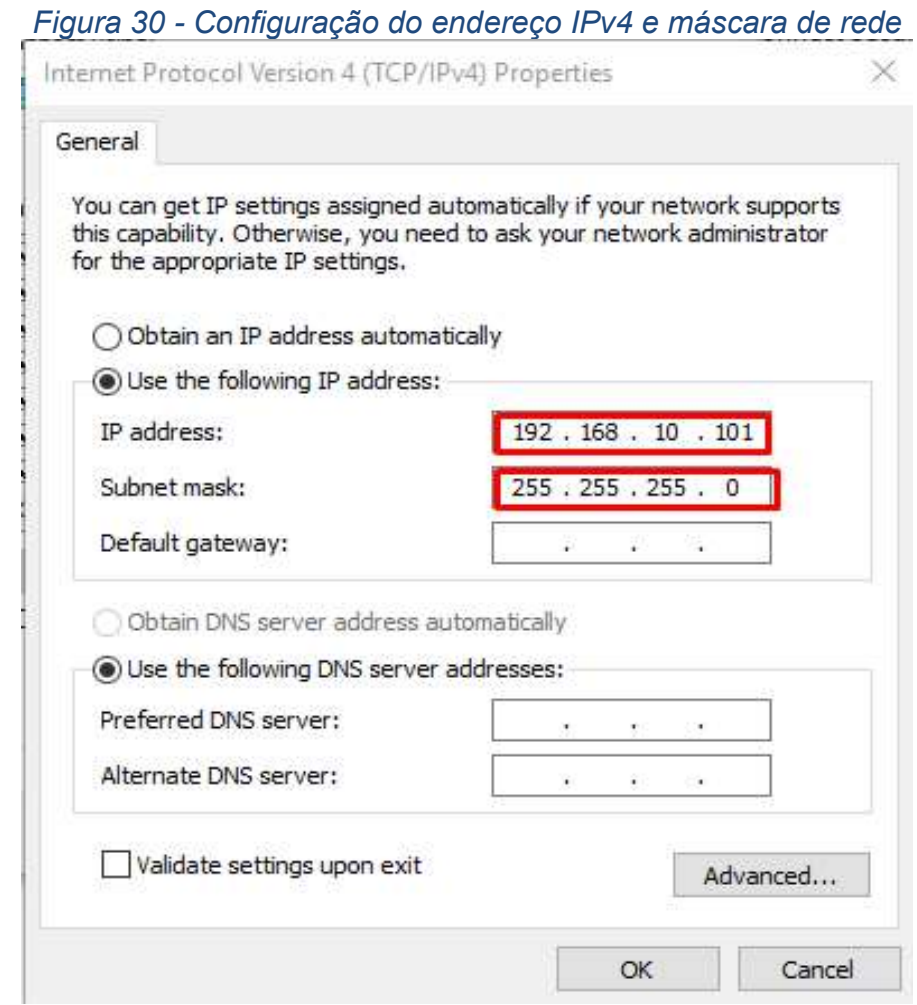

Fonte: $\mathrm{O}$ autor

\subsubsection{Configuração do switch}

Foi utilizado, no ambiente de teste, um switch gerenciável do fabricante Siemens. O equipamento modelo RX-1501 é homologado para norma IEC 61850 e da North American Electric Reliability Corporation (NERC) e Critical Infrastructure Protection (CIP).

O switch RX-1501 possibilita a configuração de VLANs nas interfaces de comunicação. Para os ensaios realizados foi necessário apenas uma VLAN.

Para acesso ao gerenciamento do switch o endereço IP 192.168.10.2 foi configurado. Após a configuração de gerência, foi adicionado o endereço IP do NTP Server para sincronismo do relógio interno.

\subsubsection{Configuração do NTP Server}

Com o objetivo de garantir o sincronismo de tempo dos dispositivos instalados na rede um NTP Server foi configurado. A Figura 31 apresenta o resultado dos comandos show plataform gps time e show ntp status. O primeiro comando apresenta 
o resultado do horário e data recebidos pelo sinal do GPS do equipamento, já o segundo apresenta o status da função de servidor de tempo do equipamento.

Figura 31 - Resultado da configuração do NTP Server

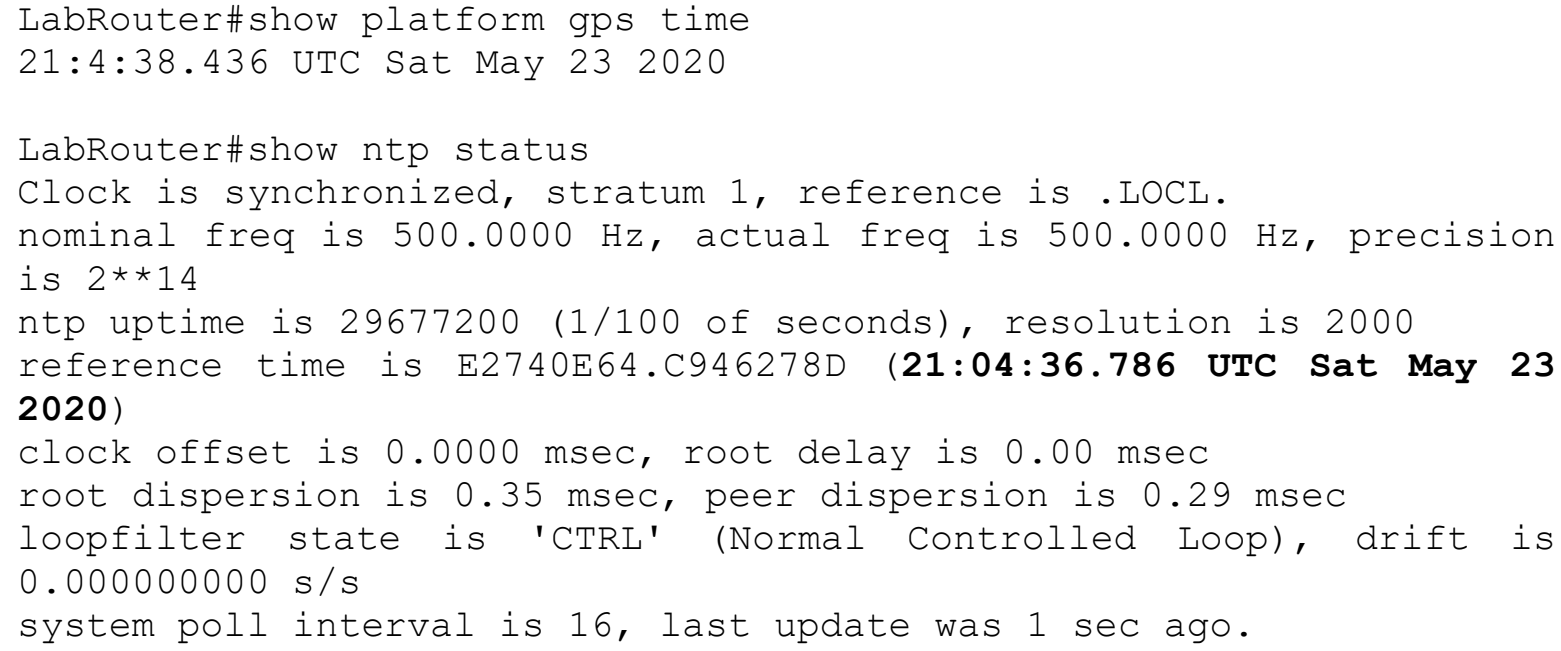

Fonte: $\mathrm{O}$ autor

\subsubsection{Configuração dos IEDs}

Os IED 451-5-R314 e 487E-3-R310 da SEL possuem mais de uma porta de comunicação ethernet. Estes dispositivos apresentam uma característica no funcionamento das suas portas de comunicação, a qual permite que elas possam trabalhar de quatro formas diferentes, utilizando apenas um endereço IP:

a) fixed: apenas uma das duas portas fica ativa no IED, mantendo a outra desativada;

b) failover: trabalha com as duas portas, sendo uma definida como primária. Somente haverá comutação para a porta secundária se houver falha na primária e depois de decorrido o tempo de ajuste;

c) switched: trabalha com as duas portas ativas mantendo uma configuração de switch para implementação com rede em anel;

d) Parallel Redundancy Protocol (PRP): é um padrão de protocolo de rede ethernet que fornece failover contínuo contra falhas de qualquer componente de rede. A informação é publicada de forma duplicada já que o dispositivo transmite o mesmo dado através das duas portas de rede. Nesta configuração o dispositivo aceita o primeiro pacote recebido e descarta o segundo (CISCO, 2018).

Para os testes apresentados neste capítulo os IEDs foram configurados com a opção failover, configuração default dos IEDs da SEL. Para os testes aqui 
apresentados apenas uma das portas de comunicação ethernet de cada IEDs foi conectada ao switch do laboratório. As configurações podem ser observadas nas Figura 32 e Figura 33.

Figura 32 - SEL-487E-3 configurado com opção failover

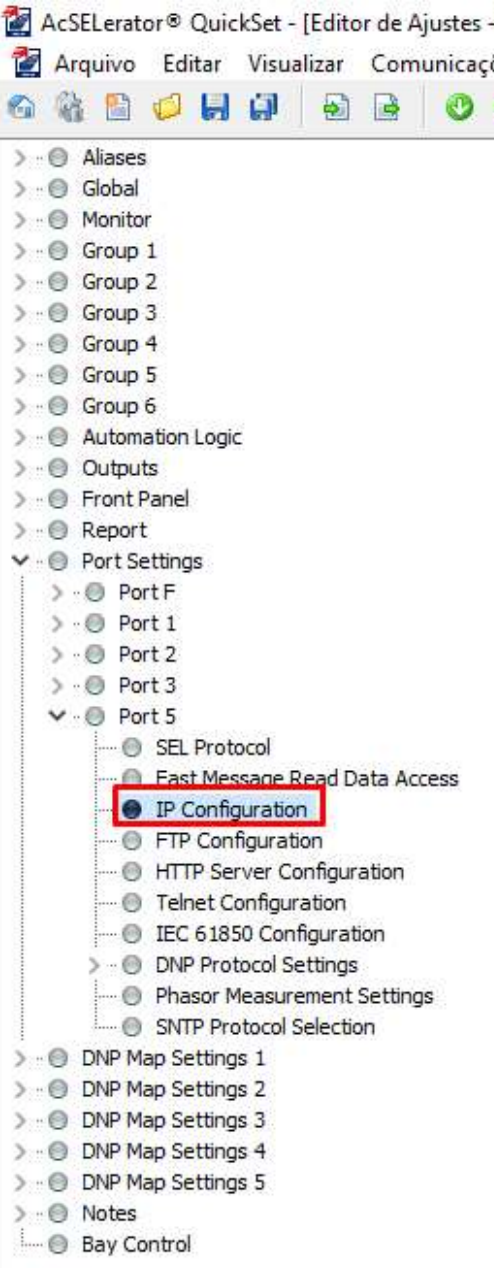

\section{IP Configuration}

IP Configuration

IPADDR Device IP Address / CIDR Prefix

$192.168 .10 .201 / 24$

DEFRTR Default Router

192.168.10.1

ETCPKA Enable TCP Keep-Alive

$Y \quad \checkmark$ Select: $Y, N$

KAIDLE TCP Keep-Alive Idle Range (seconds)

$\begin{array}{ll}10 & \text { Range }=1 \text { to } 20\end{array}$

KAINTV TCP Keep-Alive Interval Range (seconds)

1 Range $=1$ to 20

KACNT TCP Keep-Alive Count Range

\begin{tabular}{ll}
\hline 6 & Range $=1$ to 20
\end{tabular}

NETMODE Operating Mode

FAILOVER $\quad \checkmark$ Select: FIXED, FAILOVER, SWITCHED, PRP

NETPORT Primary Network Port

C $\checkmark$ Select: C, D

SECPORT Secondary Network Port

D Select: D

FIIME Failover Time-Out (ms)

1 Range $=0$ to 65535

PRPTOUT PRP Entry Timeout (ms)

$500 \quad$ Range $=100$ to 10000

Fonte: $\mathrm{O}$ autor 
Figura 34 - Resultado do comando mac para IED SEL-487E-3

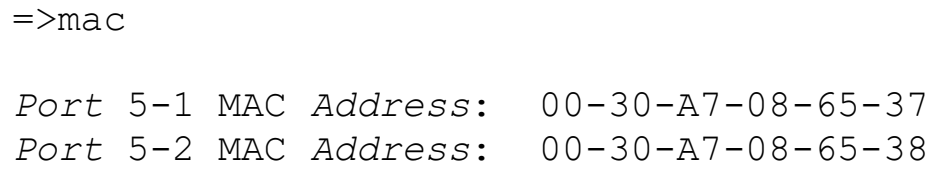

Fonte: $\mathrm{O}$ autor

Figura 35 - Resultado do comando mac para o IED SEL-451-5

$=>\operatorname{mac}$

Port 5-1 MAC Address: 00-30-A7-04-E7-3D

Port 5-2 MAC Address: 00-30-A7-04-E7-3E

Fonte: $O$ autor

\subsection{Definição das funções lógicas}

Com o objetivo de realizar a troca de mensagens GOOSE entres IEDs e capturá-las através da interface de rede Ethernet do PC, foram utilizados dois relés de proteção e, neste caso, as informações de status de push-button foram definidas para publicação.

Nas aplicações reais, as mensagens de trips e falhas de disjuntor, possuem uma maior importância se comparadas ao status do push-button, porém, do ponto de vista da construção e envio dos pacotes têm comportamentos semelhantes.

Primeiro um projeto lógico foi elaborado. Na lógica definida, um led do IED assinante acenderá quando um botão no relé publicador for pressionado. O led aceso tem o mesmo valor de sequência do push-button acionado.

O diagrama de blocos elaborado com as lógicas desenvolvidas é apresentado na Figura 36. 
IED1

IED2

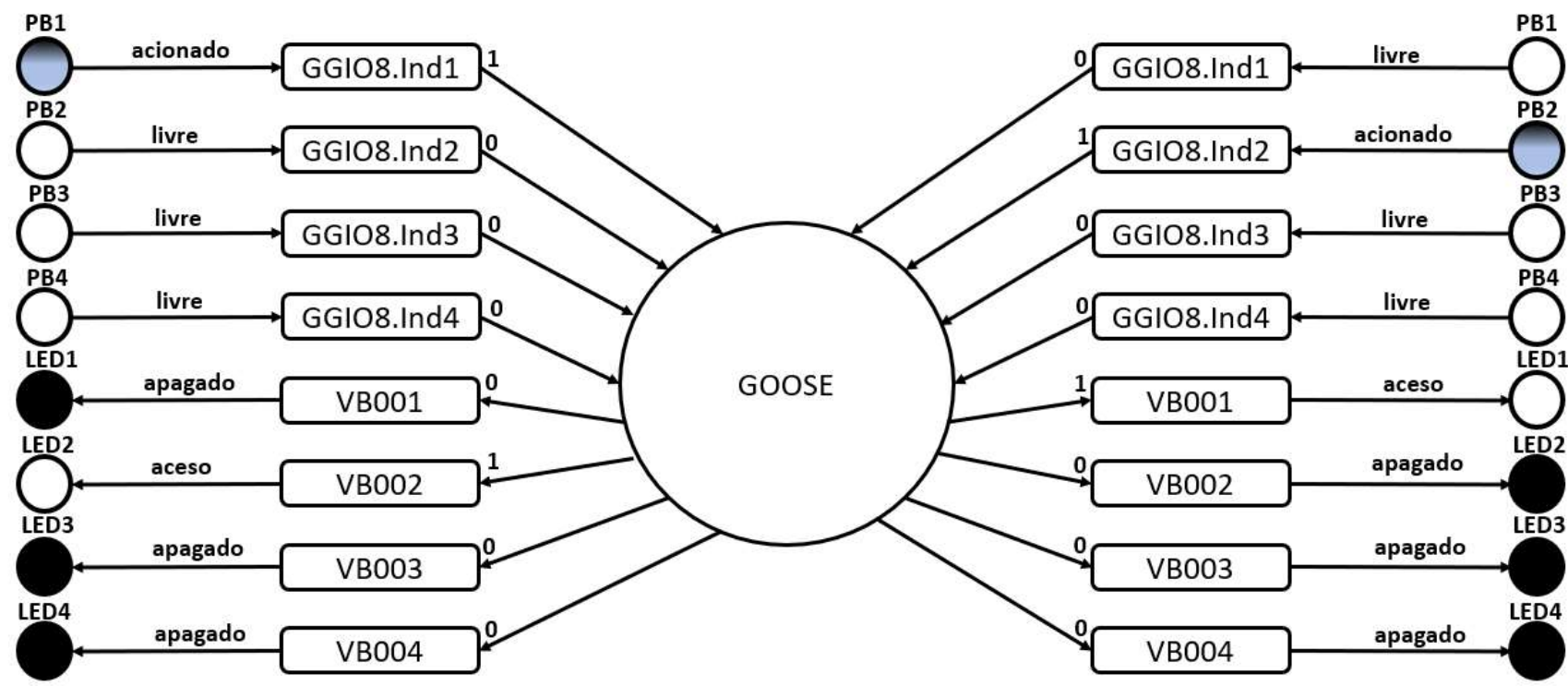

PB - Push Button

Fonte: $\mathrm{O}$ autor

Detalhando, pode-se citar o caminho para encontrar a variável binária utilizada. Acessando-se o dispositivo físico (IED1) através do seu endereço de rede, temos acesso em princípio ao dispositivo lógico. Este, uma vez acessado, disponibiliza a localização de vários tipos de dispositivos lógicos, que podem ser proteções, comandos, retornos digitais, configurações do próprio IED e o que nos interessa nesse exemplo, que são os tags digitais de status, localizadas no diretório "ANN“. Em seu interior estão os nós lógicos. O nó a ser utilizado será o PBLEDGGIO08, padronizado pela SEL para indicar os status dos push-button. Explorando o nó é possível visualizar cada uma das classes que o compoem. Na Figura 37, é possível perceber de forma mais clara como essa arquitetura é ilustrada. 


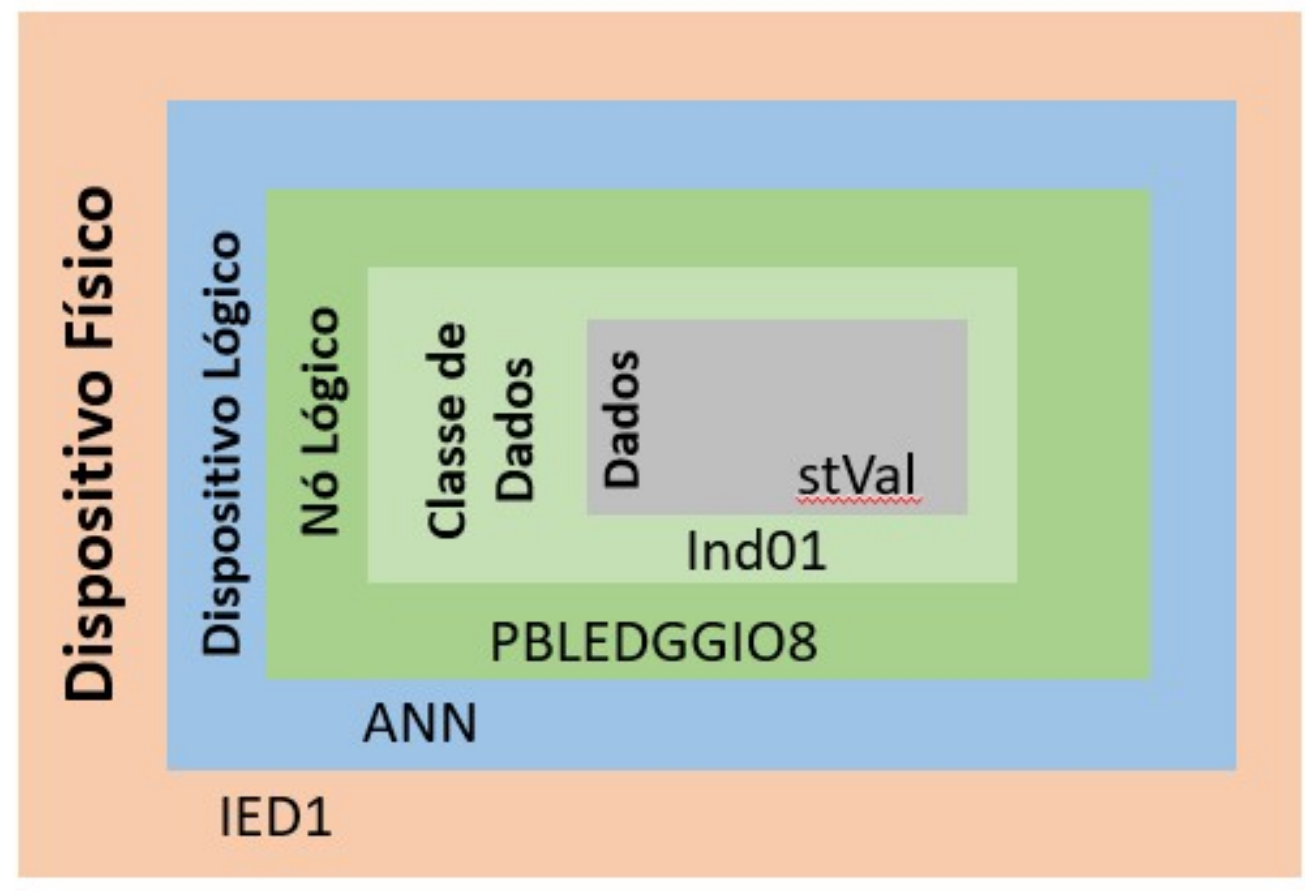

Fonte: O autor

Após identificar os atributos na estrutura, os botões frontais dos IEDs foram mapeados para os endereços lógicos. A Tabela 7 apresenta os botões frontais utilizados e os respectivos endereços dos atributos.

Tabela 7 - Botão e Atributos Lógicos

\begin{tabular}{ll}
\hline Botão & Tabela 7 - Botão e Atributos Lógicos \\
\hline 1 & IED1.ANN.PBLEDGGIO8.Ind01.stVal \\
\hline 2 & IED1.ANN.PBLEDGGIO8.Ind02.stVal \\
\hline 3 & IED1.ANN.PBLEDGGIO8.Ind03.stVal \\
\hline 4 & IED1.ANN.PBLEDGGIO8.Ind04.stVal \\
\hline & Fonte: O autor
\end{tabular}

Em seguida, foram mapeados os atributos recebidos para as variáveis virtuais de entrada, então as os leds frontais puderam ser configurados. Para os IEDs da SEL, as variáveis virtuais de entrada são identificadas pelas iniciais VB seguidas de uma sequência numérica. A Tabela 8 apresenta o mapeamento realizado para sinalizar através dos leds frontais o status do push-button. 
Tabela 8 - Relação Atributos e Leds

\begin{tabular}{lll}
\hline Atributo Recebido & Entrada Virtual & LED Frontal \\
\hline IED2.ANN.PBLEDGGIO8.Ind01.stVal & VB001 & 1 \\
\hline IED2.ANN.PBLEDGGIO8.Ind02.stVal & VB002 & 2 \\
\hline IED2.ANN.PBLEDGGIO8.Ind03.stVal & VB003 & 3 \\
\hline IED2.ANN.PBLEDGGIO8.Ind04.stVal & VB004 & 4 \\
\hline
\end{tabular}

Fonte: $\mathrm{O}$ autor

\subsection{Configuração da publicação GOOSE}

Para um IED publicar mensagens GOOSE, é necessária uma sequência de configuração a ser seguida.

Primeiro foi criado um projeto no software acSELerator Architect, identificado como SE-USP-Mestrado. Posteriormente, os dispositivos utilizados foram importados para estrutura criada. A Figura 38 apresenta a estrutura criada e os dispositivos inseridos.

Figura 38 - Projeto acSELerator Architect

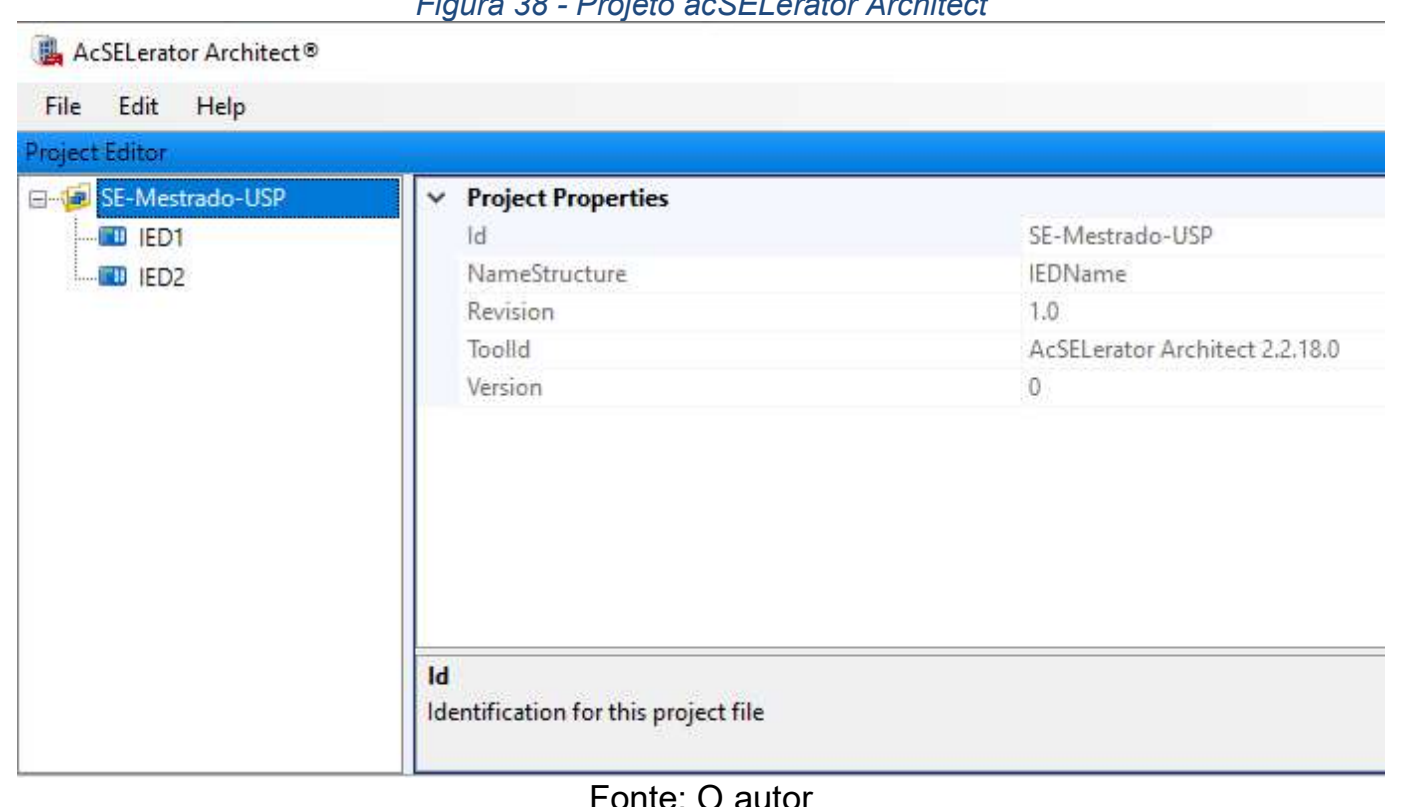

Fonte: $\mathrm{O}$ autor

Com o IED1 selecionado os atributos referentes ao status de push-button do dispositivo foram inseridos no dataset com o name DSet01. A Figura 39 apresenta o dataset criado e os atributos definidos. 
Figura 39 - Dataset IED1

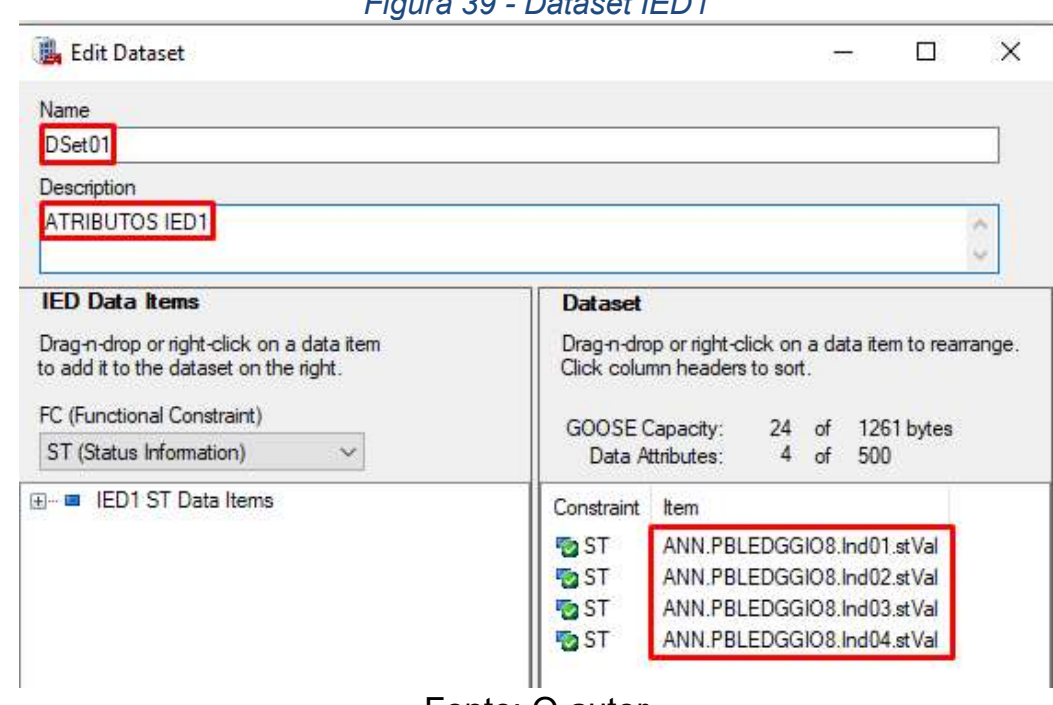

Fonte: O autor

Após o dataset ser estruturado, a mensagem GOOSE é configurada. Acessando o guia de menu GOOSE Transmit do software acSELerator Architect são preenchidos os campos que identificam as mensagens criadas. A Figura 40 apresenta os parâmetros de identificação configurados para o IED1.

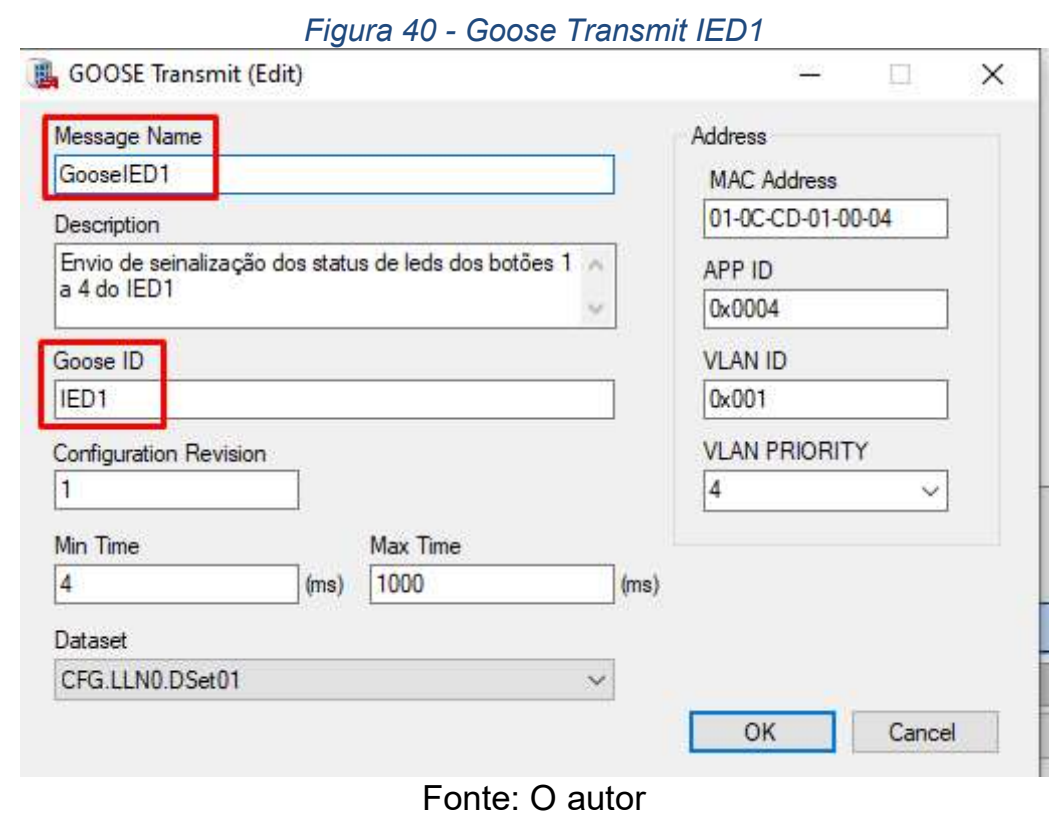

A descrição dos campos contidos na Figura 40 é apresentada a seguir:

a) message name: identificador único contendo o nome da mensagem publicada;

b) description: campo destinado para descrição de comentários;

c) GOOSE ID: identificador do dispositivo publicador GOOSE. Este campo é obrigatório; 
d) configuration revision: conforme IEC 61850-7-3, este campo identifica a instancia de configuração do dispositivo lógico.

e) $\min$ e max. time(ms): valor numérico de quatro a sessenta mil que representa um período de tempo em milissegundos. Este período é o intervalo entre as mensagens GOOSE após o decaimento exponencial e onde não há mudanças no GOOSE.

f) dataset: agrupamento de nós lógicos;

g) MAC address: um único endereço MAC para o qual múltiplos dispositivos podem se inscrever para a entrega simultânea de um fluxo de dados comum;

h) APP ID: identificador de aplicação. O usuário define este identificador na definição de uma mensagem GOOSE de saída conforme IEC 61850-8-1;

i) VLAN ID: identificador numérico de doze bits que identifica uma rede logicamente independente;

j) VLAN priority: valor numérico de zero a sete em que sete é a maior prioridade. Pacotes Ethernet com tags de prioridade são priorizados pelos switches e outros dispositivos de rede de tal forma que os pacotes de maior prioridade são processados antes dos pacotes de menor prioridade.

A mesma sequência utilizada para configurar a mensagem GOOSE no IED1 repetiu-se para o IED2. As Figura 41 e Figura 42 evidenciam a configuração.

Figura 41 - Dataset IED2

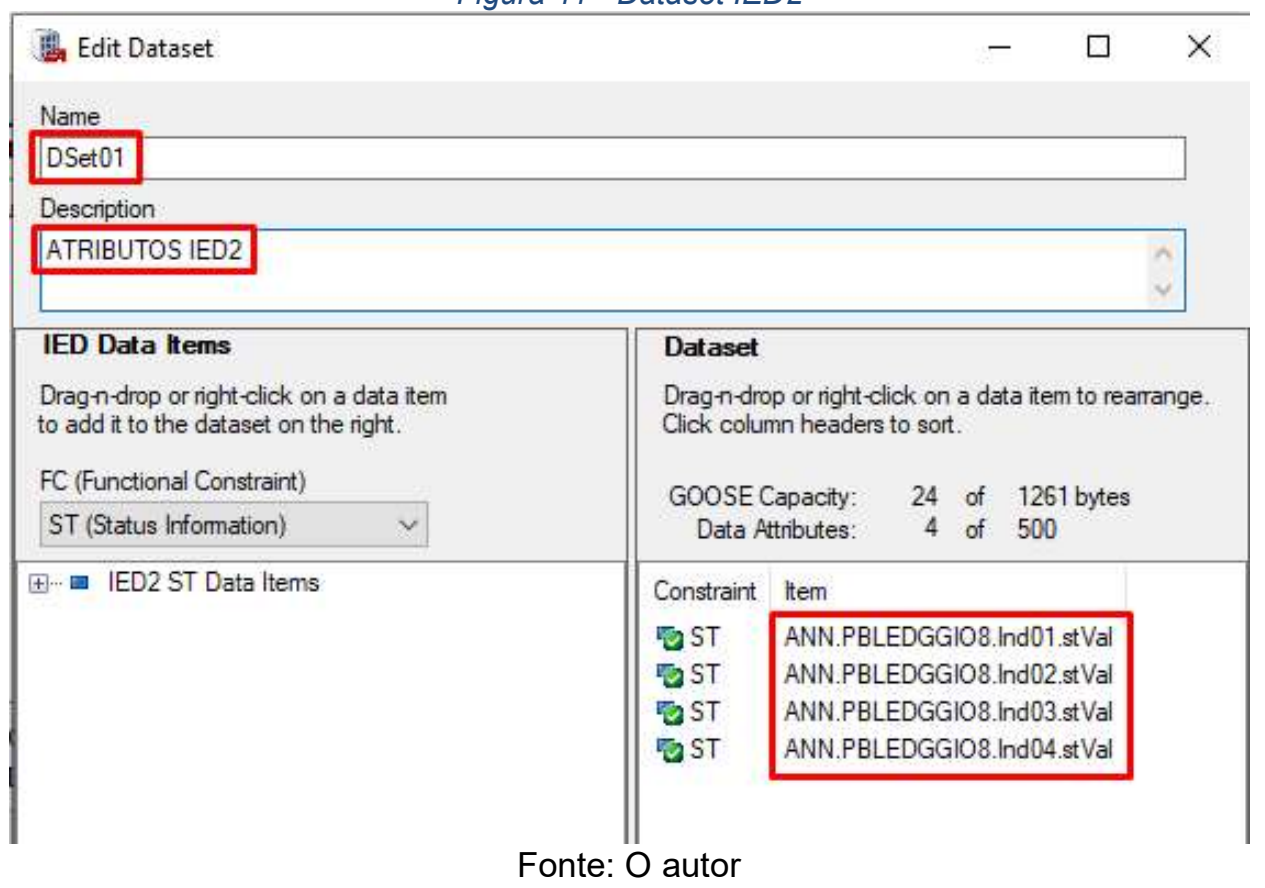


Figura 42 - Goose Transmit IED2

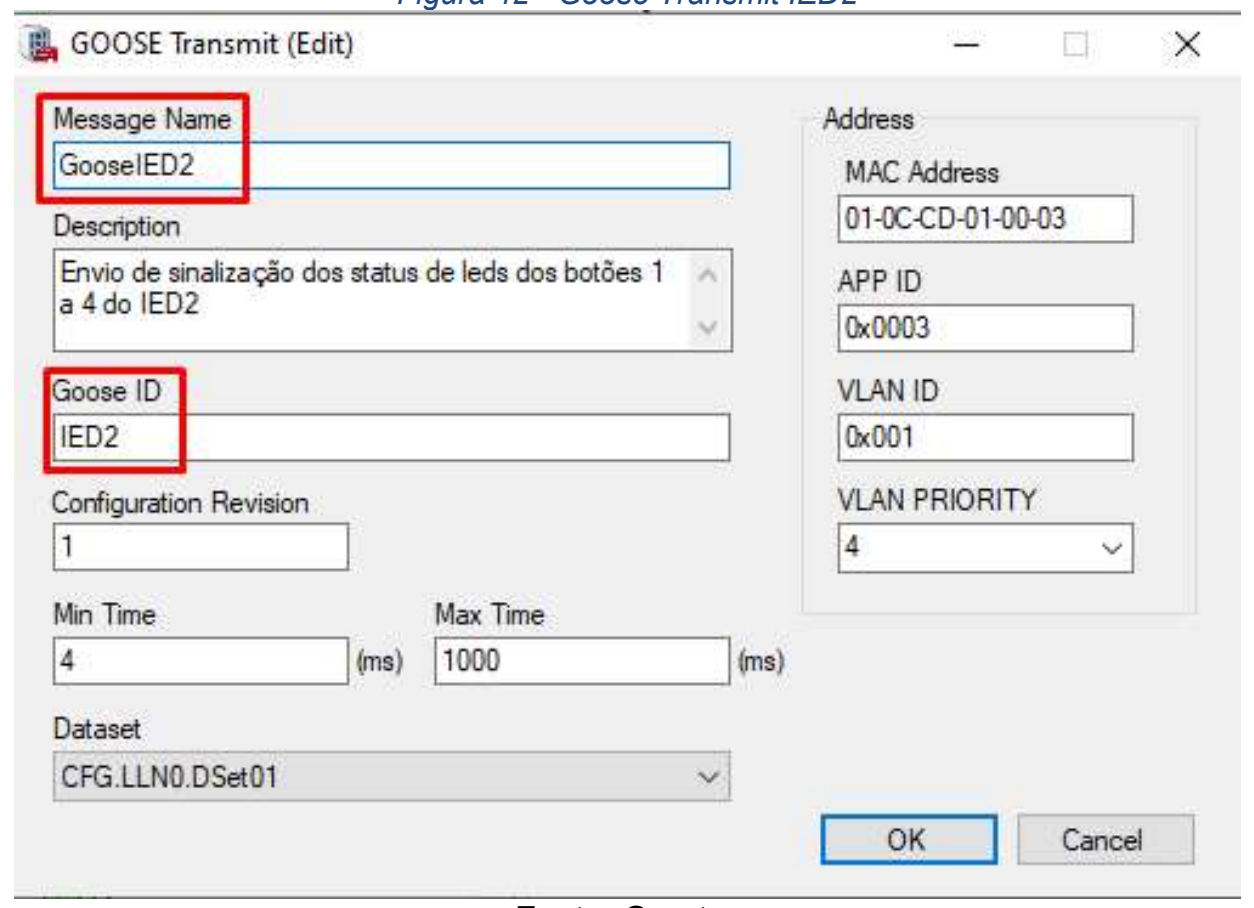

Fonte: O autor

\subsection{Configuração da assinatura das mensagens GOOSE}

Após a configuração da transmissão do GOOSE em ambos os dispositivos, a recepção da mensagem pode ser definida. Os atributos recebidos foram direcionados para as variáveis virtuais de entrada indicada no item 1.19 deste mesmo capítulo.

As Figura 43 e Figura 44 evidenciam as configurações realizadas nos IEDs para recepção das mensagens GOOSE.

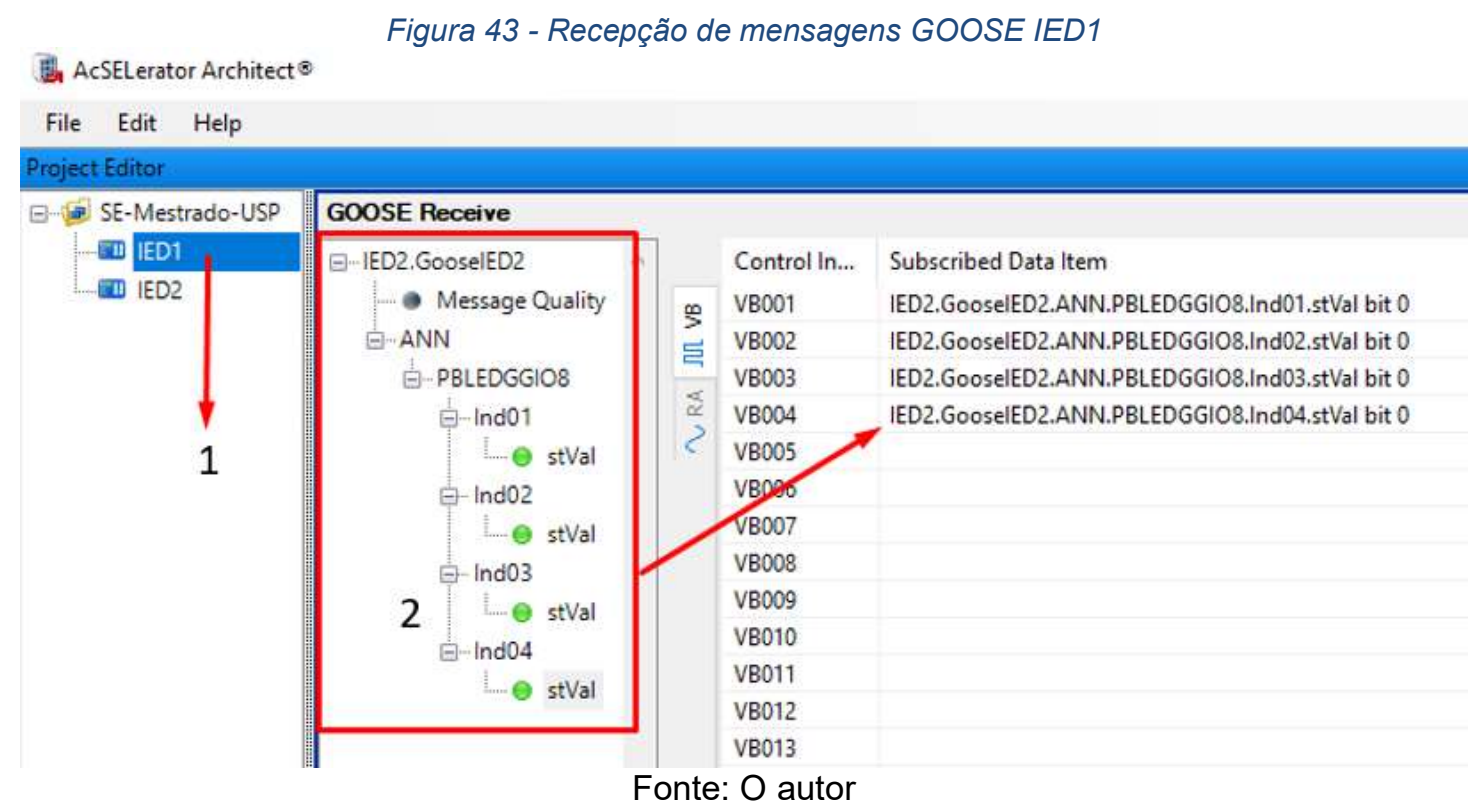


Figura 44 - Recepção de mensagens GOOS IED2

18. AcSELerator Architect ${ }^{\circ}$

File Edit Help

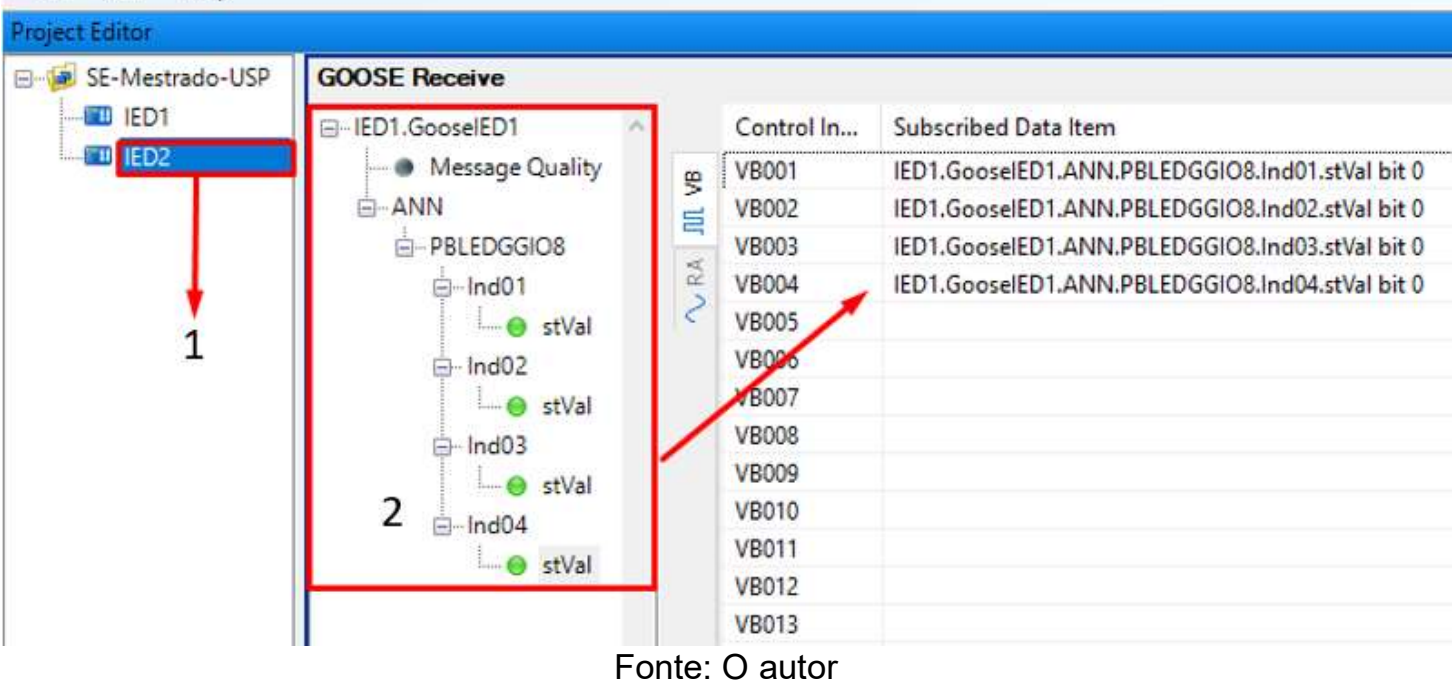

Após as configurações dos parâmetros, os arquivos CID foram descarregados nos IEDs, então o GOOSE passou a ser publicado na rede. 


\section{Ensaios e resultados}

Este capítulo tem por objetivo demonstrar que, conforme metodologia desenvolvida e, analisando as mensagens GOOSE capturadas pelo AAG, é possível identificar divergências da configuração atual dos IEDs com a definida no projeto inicial.

Além de identificar divergências de configuração, os resultados obtidos evidenciam que o software desenvolvido é capaz de indicar falhas de comunicação e de sincronismo através da interpretação da estampa de tempo das mensagens GOOSE trafegadas.

\subsection{Identificação de arquivos e interface de rede}

Como teste inicial, foi realizada a validação da interpretação dos arquivos SCD e ATG pelo AAG, somado a estes a captura do pacote GOOSE.

Primeiro o AAG localizou $\mathrm{O}$ arquivo SCD e internamente identificou os parâmetros: Message name, IED ID, dataset e a quantidade de atributos do dataset especificado pelo usuário. A Figura 45 apresenta o resultado da identificação das variáveis realizada pelo software.

Figura 45 - Identificação de IED e Dataset

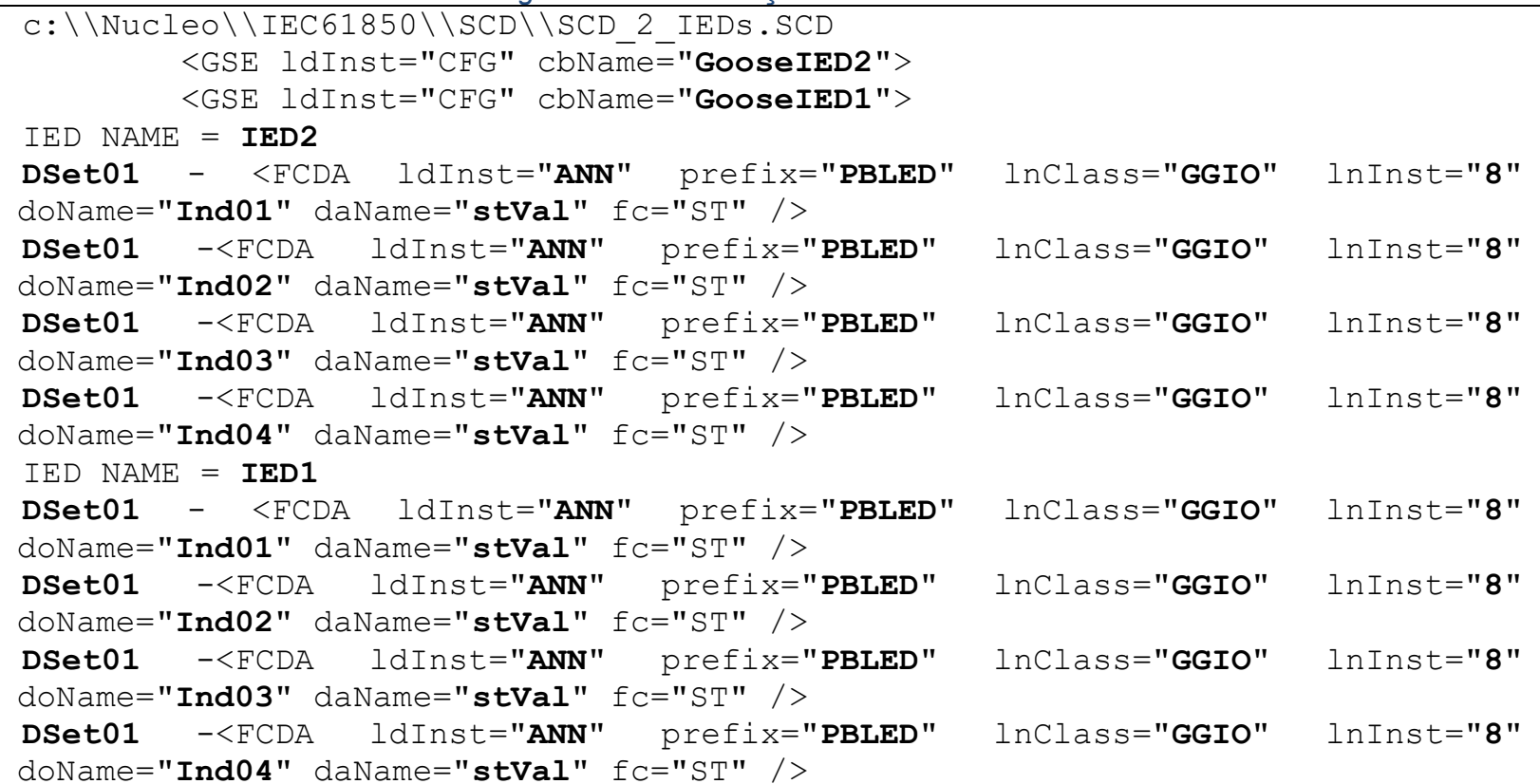

Fonte: $\mathrm{O}$ autor

Após a interpretação e identificação das variáveis no arquivo SCD, o arquivo ATG foi localizado e seu conteúdo, que são os dados preenchido pelo usuário, foram 
carregados para a memória do software auditor. O resultado da interpretação do arquivo ATG é mostrado na Figura 46.

Figura 46 - Identificação dos atributos no arquivo ATG

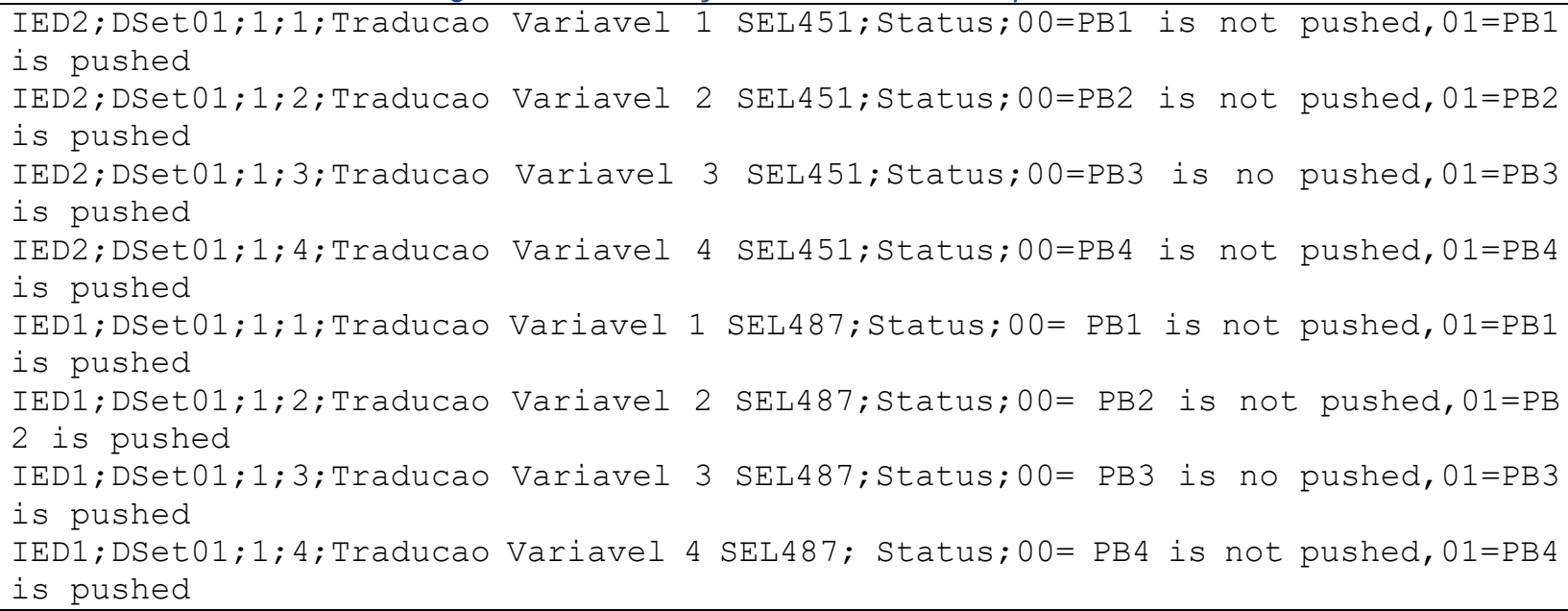

Fonte: O autor

A terceira etapa do processo de inicialização da aplicação é identificar as interfaces de rede instaladas na plataforma computacional. O AAG listou nove interfaces existentes no PC, então a interface 3 "Network adapter 'Realtek PCle Gbe Family Controller' on local host", interface que está conectada na rede do ambiente de teste, foi selecionada para captura dos pacotes GOOSE trafegados. A Figura 47 apresenta o resultado da identificação das interfaces de redes instaladas na plataforma computacional e detectadas pelo software auditor.

Figura 47 - Lista de interfaces de rede

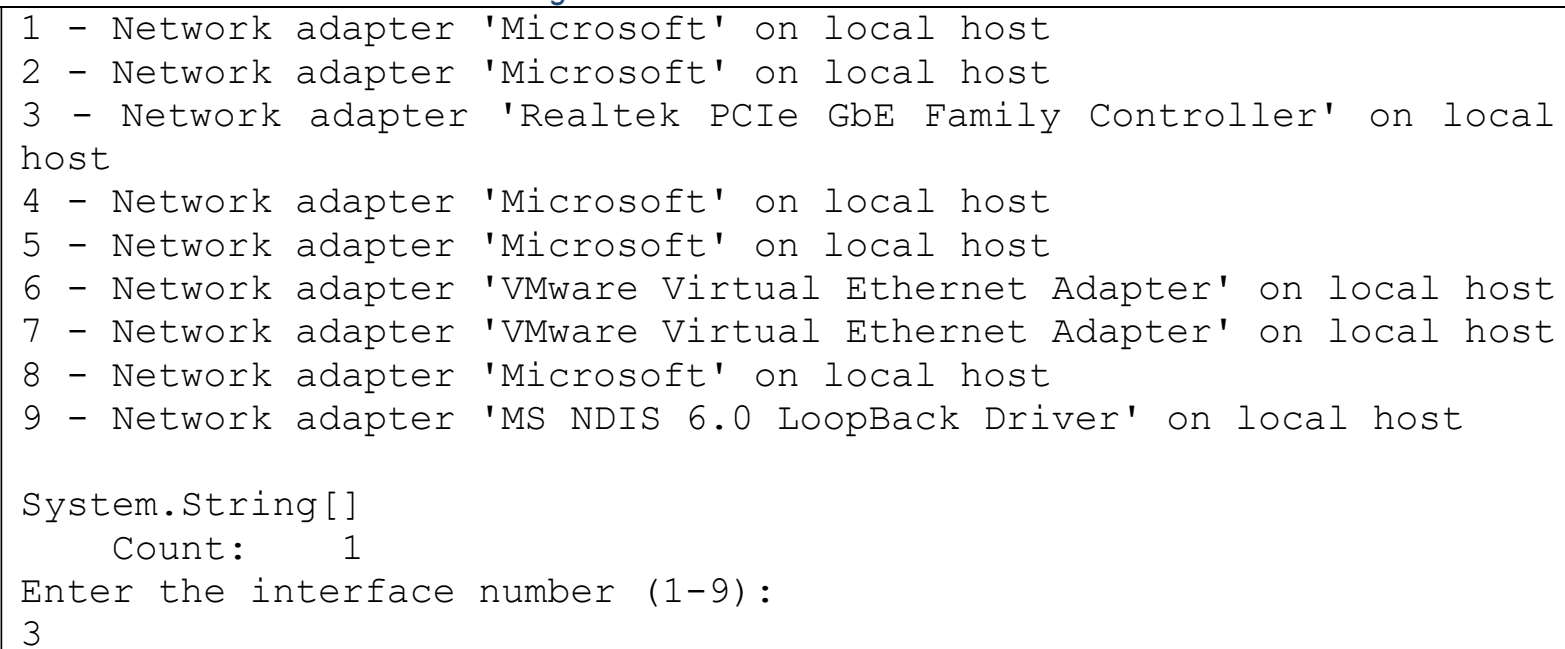




\subsection{Validação da Captura do Pacote pelo AAG}

Como foi mencionado no item 1.21, depois de descarregadas as configurações nos dispositivos, o GOOSE passou a ser publicado na rede.

Para o teste de validação da publicação das mensagens GOOSE dos IEDs e captura dos pacotes pela plataforma computacional, os push-buttons dos dispositivos não foram pressionados, assim o resultado esperado deve ser todos os atributos com valor zero "0".

Para evidenciar o tráfego de mensagens GOOSE utilizou-se o programa Wireshark. Com auxílio do software foi possível verificar a publicação do GOOSE do IED1 (endereço 00:30:a7:08:65:38) e IED2 (endereço 00:30:a7:04:e7:3e), os pacotes capturados contém as informações de Message Name, data set, GOOSE ID e os atributos configurados com o estado false das saídas PBLEDGGIO8 quando os botões frontais dos IEDs não estão pressionados, conforme Figura 48 e Figura 49. 
Figura 48 - GOOSE do IED1, botões não pressionados

*REDE USP

File Edit View Go Capture Analyze Statistics Telephony Wireless Tools Help

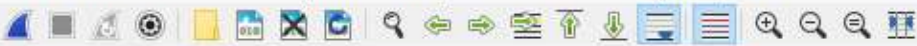

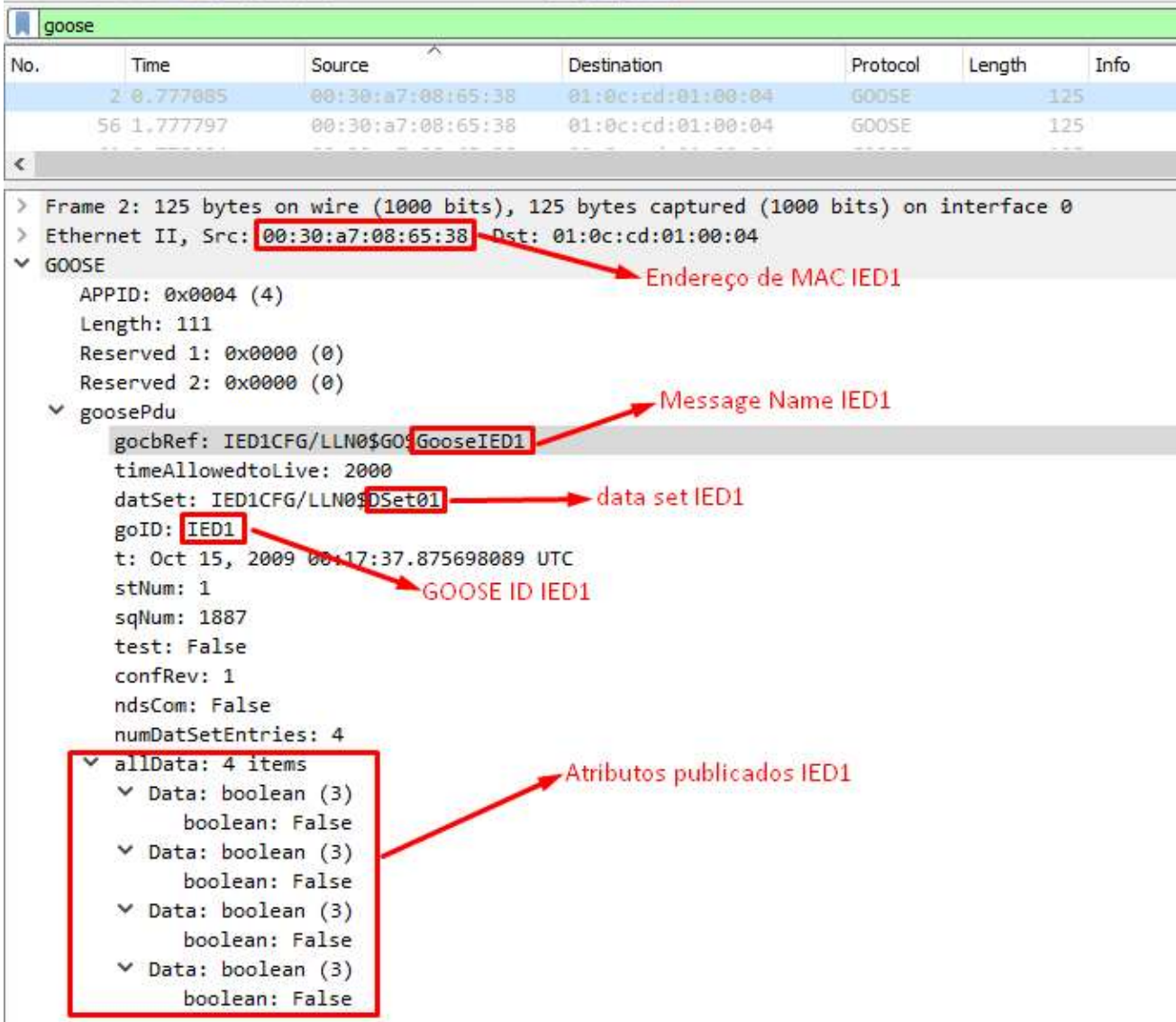

$0000 \quad 01$ oc cd $0100 \quad 04 \quad 00 \quad 30 \quad$ a7 $08 \quad 65 \quad 38 \quad 88$ b8 $00 \quad 04$

$0010 \quad 00 \quad$ ff $00 \quad 00 \quad 00 \quad 00 \quad 61 \quad 65 \quad 80 \quad 19 \quad 49 \quad 45 \quad 44 \quad 31 \quad 43 \quad 46$

$0020 \quad 47 \quad$ f 4 c 4 c 4 e $30 \quad 24 \quad 47$ 4f $24 \quad 47$ ff $6 f \begin{array}{lllllll}73 & 65 & 49\end{array}$

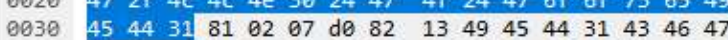

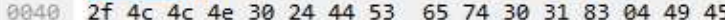

$\begin{array}{lllllllllllllllll}0059 & 44 & 31 & 84 & 08 & 4 a & \text { d6 } & 6 a & 21 & \text { e0 } & 2 d & c 0 & \text { bf } & 85 & 01 & 01 & 86\end{array}$

$\begin{array}{lllllllllllllllllll}0060 & 02 & 07 & 5 f & 87 & 01 & 00 & 88 & 01 & 01 & 89 & 01 & 00 & 8 a & 01 & 04 & a b\end{array}$

$\begin{array}{llllllllllllll}0070 & \theta C & 83 & 01 & 00 & 83 & 01 & 06 & 83 & 01 & 00 & 83 & 01 & 00\end{array}$

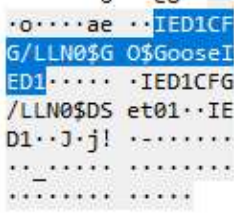

.........

Fonte: O autor 
*REDE USP

Figura 49 - GOOSE do IED2, botões não pressionados

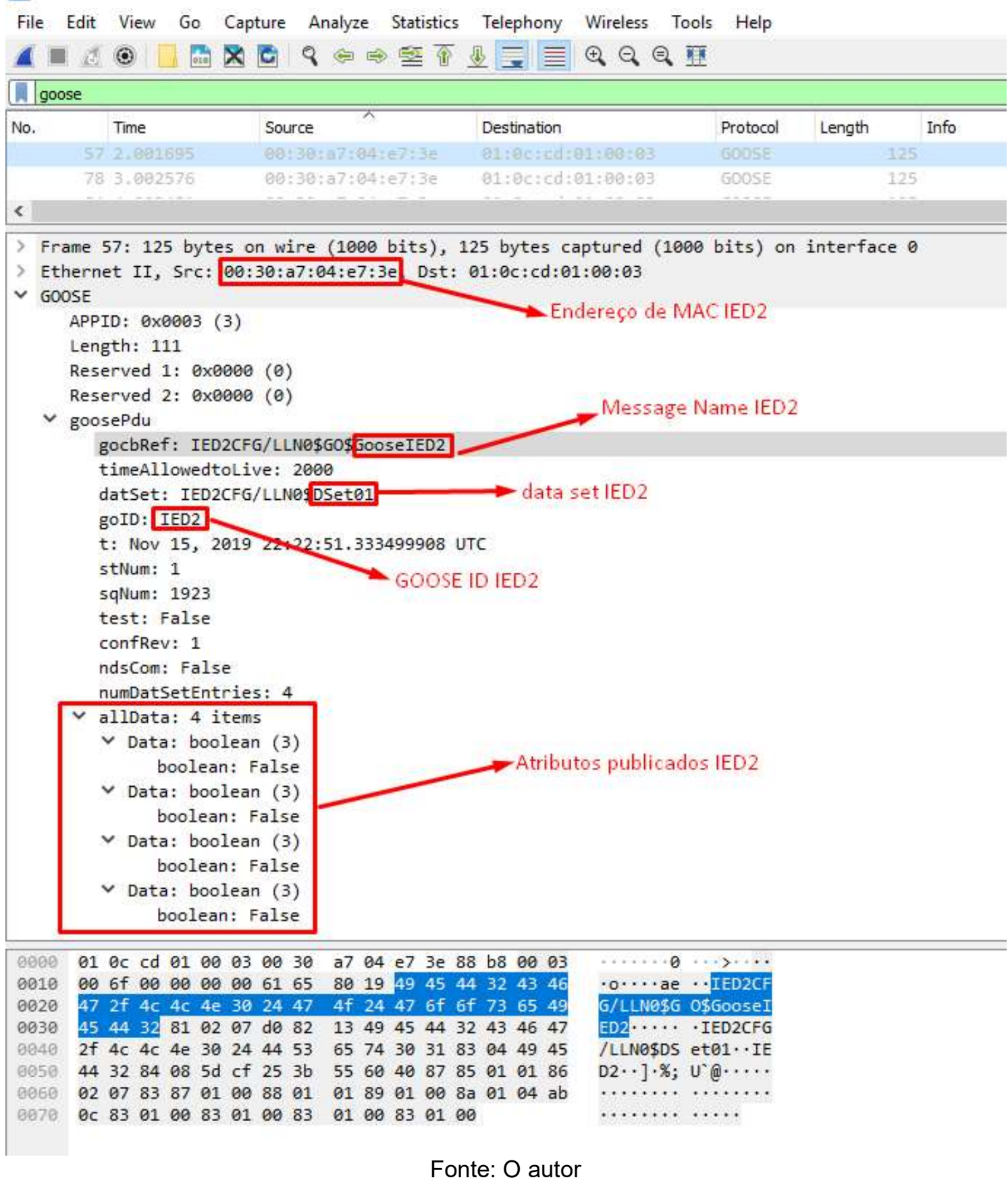

Com o auxílio do AAG, foi possível também, verificar o envio do GOOSE do IED1 (endereço 00:30:a7:08:65:38) e IED2 (endereço 00:30:a7:04:e7:3e). Foram identificadas as informações de Message Name, data set, GOOSE ID e os atributos configurados com o estado false das saídas PBLEDGGIO8 quando os botões frontais dos IEDs não estão pressionados. As Figura 50 e Figura 51 evidenciam o resultado da captura dos pacotes através do AAG. 
Figura 50 - GOOSE do IED1 capturado pelo AAG

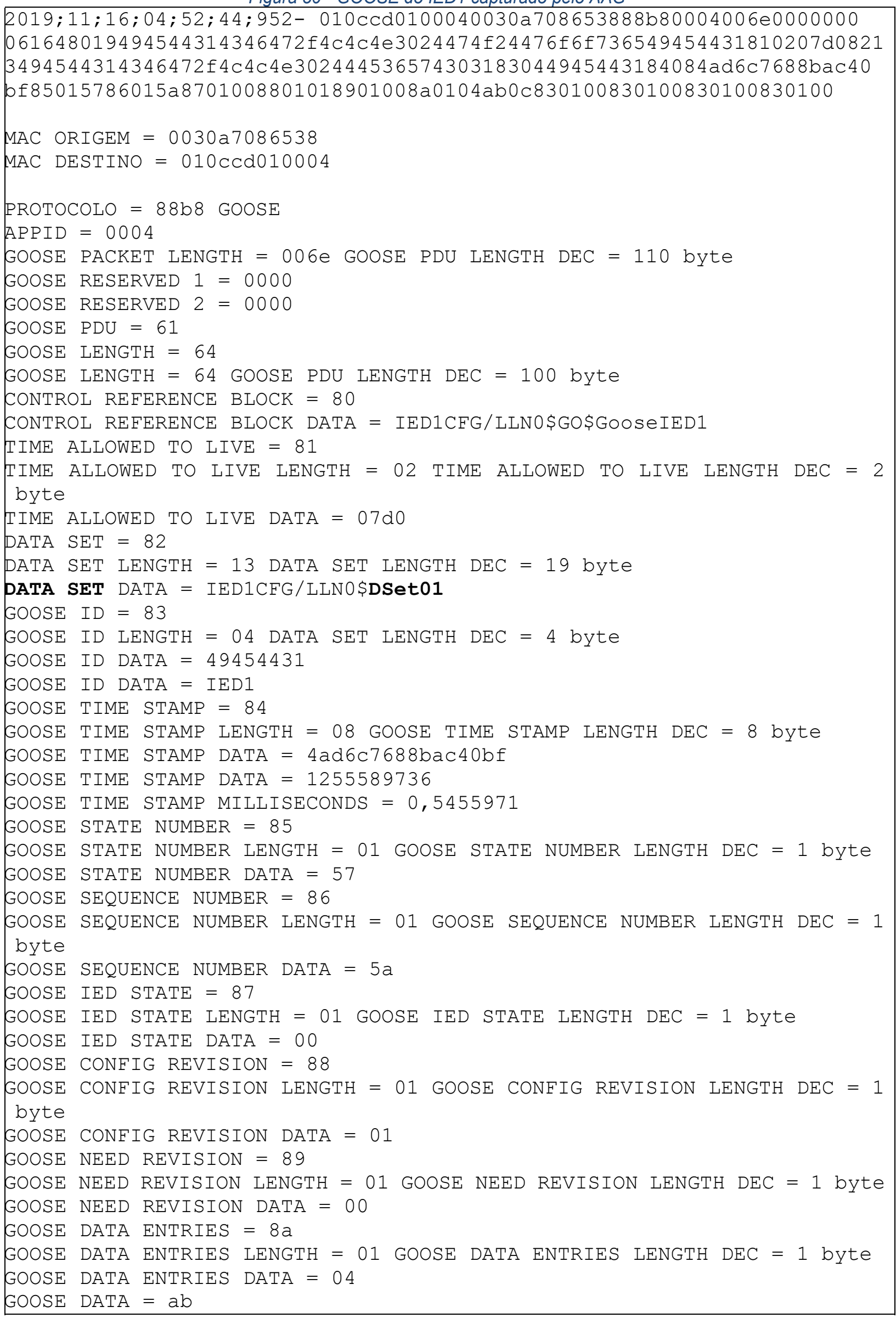




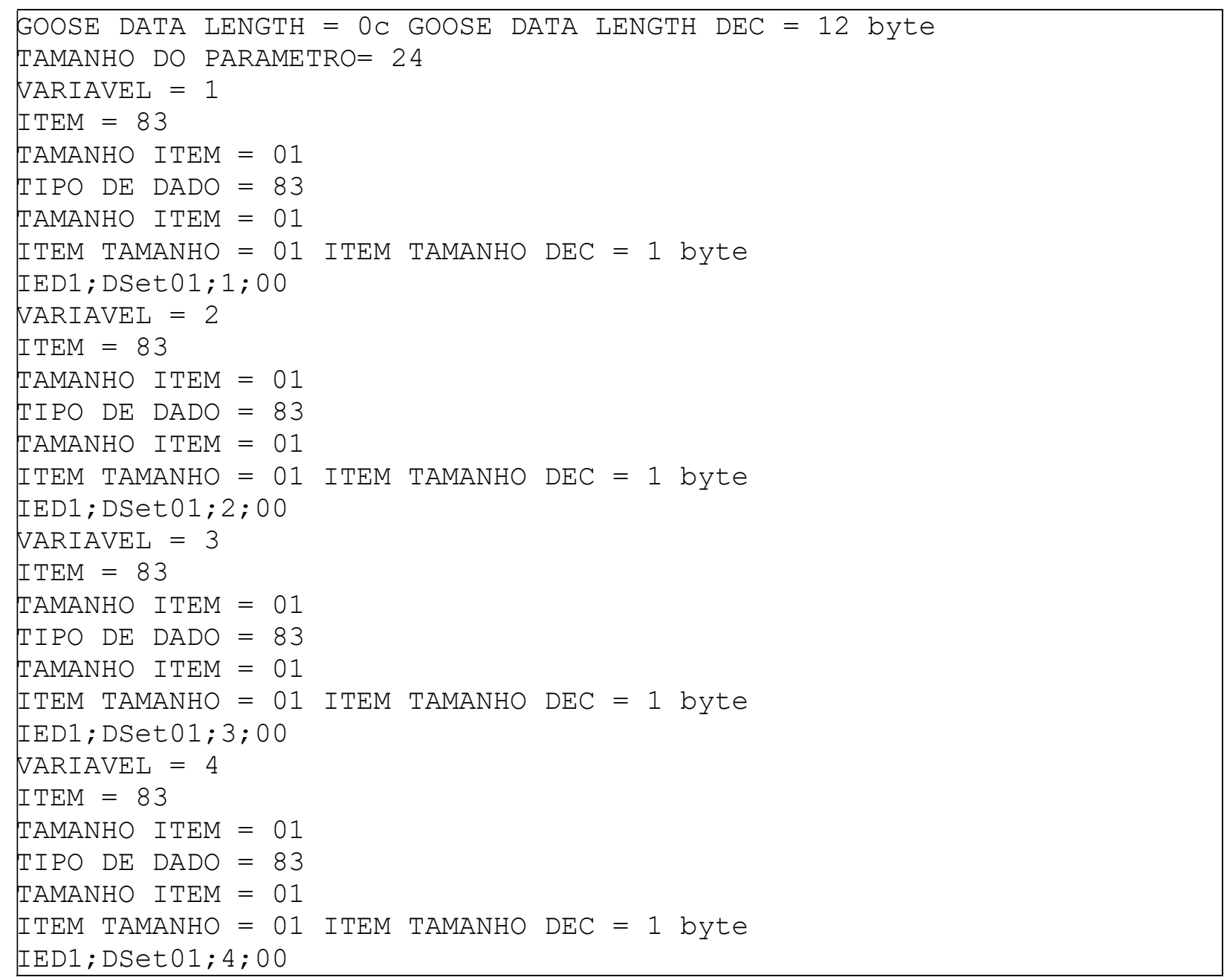

Fonte: $\mathrm{O}$ autor

Figura 51 - GOOSE do IED2 capturado pelo AAG

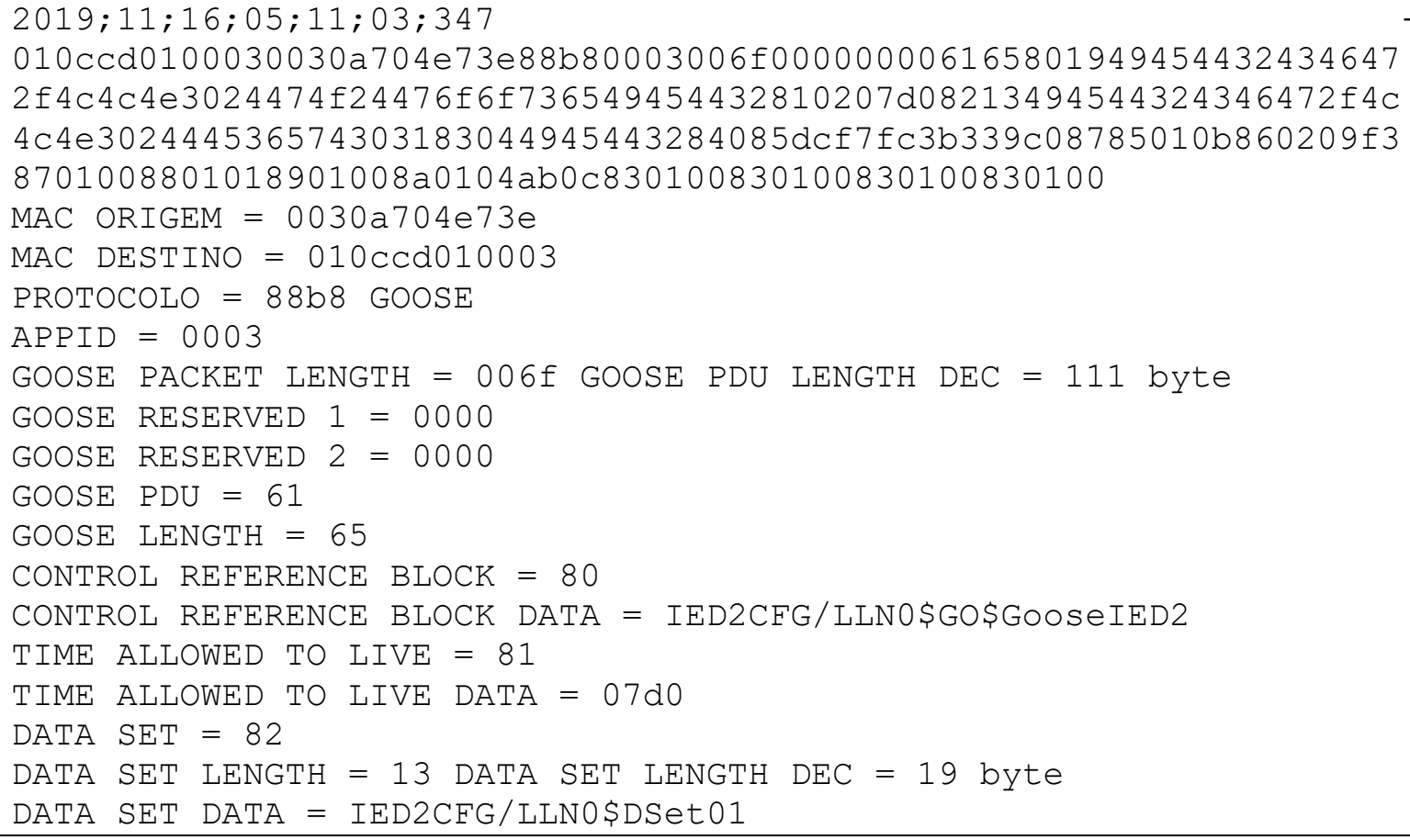




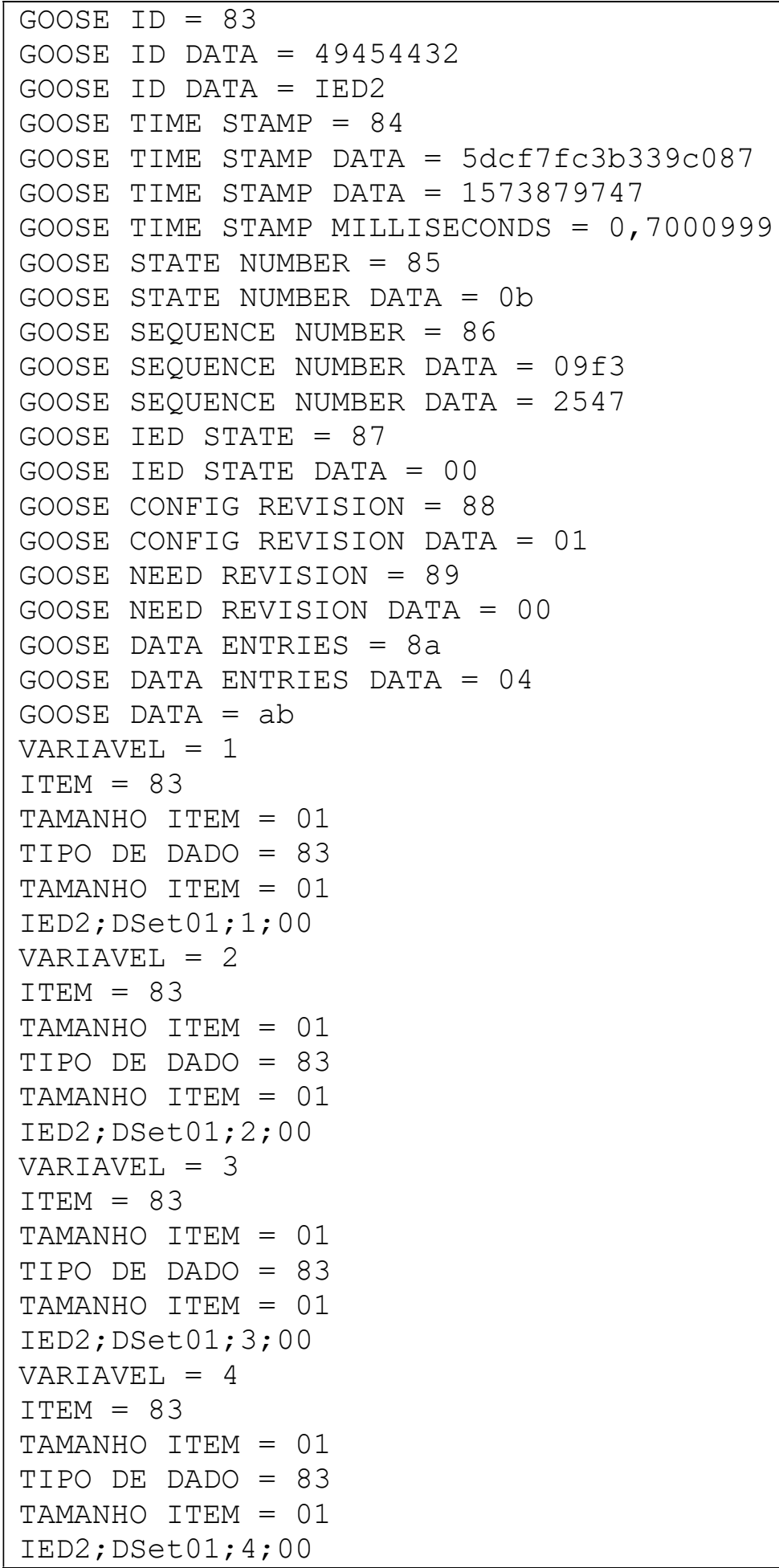

Fonte: O autor

Comprovou-se que as mensagens GOOSE publicadas pelos IEDs na camada de enlace de dados do modelo OSI, podem ser capturadas e identificadas por suas particularidades de Endereço de MAC, Message Name, DataSet, GOOSE ID e quantidade de atributos. 


\subsection{Validação da Quantidade de Atributos}

As Figura 52 e Figura 53 evidenciam a análise do AAG para quantidade de dados publicados pelos IEDs. A informação (Não encontrado divergência na quantidade de atributos para o IED) apresentada pelo software indica que a mensagem capturada contém o número exato de atributos definidos nos arquivos SCD e ATG para o IED publicador da mensagem.

Figura 52 - Não divergência na quantidade de atributos para o IED1

IED IED1 existe na tabela de IEDs.

Não foram detectadas divergências na quantidade de atributos para IED1 e DSet01

Não foram detectadas divergências na quantidade de atributos ente ATG e Mensagem Goose

Fonte: O autor

Figura 53 - Não divergência na quantidade de atributos para o IED2

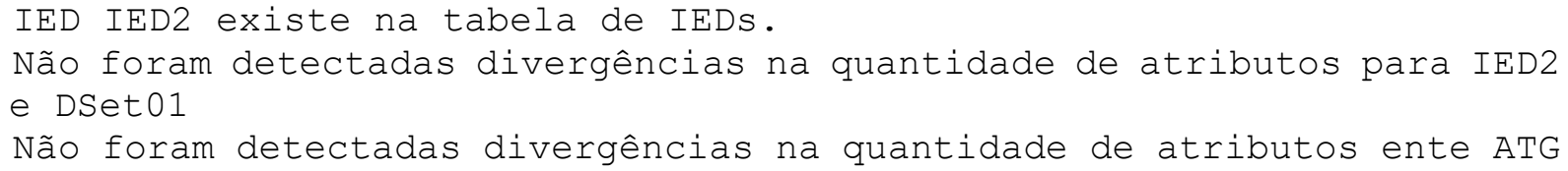

Fonte: O autor

\subsection{Tradução dos Atributos GOOSE Capturados}

Para evidenciar a funcionalidade do AAG para interpretação dos atributos recebidos, capturas com o push-button não pressionado e pressionado foram realizadas para o IED1.

Para o teste de interpretação no momento que o botão não estava pressionado um pacote GOOSE foi capturado. O software auditor interpretou os atributos contidos na mensagem e traduziu a informação conforme indicada no arquivo ATG. O resultado da tradução dos atributos é apresentado na Figura 54.

Figura 54 - Tradução dos atributos pelo software auditor

IED IED1 ---> TraducaO Push-Button $\mathbf{1}=$ PB1 IED1 is not pushed Status
IED IED1 ---> Traducao Push-Button $\mathbf{2}=$ PB2 IED1 is not pushed Status
IED IED1 ---> TraducaO Push-Button $\mathbf{3}=$ PB3 IED1 is not pushed Status
IED IED1 ---> TraducaO Push-Button $\mathbf{4}=$ PB4 IED1 is not pushed Status
Fonte: $\mathrm{O}$ autor

Em uma outra simulação, no momento que os botões 2 e 4 do IED1 estavam pressionados um pacote GOOSE foi capturado. O software auditor interpretou os 
atributos e indicou que os botões estavam pressionados. O resultado da tradução dos atributos é apresentado na Figura 55.

Figura 55 - Tradução dos atributos 2 e 4 pressionados

IED IED1 ---> Traducao Push-Button 1 = PB1 IED1 is not pushed Status

IED IED1 ---> Traducao Push-Button 2 = PB2 IED1 is pushed Status

IED IED1 -- > Traducao Push-Button $3=$ PB3 IED1 is not pushed Status

IED IED1 ---> Traducao Push-Button $\mathbf{4}=$ PB4 IED1 is pushed Status

\subsection{Identificação de Alteração da Configuração GOOSE}

O objetivo deste ensaio é evidenciar, através do software auditor, a identificação da divergência da quantidade de atributos publicado pelo IED e o indicado no arquivo ATG.

Com o auxílio do software acSELerator Architect foi excluído a publicação do atributo PBLEDGGIO8.Ind01.stVal referente ao status do push-button 1 do IED1, então a nova parametrização foi descarregada no dispositivo. A Figura 56 apresenta a tela do aplicativo com apenas três atributos configurados.

Figura 56 - Data set IED1 configurado com apenas 3 atributos

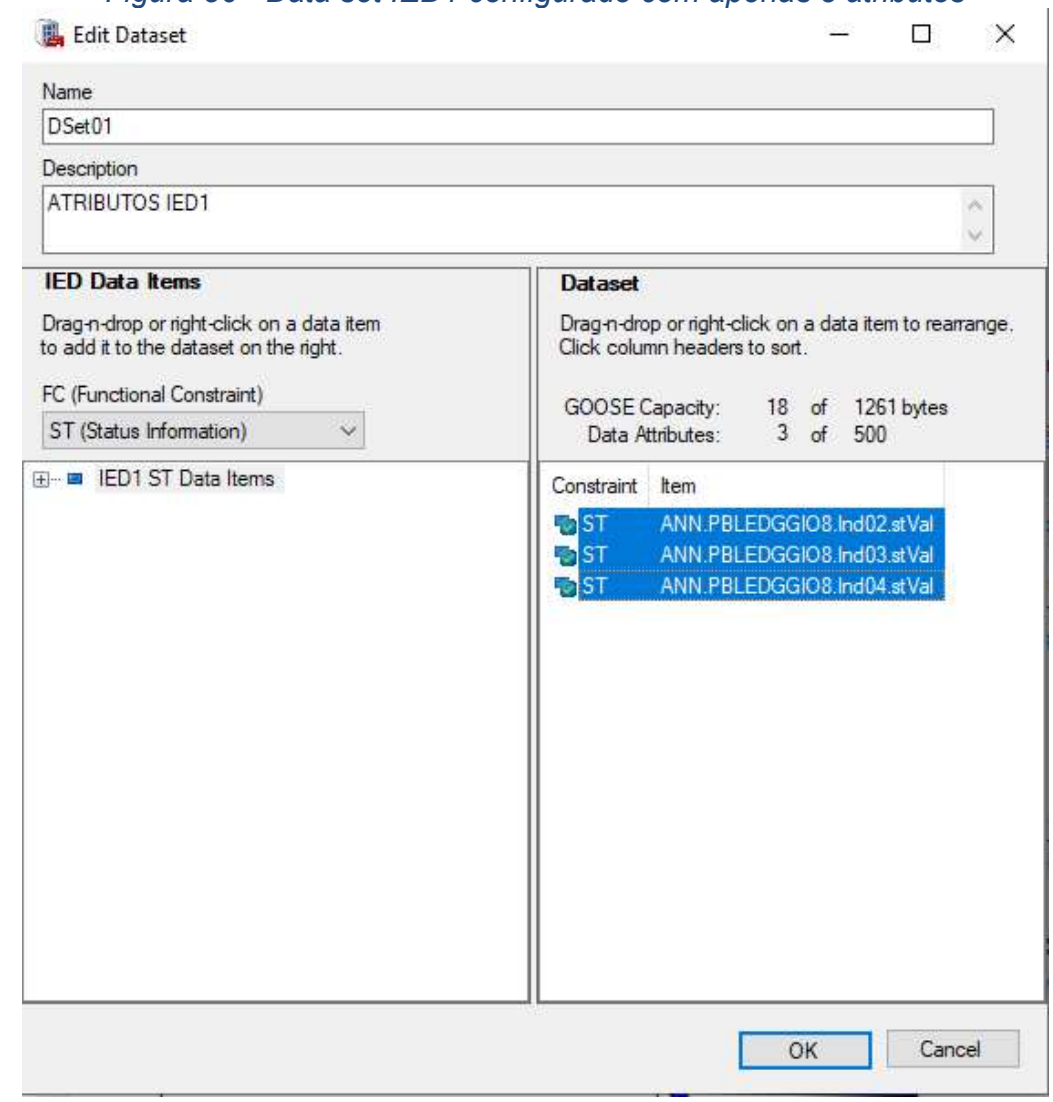

Fonte: $\mathrm{O}$ autor 
Após a parametrização do IED1, a mensagem GOOSE configurada com um atributo a menos foi publicada e capturada pela interface de rede do PC. Após análise do AAG foi identificada a divergência da quantidade de atributos. Como resultado, o software auditor apresentou um alerta com a informação da discordância encontrada. Evidências da detecção da diferença da quantidade de atributos é apresentada na Figura 57.

Figura 57 - Mensagem de divergência encontrada para o IED1

IED IED1 existe na tabela de IEDs.

Detectado divergencia no numero de variaveis para IED1 e DSet01

Variavel 3 não detectada no arquivo SCD.

Detectado divergencia na quantidade de atributos ente ATG e mensagem Goose capturada

Quantidade de variaveis encontradas no ATG para O IED $=4$

Quantidade de variaveis encontradas no Dataset Goose $=3$

Fonte: $\mathrm{O}$ autor

\subsection{Detecção de falha no sincronismo}

O software auditor é capaz de identificar falha de sincronismo do IED através da comparação da estampa de tempo da mensagem GOOSE recepcionada e a tag de tempo inserida no momento da captura do pacote. Esta função também pode ser utilizada para estimar e supervisionar a latência da rede.

O cálculo utilizado para identificar a diferença do sincronismo é apresentado abaixo:

Sincronismo $=$ timestamp recebido - timestamp GOOSE

Para simular a detecção da falha de sincronismo, o horário do IED1 foi atrasado trinta e cinco minutos em relação a plataforma computacional. Após a comparação dos tempos e identificado o atraso, o AAG apresentou alarme indicando possível problema de sincronismo do IED1.

A Figura 58 apresenta o resultado da identificação da falha de sincronismo do IED1 pelo software auditor. O valor apresentado, < 2100 segundos, é o resultado do valor do timestamp da recepção do GOOSE subtraído do valor do timestamp da mensagem GOOSE.

Figura 58 - Identificação da falha de sincronismo

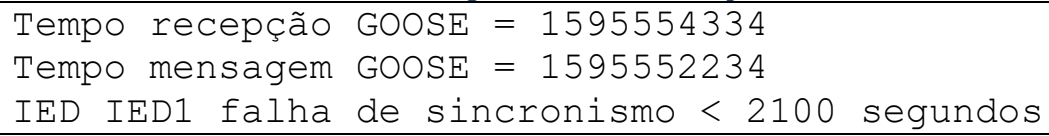




\subsection{Detecção da Ausência de Mensagens GOOSE}

O objetivo deste ensaio é apresentar a funcionalidade do AAG para identificar falha da recepção de mensagens GOOSE, indicando a possibilidade de problemas no relé ou na infra de rede de comunicação.

Para simular ausência das mensagens GOOSE publicadas pelo IED2, foi desconectada a fibra óptica da porta do dispositivo, interrompendo a comunicação do mesmo na rede.

Como indicado no item 1.15, o software auditor foi parametrizado para identificar ausência de GOOSE após vinte segundos do não recebimento de mensagens de qualquer IED. $O$ valor do tempo pode ser ajustado para valores menores.

A Figura 59 apresenta o resultado da identificação da ausência de mensagem GOOSE para o IED2 identificado pelo software de auditoria. A classe que identifica a ausência da mensagem GOOSE é apresentada no ANEXO Q.

Figura 59 - Identificação da ausência de mensagens GOOSE

Tempo sem receber GOOSE $=26$ segundos

IED IED2 falha no envio goose devido ao tempo $>20$ segundos

Fonte: $\mathrm{O}$ autor 


\section{Conclusão}

O trabalho abordou e discutiu os diversos aspectos referentes a troca de mensagens GOOSE entre equipamentos eletrônicos inteligentes instalados em subestações de energia elétrica. Como a norma que deu origem a este tipo de comunicação é recente, as formas para identificar problemas na configuração dos arquivos de projetos da subestação e o correto funcionamento dos equipamentos com base nas mensagens trafegadas ainda não foram definidas.

Nesse cenário, o trabalho propôs uma solução que resultou no desenvolvimento de um aplicativo, baseado na norma IEC-61850, para auxiliar na identificação de possíveis falhas de configuração e comunicação entre equipamentos elétricos inteligentes instalados em subestações de energia elétrica. Essa solução baseia-se na implantação de uma plataforma computacional que captura e traduz as mensagens GOOSE trafegadas no barramento de processo em seguida compara os dados capturados com a configuração do arquivo SCD prevista no projeto inicial.

Através dos testes de laboratório realizados com uma plataforma computacional contendo o aplicativo desenvolvido, foram verificadas e testadas a identificação de divergências entre as mensagens capturadas e o arquivo de configuração dos equipamentos. Com os resultados apresentados, foram evidenciadas as funções do software desenvolvido para auditoria e a tradução da informação capturada para os agentes envolvidos.

A análise de defeitos em instalações baseadas na norma IEC-61850 é algo complexo e que deve ser efetuada por profissionais com conhecimento específicos. A modernização de equipamentos realizados em períodos diferentes, em uma mesma subestação, pode acarretar modificações nos projetos físicos e lógicos que muitas vezes não são previstos, pois podem ser realizadas por empresas diferentes e em momentos distintos. A fase de projeto, portanto, deve ser muito bem trabalhada e discutida, sendo proposto a utilização de um padrão de documentação dos projetos e das mensagens GOOSE para consultas futuras.

Muito tem se falado em digitalização de subestação de energia, porém há de se enfatizar que toda inovação seja ela física ou digital requer conhecimento técnico e ferramentas adequadas para operação e análise de falhas no ambiente. Neste cenário o objetivo de um aplicativo de auditoria de mensagens GOOSE é o de identificar divergência da configuração dos arquivos SCD em relação as mensagens 
GOOSE trafegadas e de minimizar o tempo de análise de ocorrência com a tradução das mensagens capturadas.

O aprimoramento nas questões de monitorar as mensagens GOOSE para identificar problemas em subestações de energia, minimizar o tempo de indisponibilidade de operação e risco de acidentes, são questões que devem ser melhor exploradas através de uma futura tese de doutorado, bem como em programas de Pesquisa e Desenvolvimento (P\&D).

A adoção dos padrões IEC-61850 é um processo que exige um plano estratégico, quebra do tradicionalismo e adoção de tecnologias por parte das companhias que pretendem implementá-los. Os benefícios indicados pela utilização da norma, são garantidos quando a norma é aplicada na sua totalidade.

Fica evidente que o aprendizado contínuo dos envolvidos e pesquisas em ambientes modernos e equipados são importantes para consolidar as soluções pesquisadas. Apenas o conhecimento superficial dos conceitos da norma não é o suficiente para garantir o total domínio de sua aplicação, testes exaustivos em ambientes práticos e reais devem ser realizados.

Como evidenciado neste trabalho, a viabilidade da metodologia proposta, em seus aspectos de documentar projetos lógicos e traduzir mensagens GOOSE capturadas no barramento de processos, pode ser utilizada para otimizar o processo de operação e análise de ocorrências em subestação de energia IEC-61850. A aplicação dessa solução em ambientes controlados como testes de aceitação de fabricada e testes de aceitação de campo, torna-se uma excelente oportunidade para avaliar o seu desempenho e refletir sobre as práticas aplicadas. 
Referências Bibliográficas

ADAMIAK, M. et al. Design of a protection relay incorporating UCA2/MMS communcations, 24 abr. 2002.

ARAUJO, A. R. D.; CAMPELLO, S.; GUALTIERI, S. Aplicação da norma IEC61850-8-1 nas redes de proteção do sistema elétrico. Recife. 2011.

CISCO. Parallel Redundancy Protocol (PRP) for IE 4000, IE 4010 and IE 5000 $\begin{array}{lllll}\text { Switches, } & 26 & \text { jun. } & 2018 . & \text { Disponivel }\end{array}$ <https://www.cisco.com/c/en/us/td/docs/switches/lan/industrial/software/configuration /guide/b_prp_ie4k_5k.pdf>. Acesso em: 10 nov. 2019.

CLAVEL, F. et al. Integration of a new Standard: A network simulatior of IEC 61850 architectures for electrical substations. Industry Applications Magazine, v. 21, n. 1, p. 41-48, 2014.

COMACCIO, A. F.; SILVA, A. F.; COSTA, D. T. Norma IEC 61850: testes de velocidade das mensagens Goose. [S.I.]. 2017.

COMACCIO, A.; SILVA, A.; COSTA, D. Norma IEC 61850 - testes de velocidade das mensagens goose. [S.I.]. 2017.

DUARTE, A. B. Fundamentos da série de normas IEC 61850 e sua aplicação nas subestações. Curitiba. 2012.

IEC-61850-1, I. E. C. Communication Networks and Systems for Power Utility Automation. Geneva. 2013.

IEC-61850-7-2. Communication networks and system for power utility automation. [S.I.]. 2010.

IEC61850-7-4. Basic communication structure - Compatible logical node classes and data object classes. [S.I.]. 2010.

IEC-61850-8-1. Communication anetowrk and system for power utility automation. [S.I.]. 2011.

JARDINI, A. J. Sistemas Elétrico de Potência: Automação. São Paulo. 1997.

KIMURA, S. et al. Aplicação do IEC61850 no Mundo Real: Projeto de Modernização de 30 Subestações Elétricas, Dublin, Irlanda, 2008.

LABORATORIES, S. E. SEL-451 Relay Protection, Atuomation, and Control System. Pullman. 2012. 
LU, X.; SUN, W.; LI, H. Design and Research /based on WinPcap Protocol Analysus System, 2010.

MME, M. D. M. E. E.; ANEEL, A. N. D. E. E. Resolução Normativa No 864. Brasília. 2019.

NETTO, U. C. Determinação de um parâmetro para monitoramento do desempenho de mensagens GOOSE do padrão IEC 61850 utilizadas em subestações de energia elétrica. São Carlos: http://teses.usp.br/teses/disponiveis/18/18154/tde-16102012-083711/pt-br.php, 2012.

RUSH, P. Proteção e Automação de Redes. São Paulo: Edgard Blucher Ltda, 2010. em: $<$ https://industriaautomatica.wordpress.com/2015/09/24/evolucao-dos-reles-deprotecao/>. Acesso em: 26 Abril 2019.

SIDHU, T. S.; KANABAR, M. G.; PARICH, P. P. Implementation Issues with IEC 61850 Based Substation Automation System, Bombay, December 2008.

SOUZA, D.; MARCOS, A. Proposta de um sistema de monitoramento e validações de comunicação de subestações elétrica. Campo Limpo Pta-SP. 2012.

STEINHAUSER, F. New Challenges with Substations utilizing Communication Networks, Bologna, 2003.

SYMANTEC. Symantec Connect, 23 Jul 2010. Disponivel em: $<$ https://www.symantec.com/connect/articles/what-epoch-time-and-how-converthuman-understandable-format>. Acesso em: 06 dez. 2019.

TANENBAUM, A. S. Redes de Computadores. Rio de Janeio: Campus, 1997.

TANENBAUM, A.; WETHERALL, D. Redes de Computadores. São Paulo: Pearson, 2011.

VICENTE, D. T. D.; SENGER, E. C. Aplicação dos padrões a aorma IEC61850 a subestações compartilhadas de transmissão/distribuição de energia elétrica. São Paulo. 2011. 


\section{ANEXO A}

Figura 60 - Classe Program

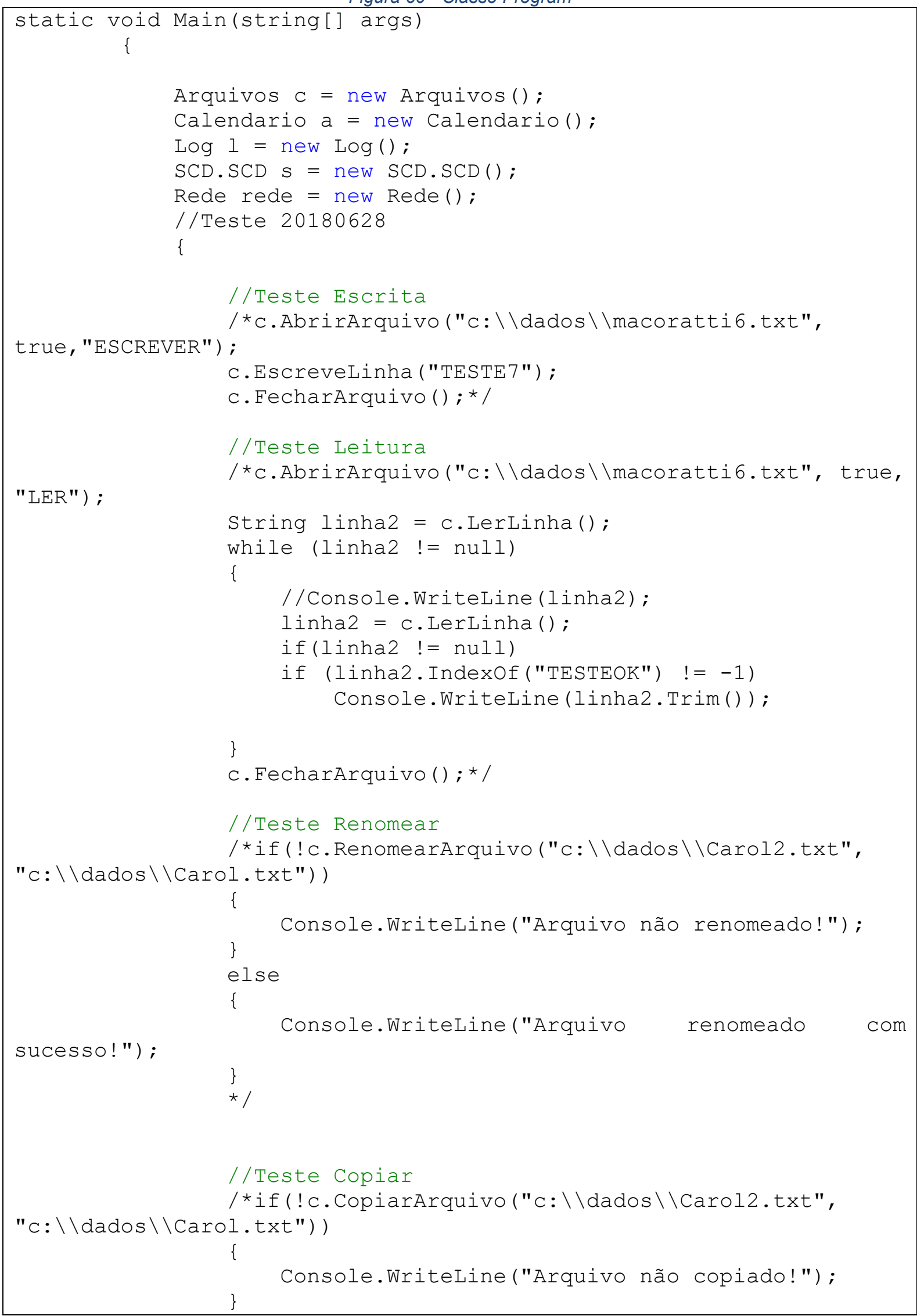




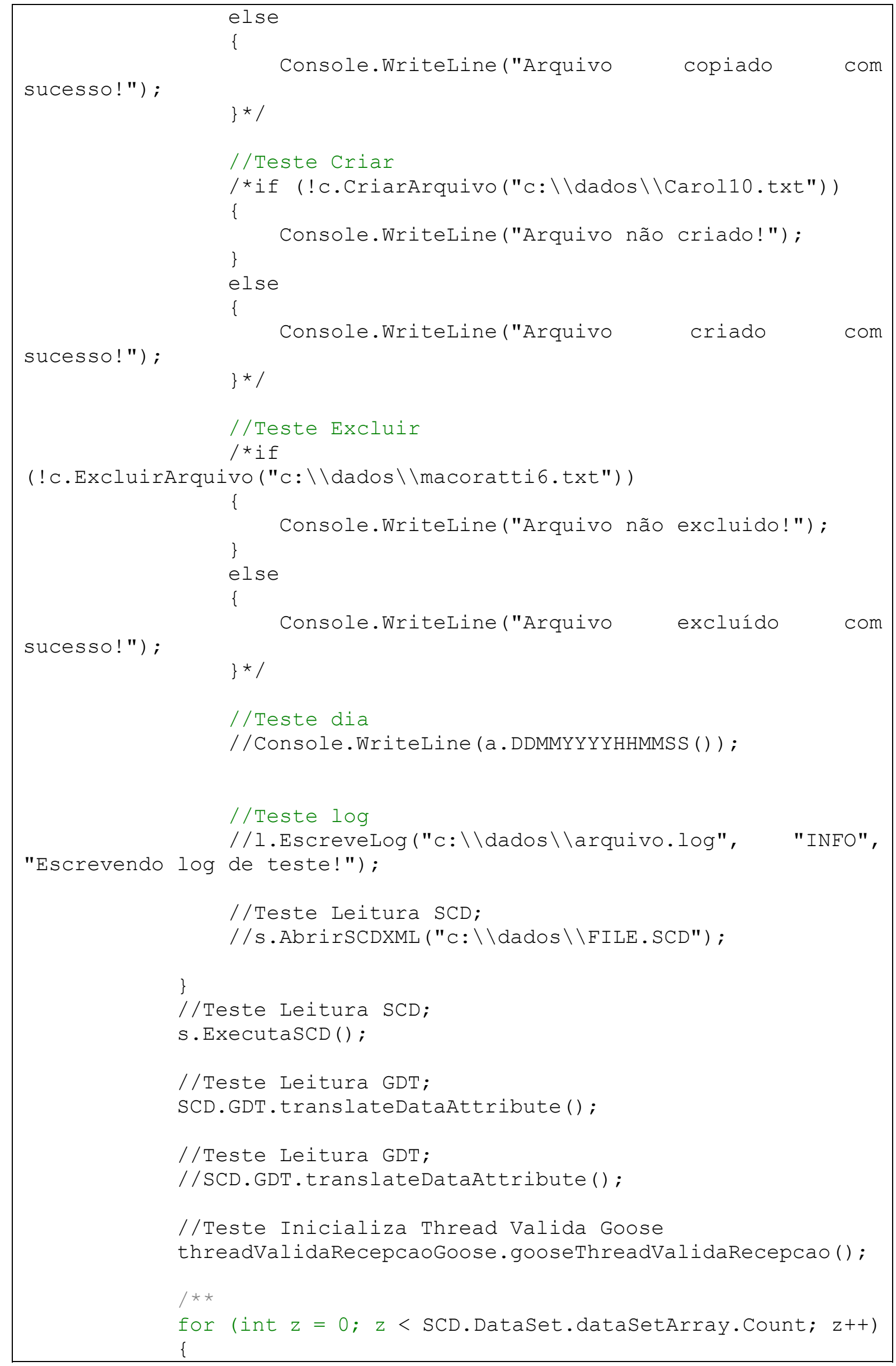




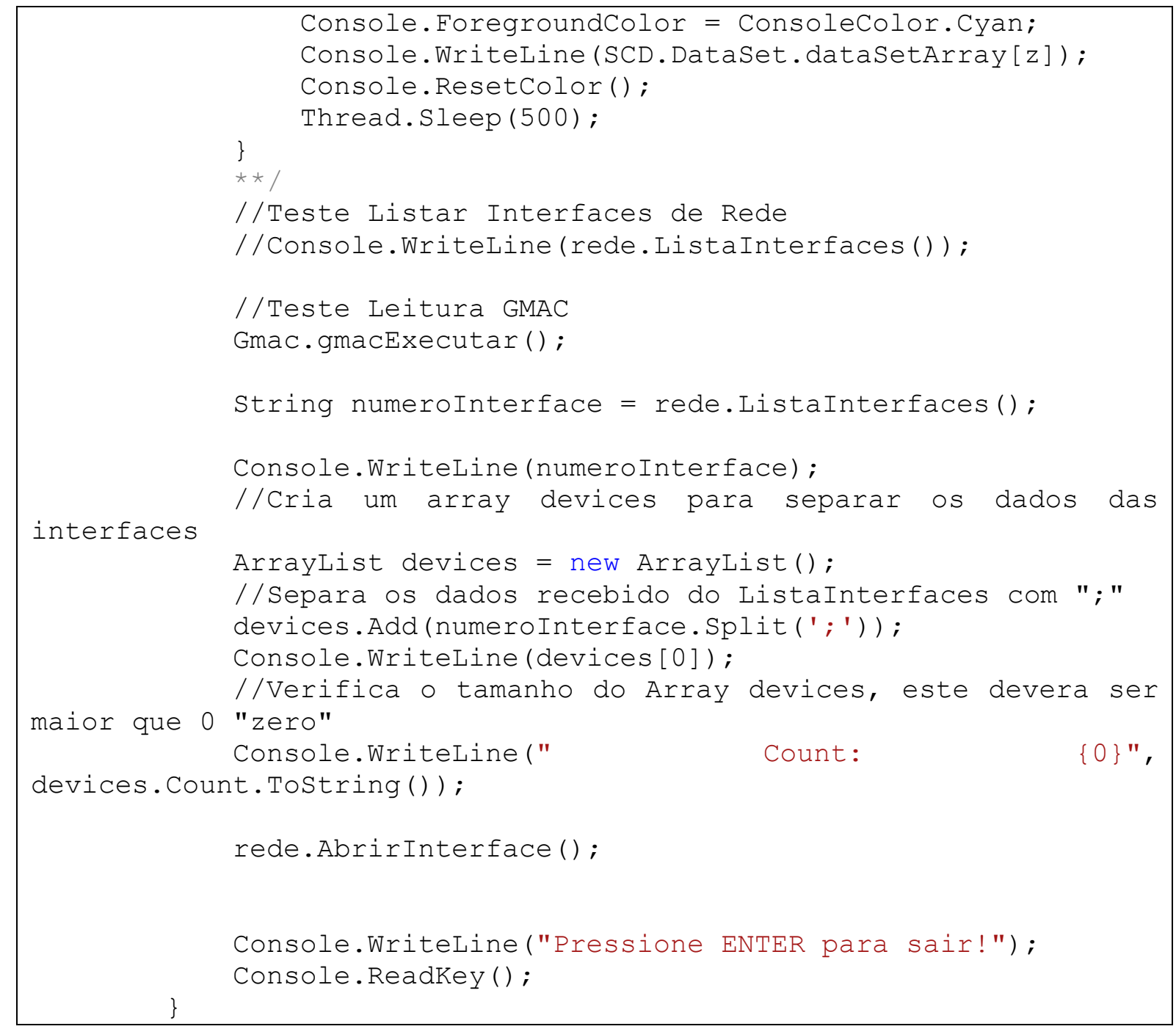




\section{ANEXO B}

Figura 61 - Classe AppID

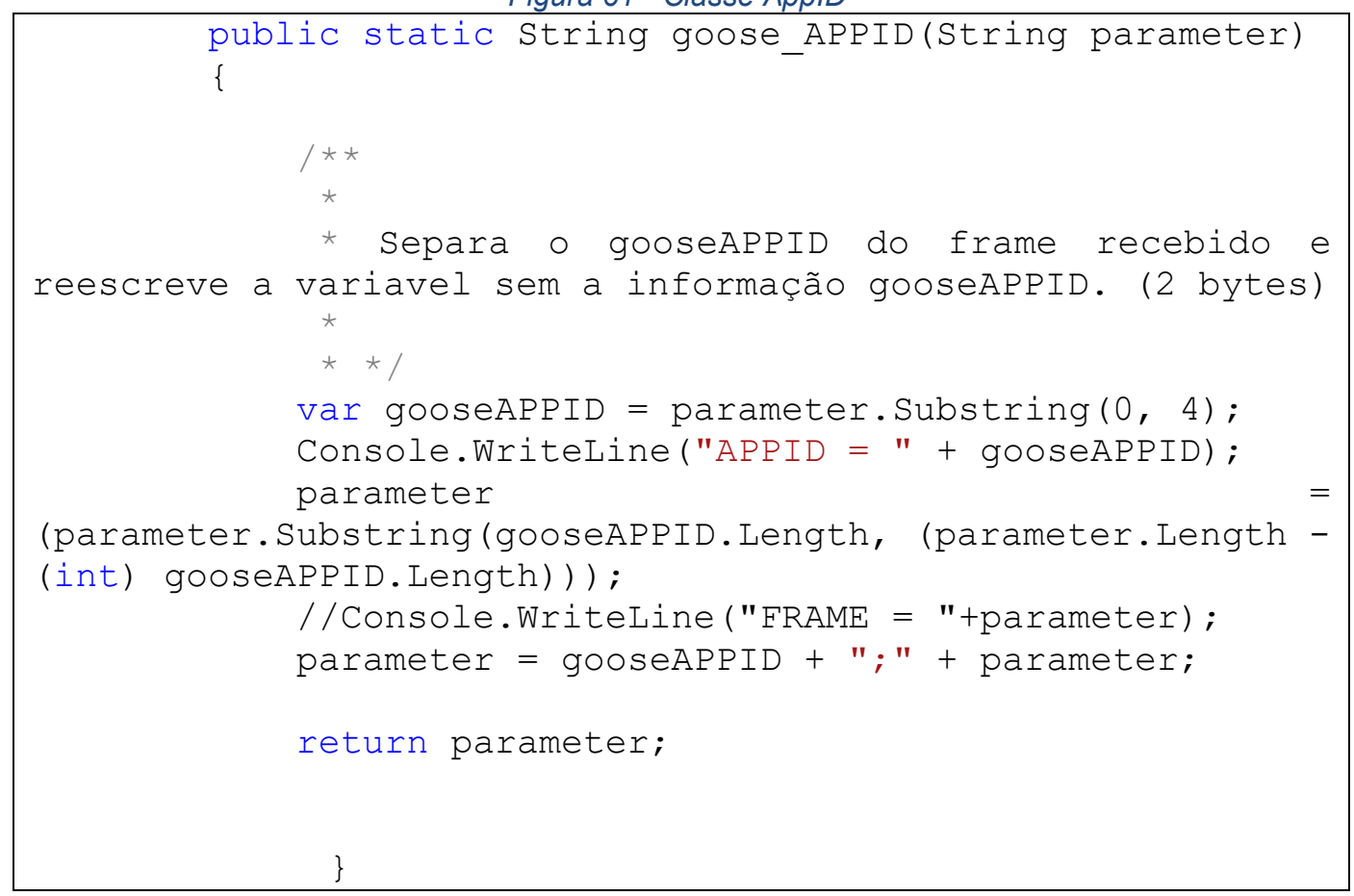

Fonte: $\mathrm{O}$ autor 
ANEXO C

Figura 62 - Classe GooseLength

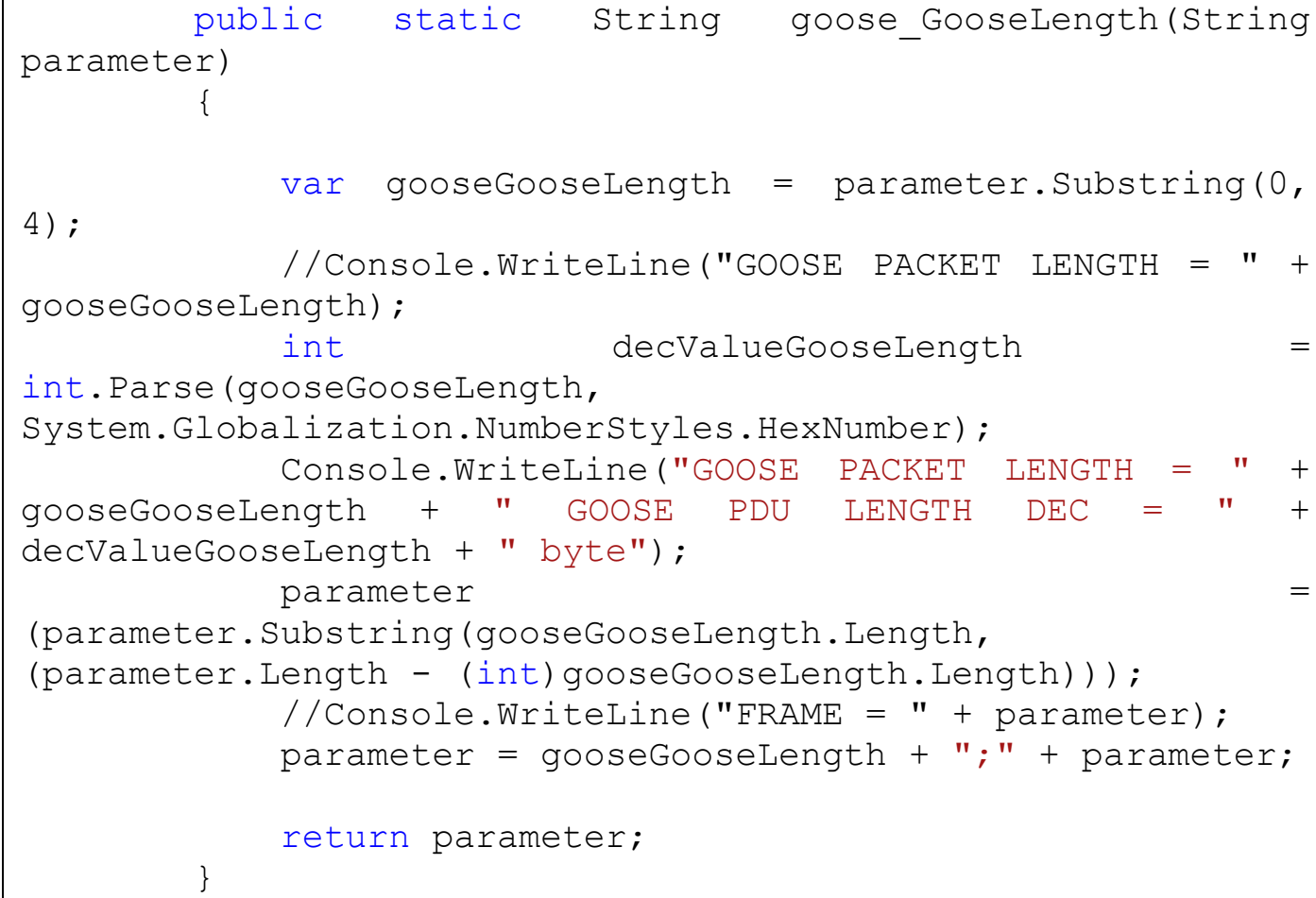

Fonte: $\mathrm{O}$ autor 


\section{ANEXO D}

Figura 63 - Classe PDU

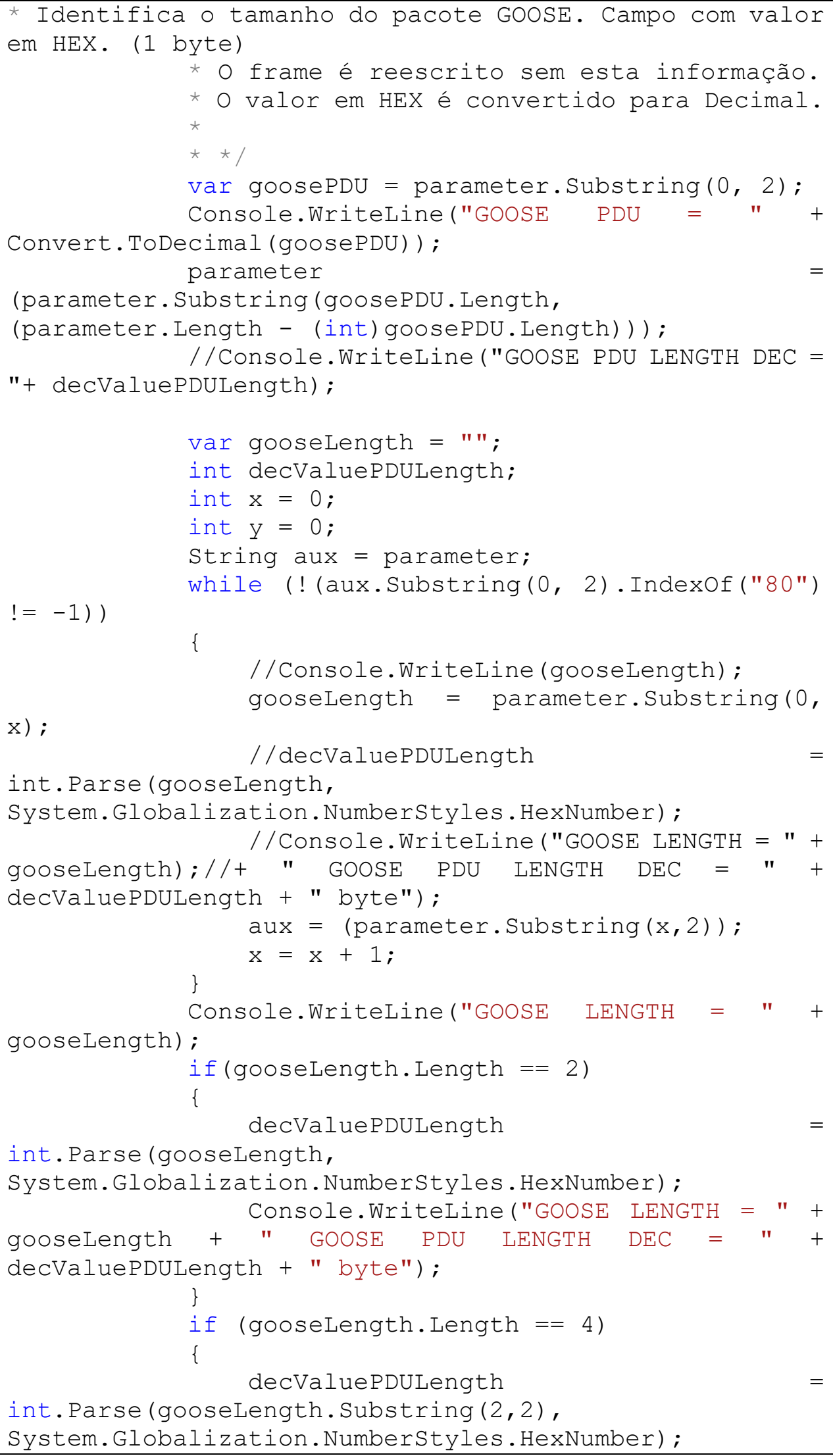




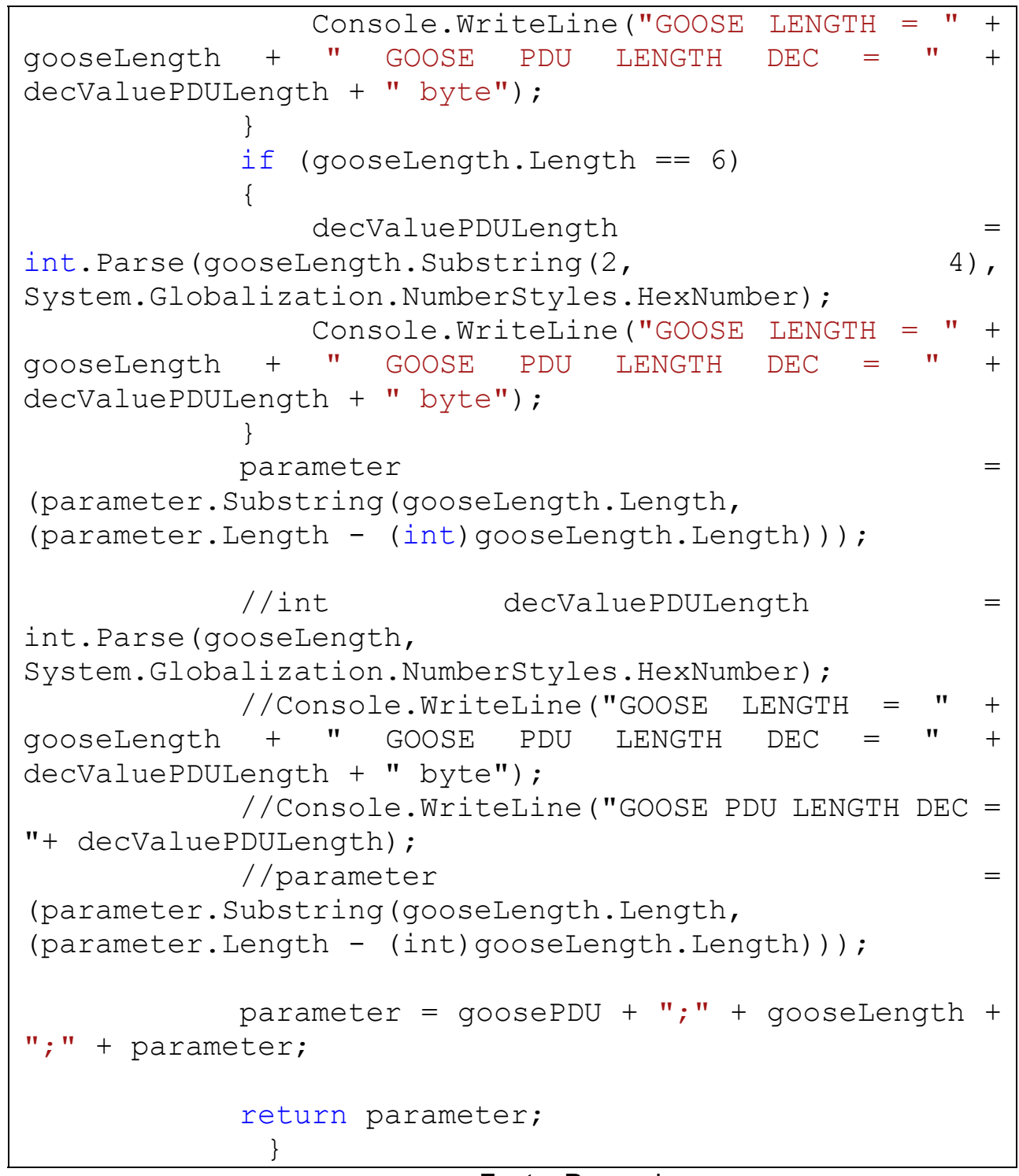

Fonte: Pessoal 


\section{ANEXO E}

Figura 64 - Classe ControlRefBlock

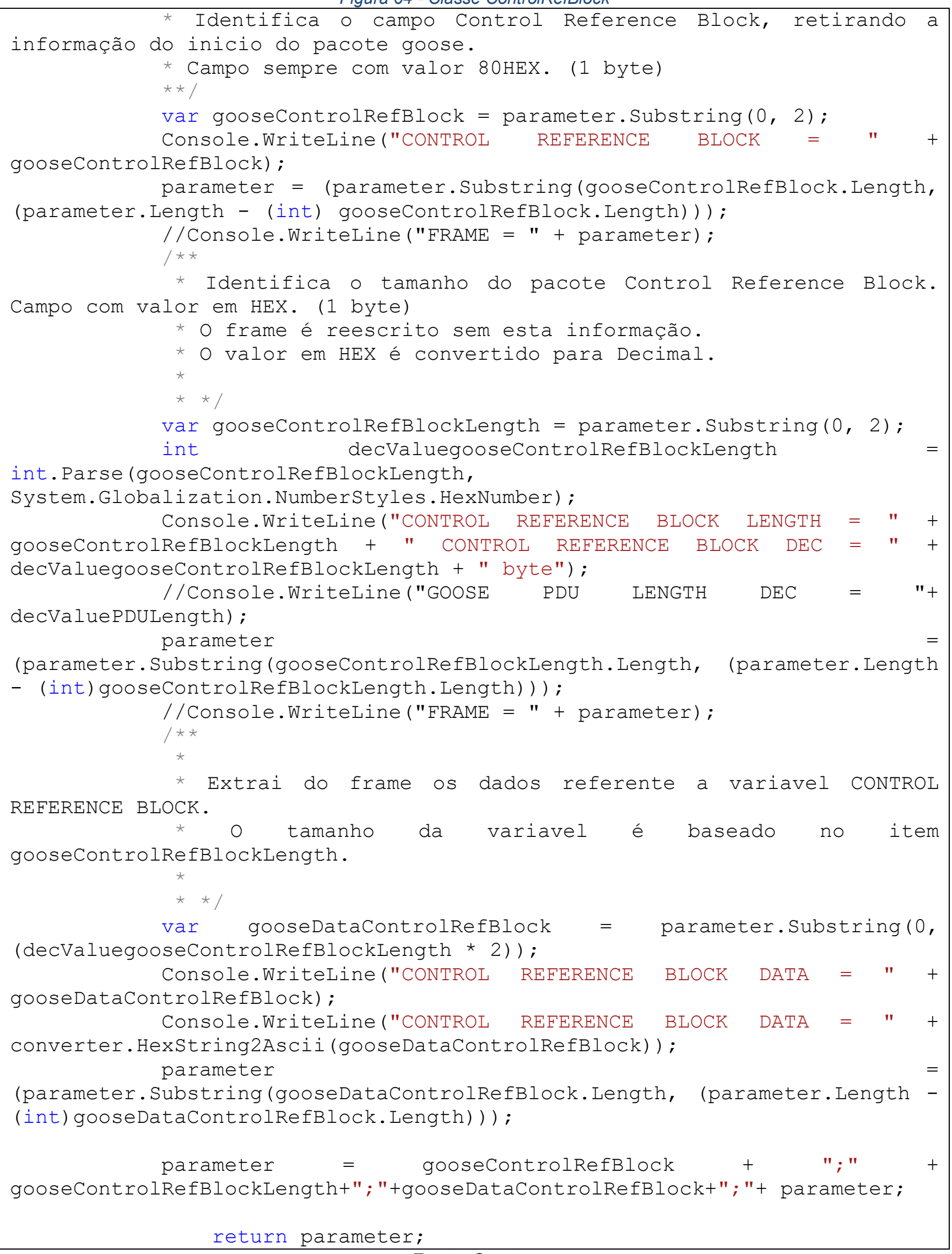




\section{ANEXO F}

Figura 65 - Classe Time2LiveAllowed

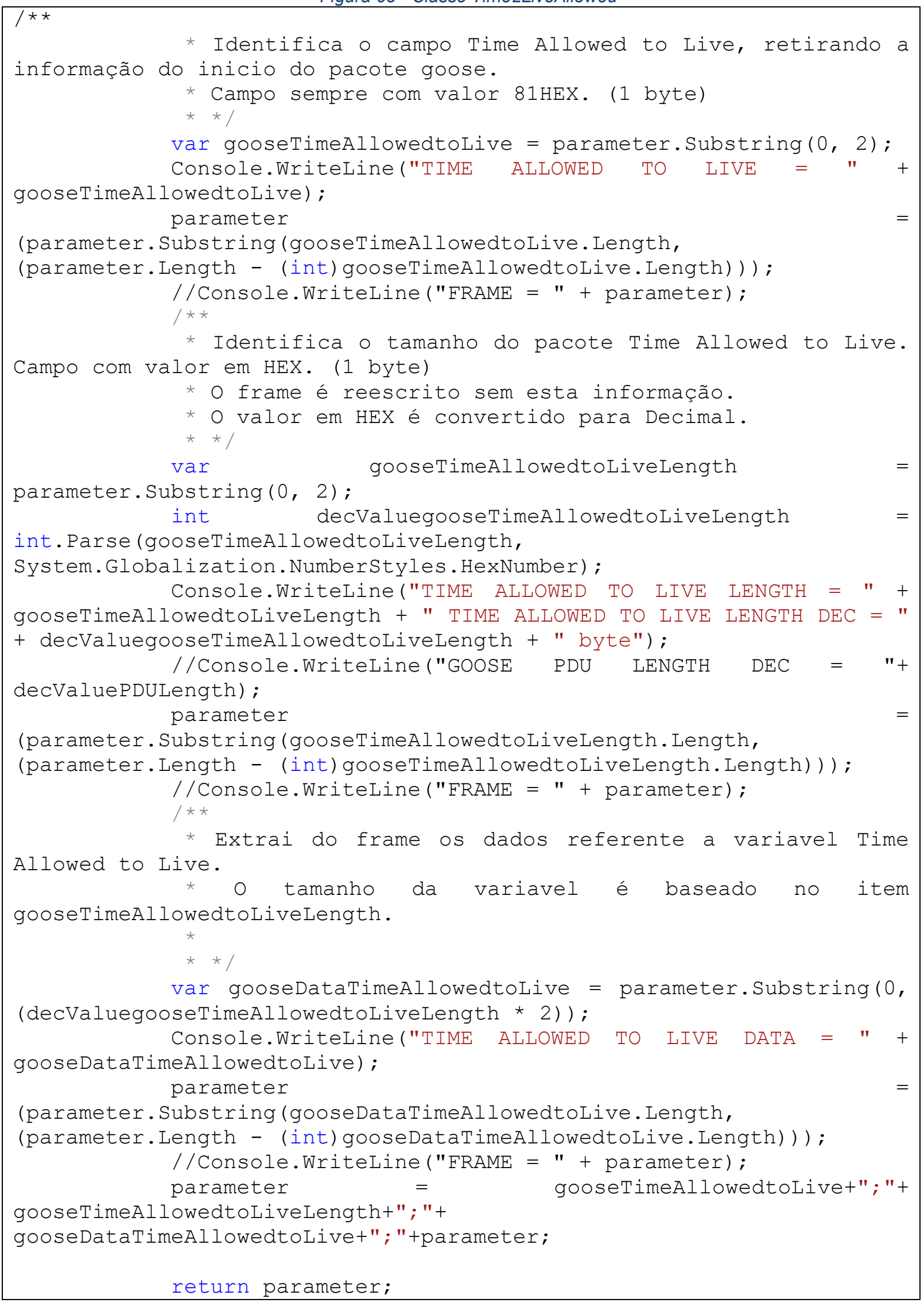




\section{ANEXO G}

Figura 66 - Classe DataSet

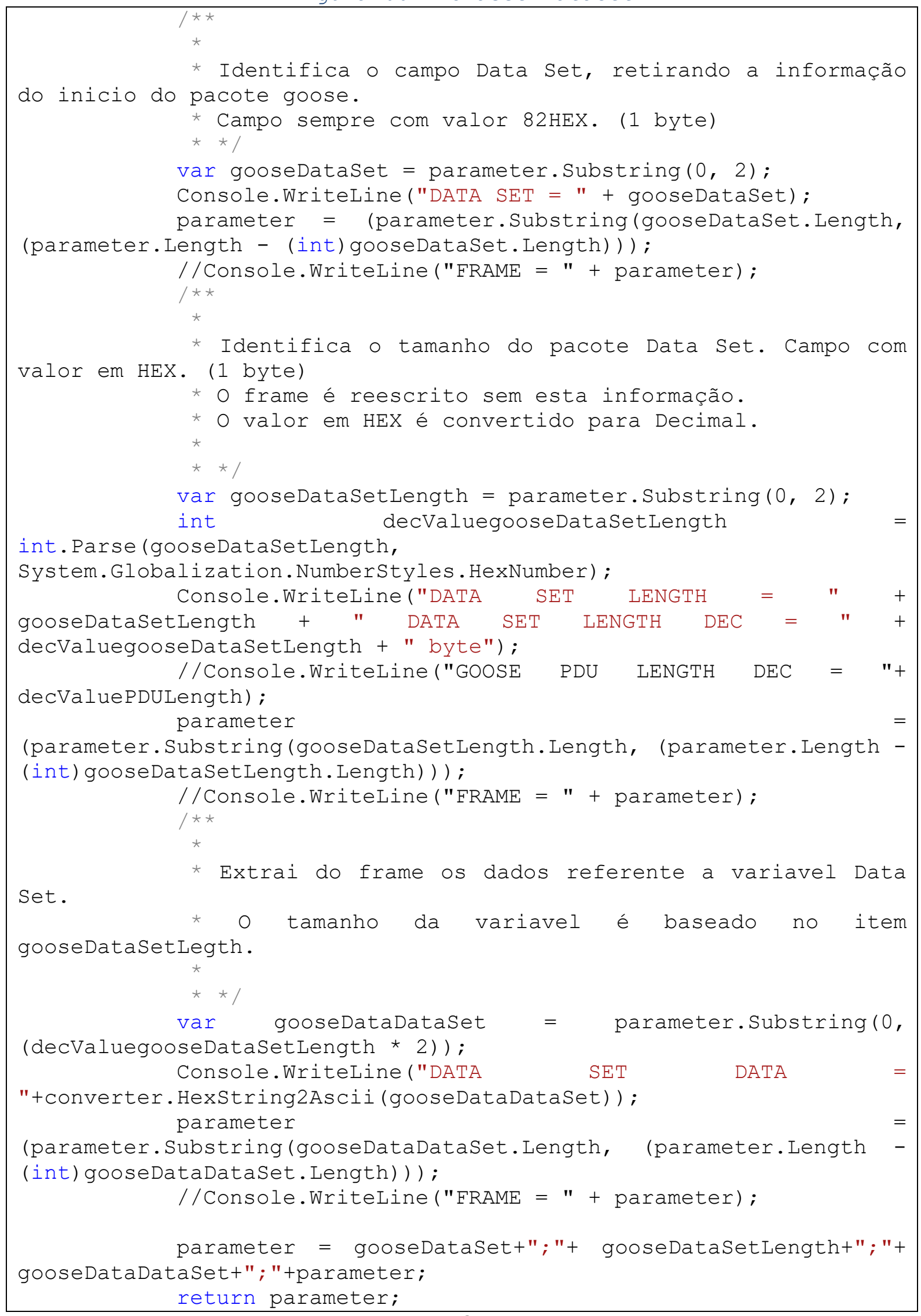




\section{ANEXO H}

Figura 67 - Classe GooselD

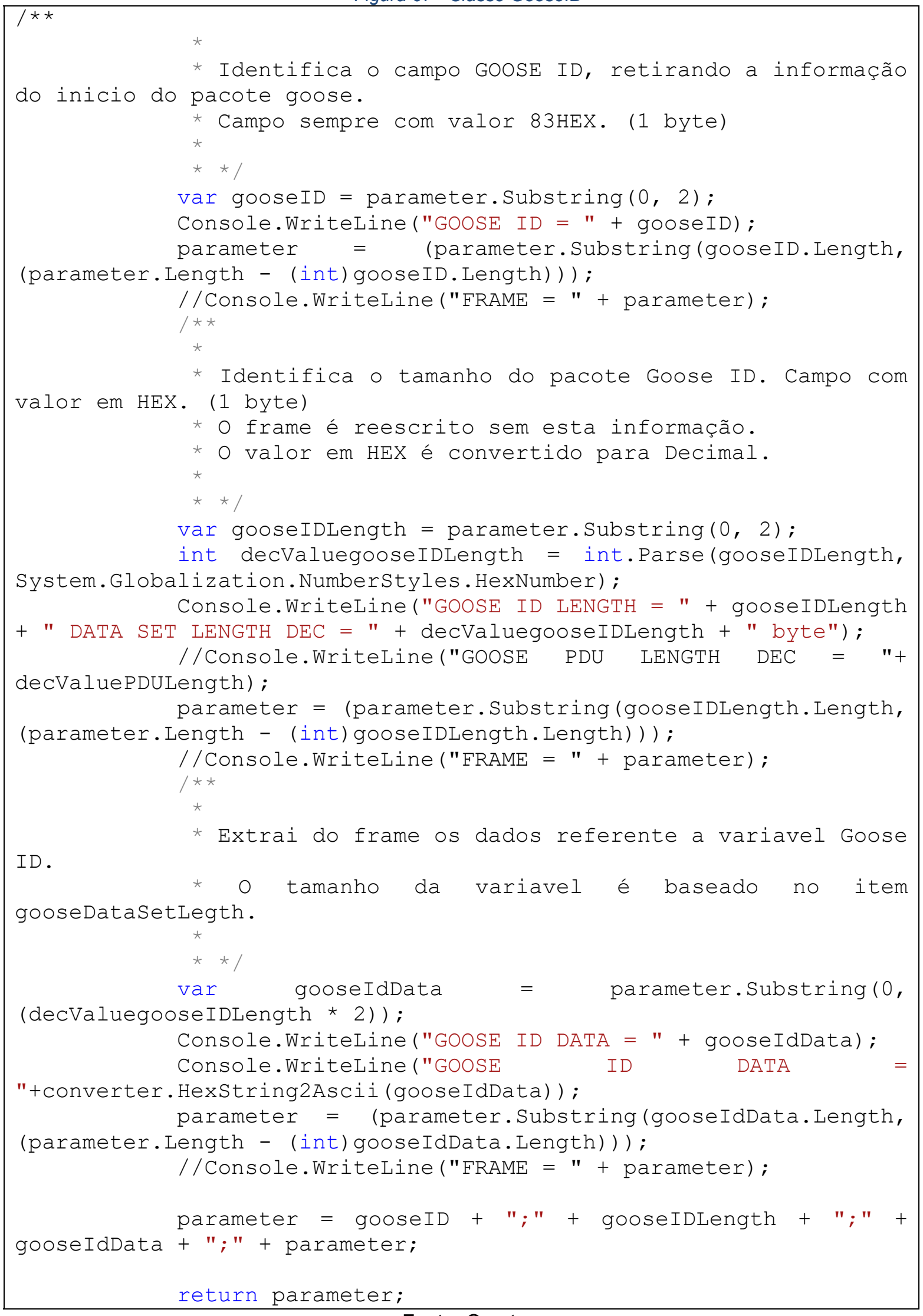




\section{ANEXO I}

Figura 68 - Classe TimeStamp

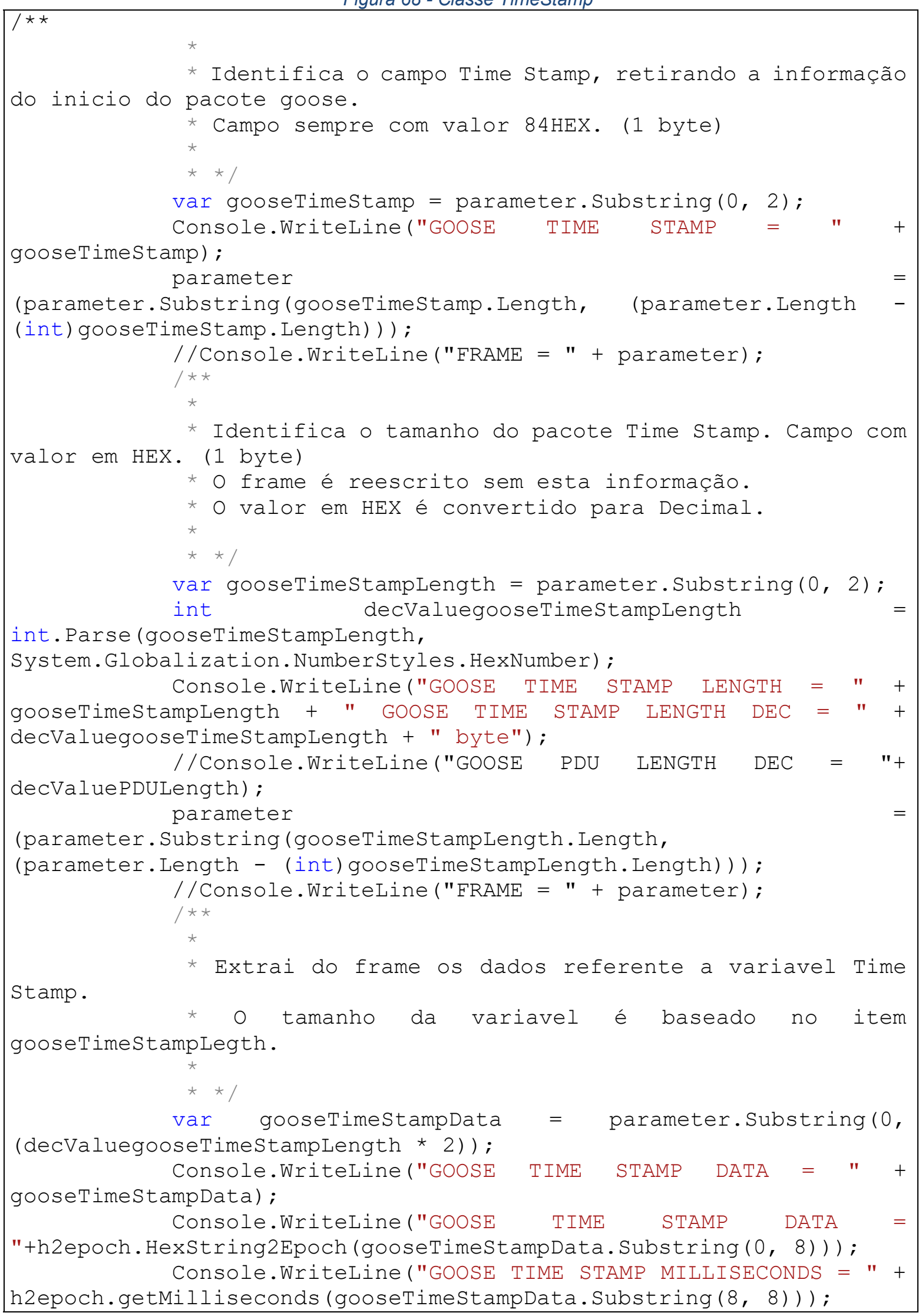


parameter

(parameter.Substring (gooseTimestampData.Length, (parameter.Length - (int)gooseTimestampData.Length)));

//Console.WriteLine("FRAME = " + parameter);

parameter = gooseTimestamp+";"+

gooseTimeStampLength+" ;"+gooseTimeStampData + ";" + parameter; 


\section{ANEXO J}

Figura 69 - Classe StateNumber

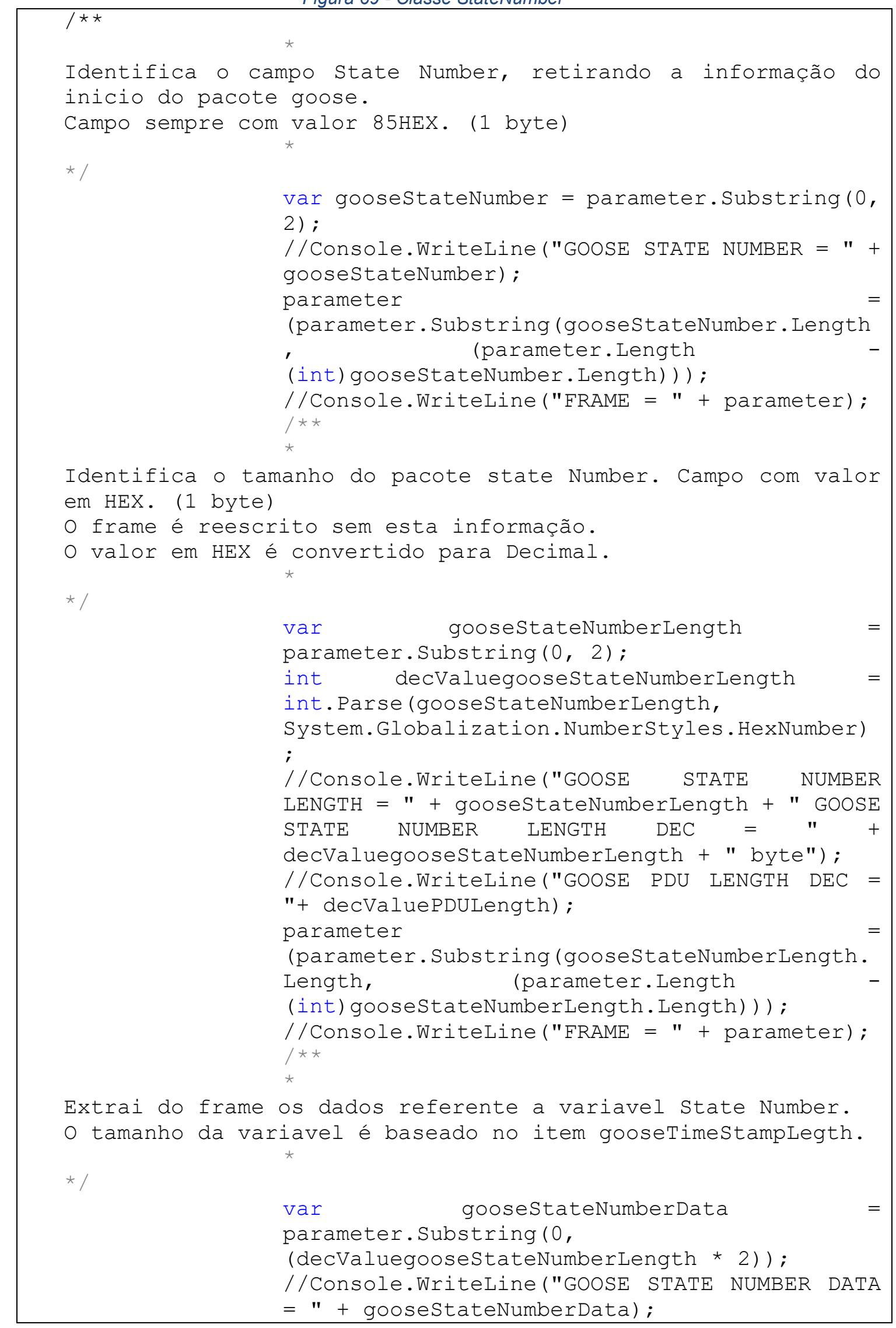


parameter

(parameter.Substring (gooseStateNumberData. Le ngth, (parameter.Length

(int) goosestateNumberData.Length)));

//Console.WriteLine("FRAME = " + parameter);

parameter $=$ goosestateNumber + "; $\quad+$ goosestateNumberLength + + gooseStateNumberData + ";" + parameter; 


\section{ANEXO K}

Figura 70 - Classe SequenceNumber

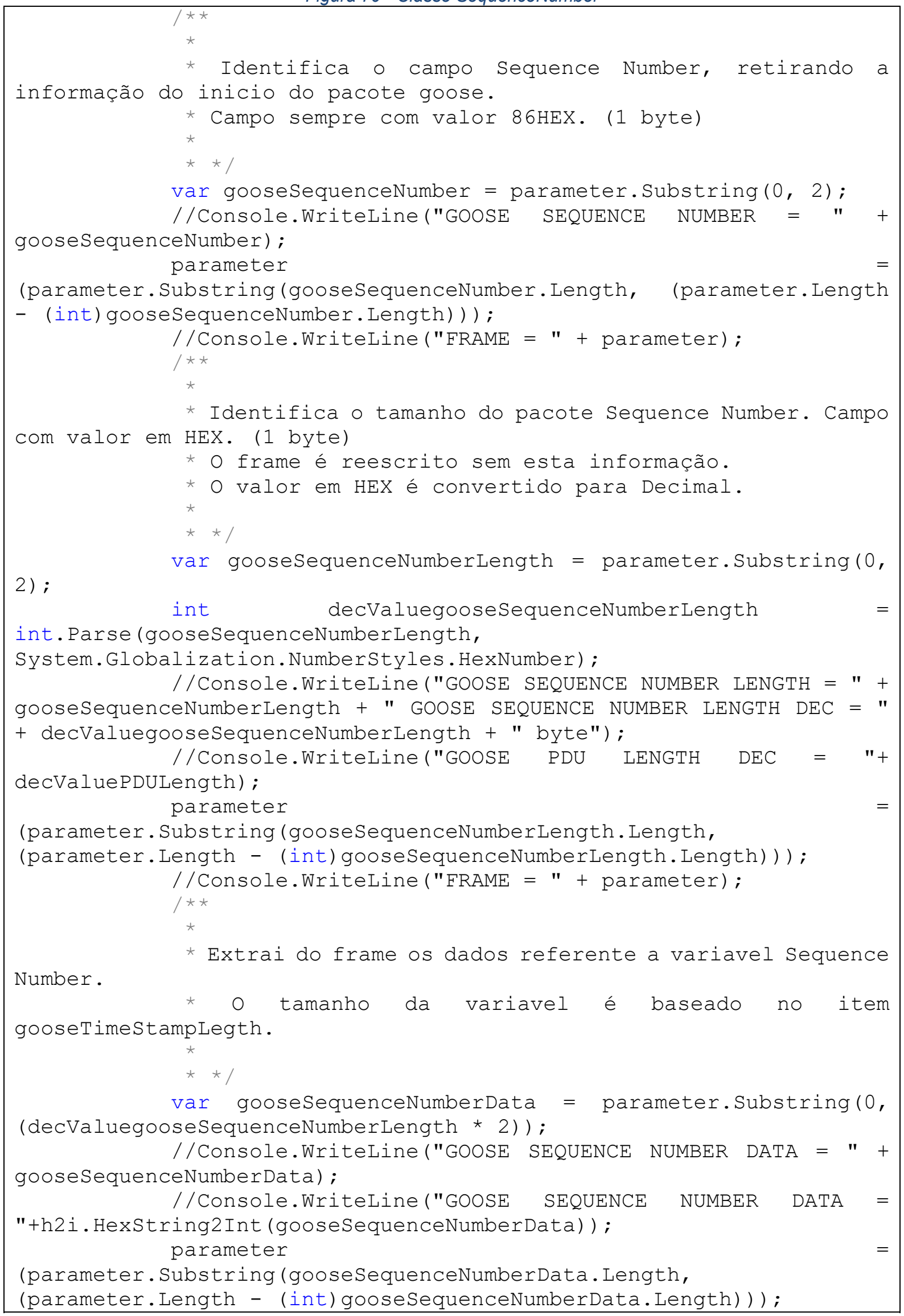




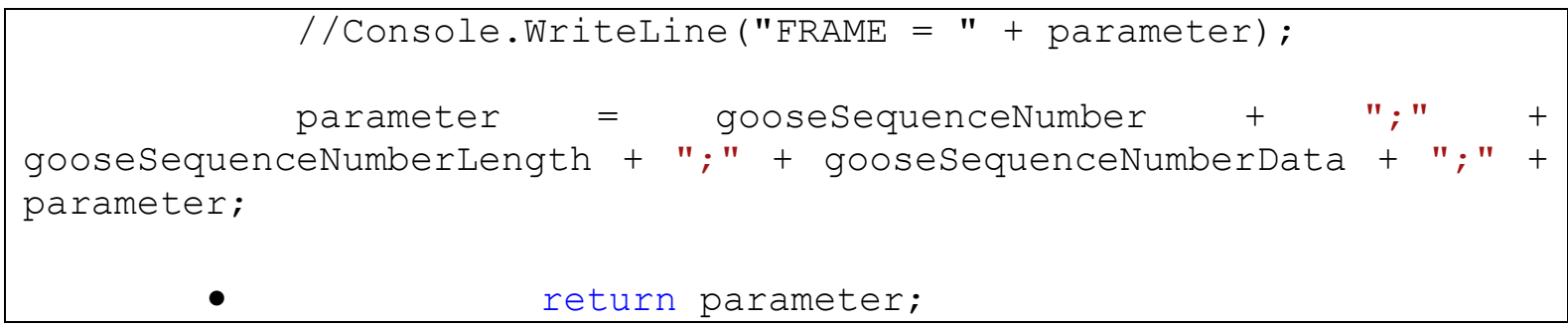

Fonte: $\mathrm{O}$ autor 


\section{ANEXO L}

Figura 71 - Classe IEDState

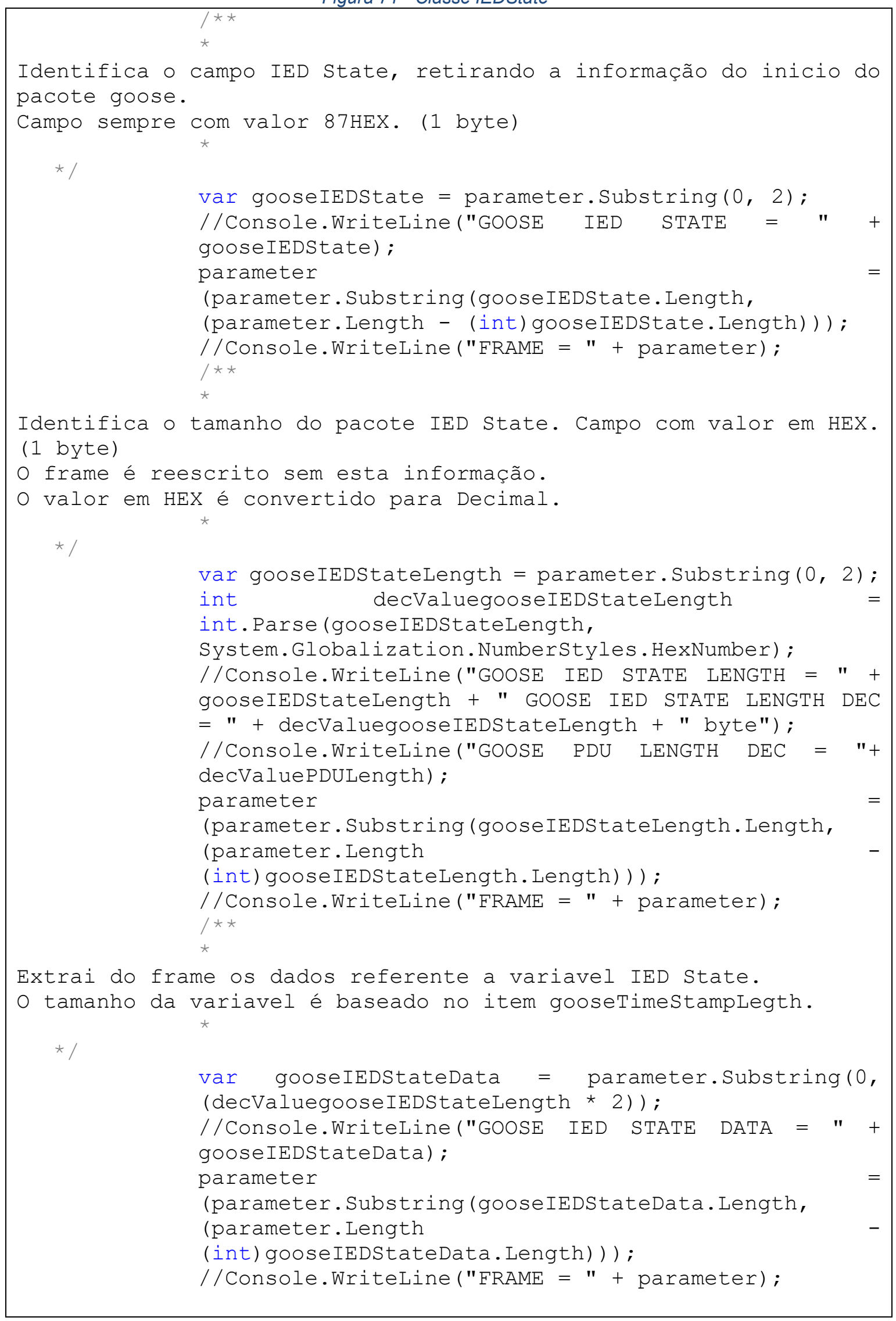




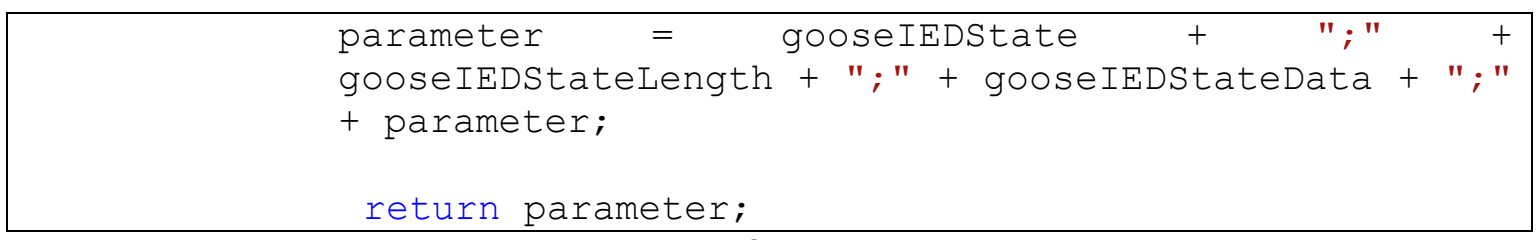

Fonte: $\mathrm{O}$ autor 


\section{ANEXO M}

Figura 72 - Classe ConfigRevision

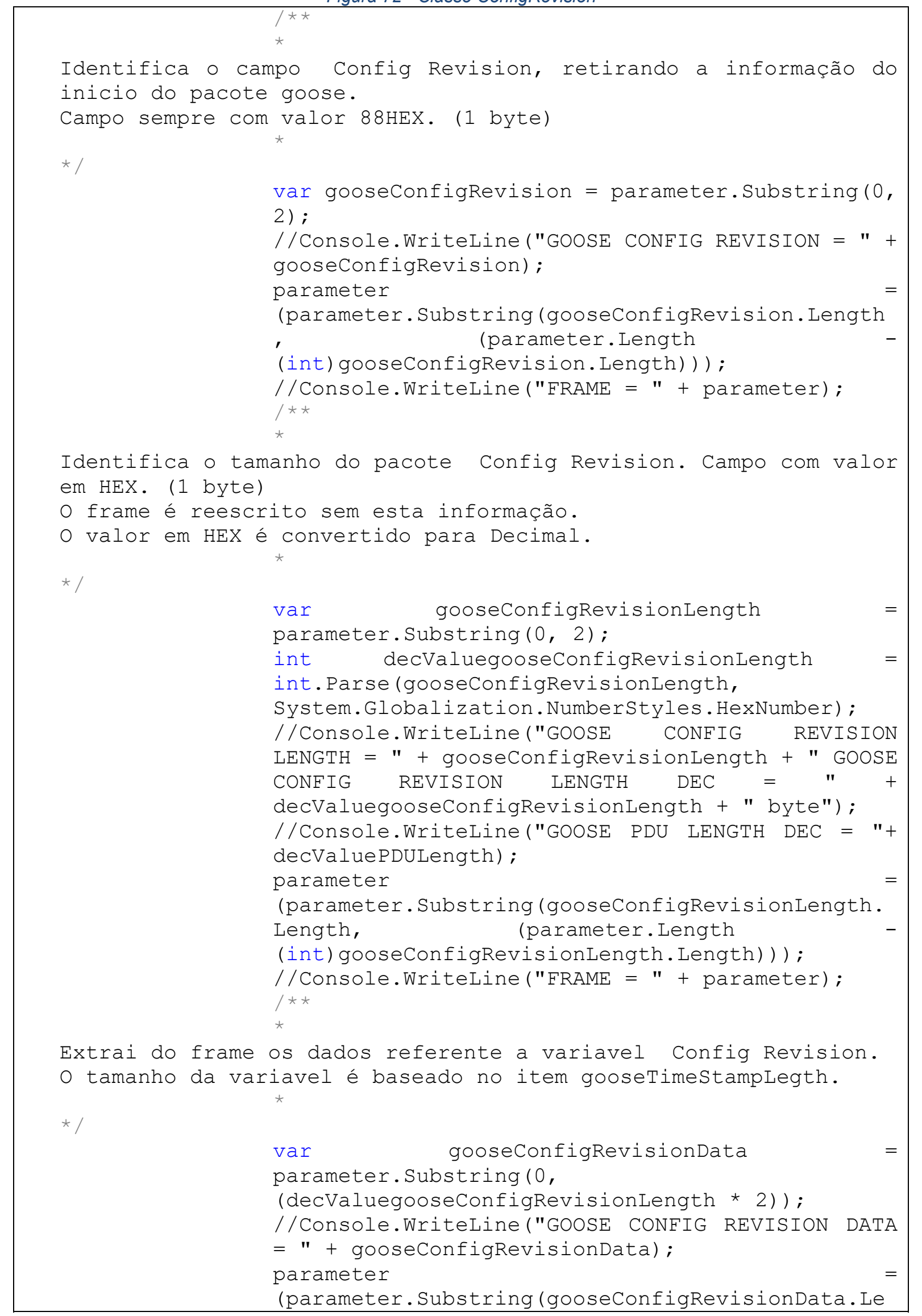




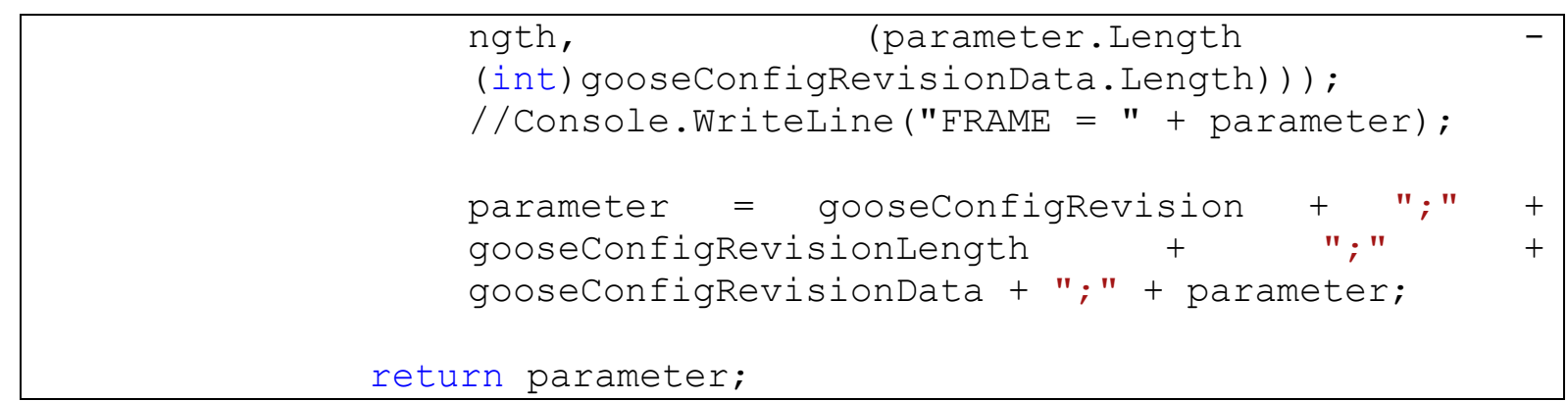

Fonte: $\mathrm{O}$ autor 


\section{ANEXO N}

Figura 73 - Classe NeedRevision

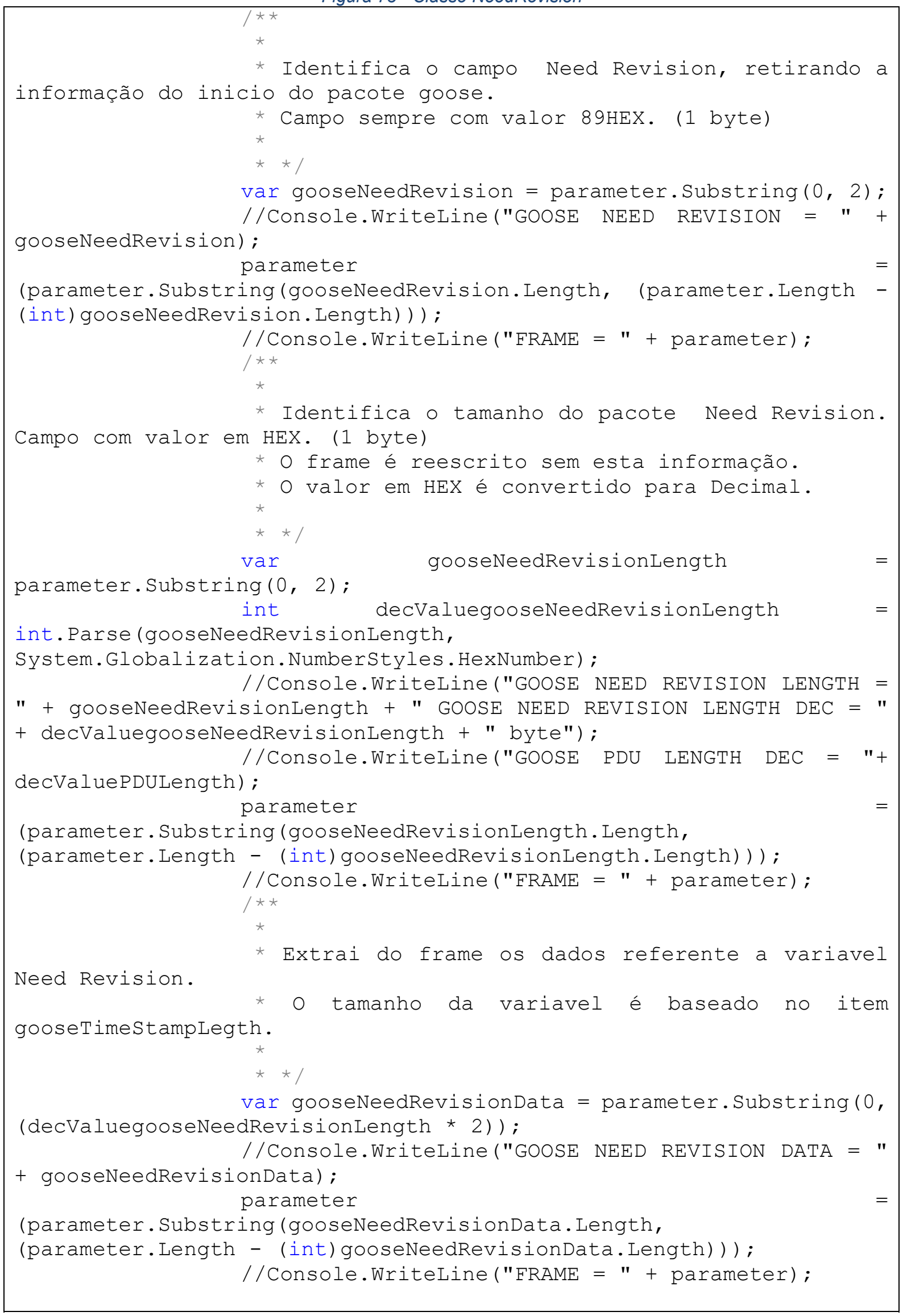




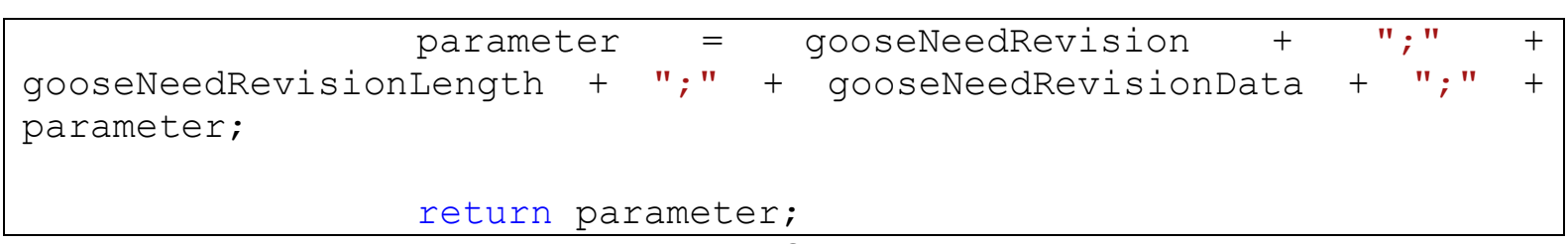

Fonte: O autor 


\section{ANEXO O}

Figura 74 - Classe DataEntries

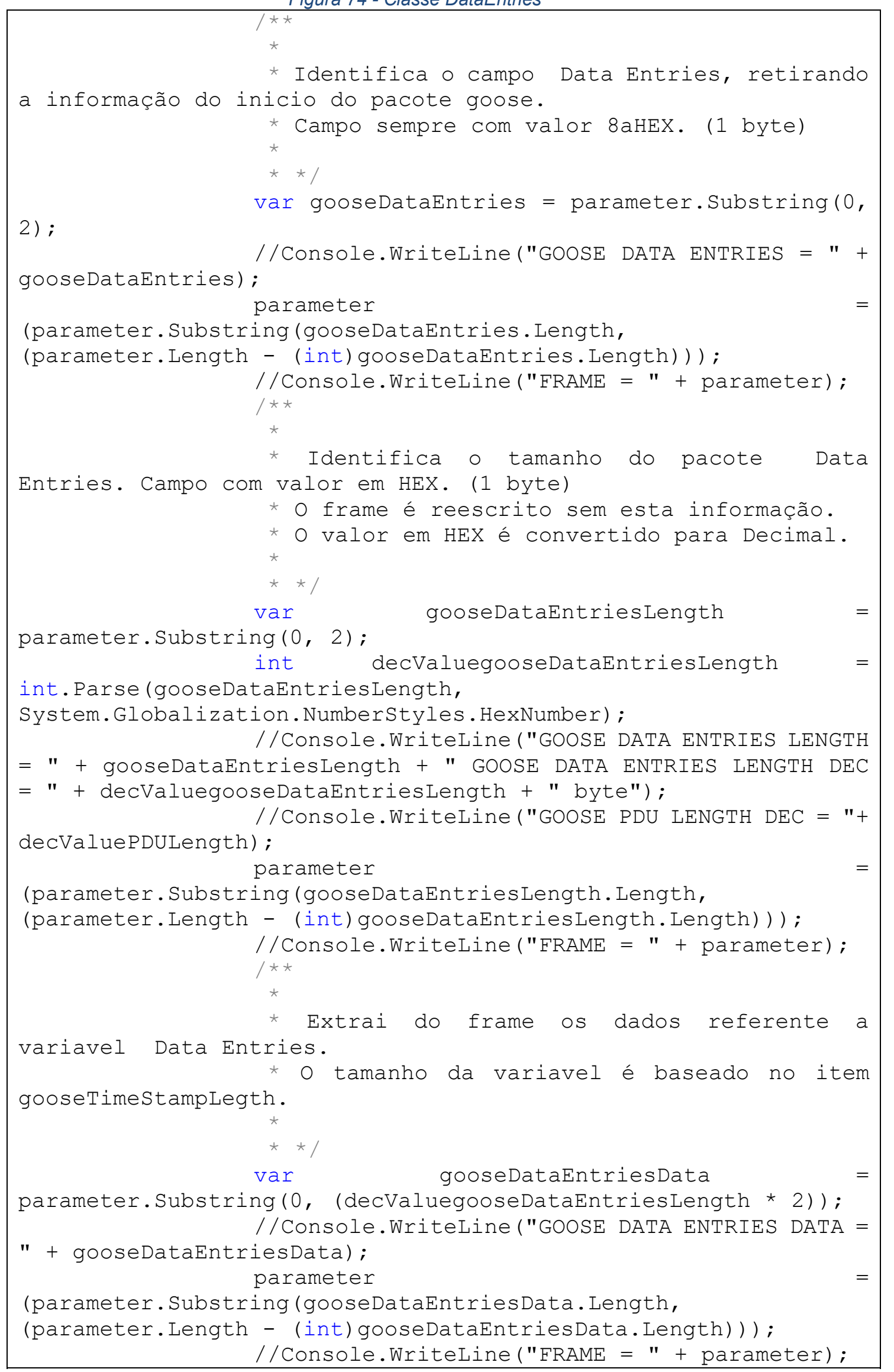


parameter = gooseDataEntries + " ;" + gooseDataEntriesLength + ";" + gooseDataEntriesData + "; " + parameter;

- return parameter;

Fonte: $\mathrm{O}$ autor 


\section{ANEXO P}

A estampa de tempo de uma mensagem GOOSE é localizada no bloco 23 do quadro Ethernet IEEE 802.3, já apresentado na Tabela 3. A informação de estampa de tempo localizada no bloco 23 é constituída por um conjunto de 8 bytes no formato hexadecimal, sendo os quatros primeiros bytes utilizados para conversão do total de segundos e os quatros últimos utilizados para conversão dos milissegundos. (IEC61850-7-2, 2010)

Para conversão dos segundos, o valor hexadecimal constituído por quatro bytes é convertido para um valor binário formado por trinta e dois bits, sendo o primeiro bit "0" menos significativo e o último bit "31" o mais significativo.

A Tabela 9 apresenta o cálculo utilizado para conversão do valor hexadecimal 4ADA86F4 para segundos. Nota-se que o valor convertido para binário é 01001010110110101000011011110100 e o valor binário convertido para decimal é 1255835380 total de segundos desde 01/01/1970 00:00:00.000.

Tabela 9 - Conversão de segundos epoch

\begin{tabular}{llll}
\hline bit & $2^{\wedge}$ bit & Valor do bit & $\left(2^{\wedge}\right.$ bit $\times$ Valor do bit $)$ \\
\hline 31 & 2147483648 & 0 & 0 \\
\hline 30 & 1073741824 & 1 & 1073741824 \\
\hline 29 & 536870912 & 0 & 0 \\
\hline 28 & 268435456 & 0 & 0 \\
\hline 27 & 134217728 & 1 & 134217728 \\
\hline 26 & 67108864 & 0 & 0 \\
\hline 25 & 33554432 & 1 & 33554432 \\
\hline 24 & 16777216 & 0 & 0 \\
\hline 23 & 8388608 & 1 & 8388608 \\
\hline 22 & 4194304 & 1 & 4194304 \\
\hline 21 & 2097152 & 0 & 0 \\
\hline 20 & 1048576 & 1 & 1048576 \\
\hline 19 & 524288 & 1 & 524288 \\
\hline 18 & 262144 & 0 & 0 \\
\hline 17 & 131072 & 1 & 131072 \\
\hline
\end{tabular}




\begin{tabular}{llll}
\cline { 2 - 4 } 16 & 65536 & 0 & 0 \\
\hline 15 & 32768 & 1 & 32768 \\
\hline 14 & 16384 & 0 & 0 \\
\hline 13 & 8192 & 0 & 0 \\
\hline 12 & 4096 & 0 & 0 \\
\hline 11 & 2048 & 0 & 0 \\
\hline 10 & 1024 & 1 & 1024 \\
\hline 9 & 512 & 1 & 512 \\
\hline 8 & 256 & 0 & 0 \\
\hline 7 & 128 & 1 & 128 \\
\hline 6 & 64 & 1 & 64 \\
\hline 5 & 32 & 1 & 32 \\
\hline 4 & 16 & 1 & 16 \\
\hline 3 & 8 & 0 & 0 \\
\hline 2 & 4 & 1 & 4 \\
\hline 1 & 2 & 0 & 0 \\
\hline 0 & 1 & 0 & 0 \\
\hline Total de segundos $=\sum\left(2^{\wedge}\right.$ bit $\times$ Valor do bit $)$ & 1255835380 \\
\hline
\end{tabular}

Fonte: $\mathrm{O}$ autor

Para conversão dos milissegundos, o valor hexadecimal constituído pelos quatro últimos bytes é convertido para um valor binário formado por trinta e dois bits, sendo o primeiro bit "1" mais significativo e o último bit "32" o menos significativo. Para conversão dos milissegundos são utilizados os vinte e quatros primeiros bits, os oitos bits restantes são utilizados para qualidade.

A Tabela 10 apresenta o cálculo utilizado para conversão do valor hexadecimal 7D1B40 para milissegundos. Nota-se que o valor convertido para binário é 011111010001101101000000 e o valor binário convertido para decimal é 0,488697052 total de milissegundos do valor epoch. 
Tabela 10 - Conversão epoch milissegundos

\begin{tabular}{llll}
\hline bit & $1 /\left(2^{\wedge} b i t\right)$ & Valor do bit & $(1 /$ (2^bit) $\times$ (Valor do bit) \\
\hline 1 & 0,5 & 0 & 0 \\
\hline 2 & 0,25 & 1 & 0,25 \\
\hline 3 & 0,125 & 1 & 0,125 \\
\hline 4 & 0,0625 & 1 & 0,0625 \\
\hline 5 & 0,03125 & 1 & 0,03125 \\
\hline 6 & 0,015625 & 1 & 0,015625 \\
\hline 7 & 0,0078125 & 0 & 0 \\
\hline 8 & 0,00390625 & 1 & 0,00390625 \\
\hline 9 & 0,001953125 & 0 & 0 \\
\hline 10 & 0,000976563 & 0 & 0 \\
\hline 11 & 0,000488281 & 0 & 0 \\
\hline 12 & 0,000244141 & 1 & 0,000244141 \\
\hline 13 & 0,00012207 & 1 & 0,00012207 \\
\hline 14 & $6,10352 \mathrm{E}-05$ & 0 & 0 \\
\hline 15 & $3,05176 \mathrm{E}-05$ & 1 & $3,05176 \mathrm{E}-05$ \\
\hline 16 & $1,52588 \mathrm{E}-05$ & 1 & $1,52588 \mathrm{E}-05$ \\
\hline 17 & $7,62939 \mathrm{E}-06$ & 0 & 0 \\
\hline 18 & $3,8147 \mathrm{E}-06$ & 1 & $3,8147 \mathrm{E}-06$ \\
\hline 19 & $1,90735 \mathrm{E}-06$ & 0 & 0 \\
\hline 20 & $9,53674 \mathrm{E}-07$ & 0 & 0 \\
\hline 21 & $4,76837 \mathrm{E}-07$ & 0 & 0 \\
\hline 22 & $2,38419 \mathrm{E}-07$ & 0 & 0 \\
\hline 23 & $1,19209 \mathrm{E}-07$ & 0 & 0,488697052 \\
\hline 24 & $5,96046 \mathrm{E}-08$ & 0 & 0 \\
\hline
\end{tabular}

Total de milissegundos $=\left(\left(1 /\left(2^{\wedge}\right.\right.\right.$ bit $\left.)\right) \times$ Valor do bit $) \quad 0,488697052$ 


\section{ANEXO Q}

Figura 75 - Código parametrizado para detectar falha GOOSE

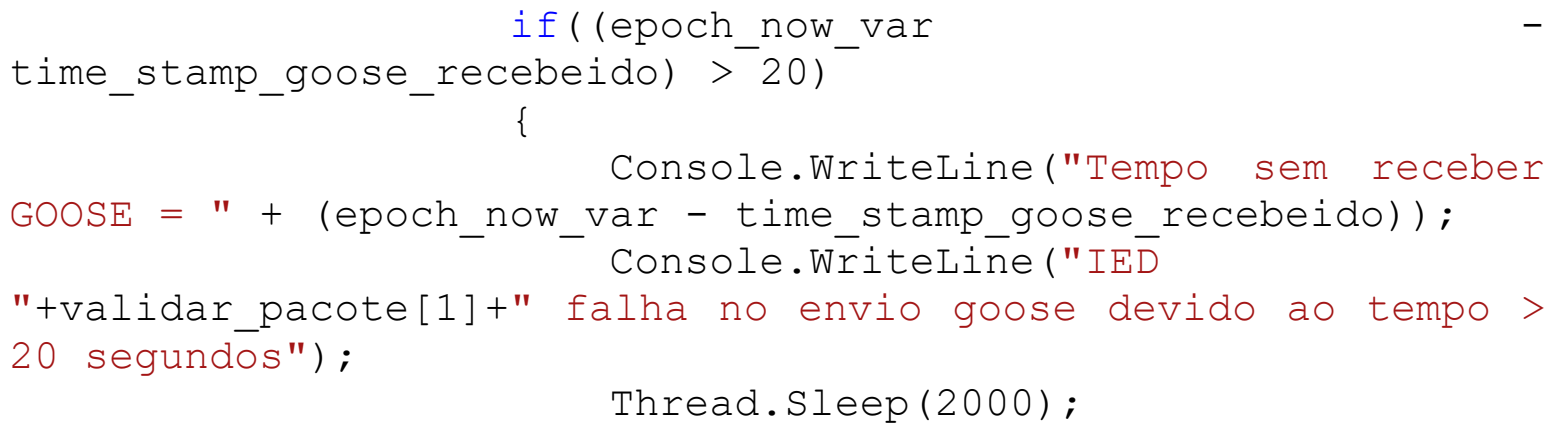

